Argonne

\title{
User's Guide for RESRAD-ONSITE Code
}

Version 7.2

\author{
Environmental Science Division
}




\begin{abstract}
About Argonne National Laboratory
Argonne is a U.S. Department of Energy laboratory managed by UChicago Argonne, LLC under contract DE-AC02-06CH11357. The Laboratory's main facility is outside Chicago, at 9700 South Cass Avenue, Argonne, Illinois 60439. For information about Argonne and its pioneering science and technology programs, see www.anl.gov.
\end{abstract}

\title{
DOCUMENT AVAILABILITY
}

Online Access: U.S. Department of Energy (DOE) reports produced after 1991 and a growing number of pre-1991 documents are available free via DOE's SciTech Connect (http://www.osti.gov/scitech/).

Reports not in digital format may be purchased by the public from the National Technical Information Service (NTIS):

U.S. Department of Commerce

National Technical Information Service

5301 Shawnee Road

Alexandria, VA 22312

www.ntis.gov

Phone: (800) 553-NTIS (6847) or (703) 605-6000

Fax: (703) 605-6900

Email: orders@ntis.gov

Reports not in digital format are available to DOE and DOE contractors from:

U.S. Department of Energy

Office of Scientific and Technical Information

P.O. Box 62

Oak Ridge, TN 37831-0062

\footnotetext{
Disclaimer

This report was prepared as an account of work sponsored by an agency of the United States Government. Neither the United States Government nor any agency thereof, nor UChicago Argonne, LLC, nor any of their employees or officers, makes any warranty, express or implied, or assumes any legal liability or responsibility for the accuracy, completeness, or usefulness of any information, apparatus, product, or process disclosed, or represents that its use would not infringe privately owned rights. Reference herein to any specific commercial product, process, or service by trade name, trademark, manufacturer, or otherwise, does not necessarily constitute or imply its endorsement, recommendation, or favoring by the United States Government or any agency thereof. The views and opinions of document authors expressed herein do not necessarily state or reflect those of the United States Government or any agency thereof, Argonne National Laboratory, or UChicago Argonne, LLC.
} 


\section{User's Guide for RESRAD-ONSITE Code}

Version 7.2

by

S. Kamboj, E. Gnanapragasam, and C. Yu

Environmental Science Division, Argonne National Laboratory

March 2018 



\section{CONTENTS}

ACKNOWLEDGEMENTS ....................................................................................... ix

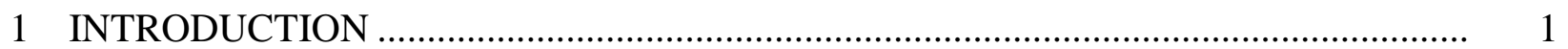

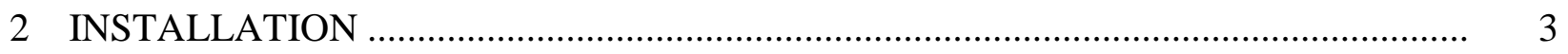

2.1 Installing from the RESRAD Website ............................................................... 3

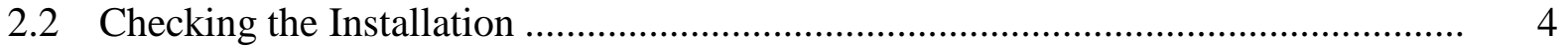

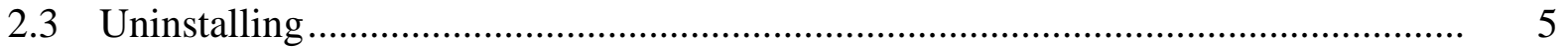

3 NAVIGATION ............................................................................................. 6

3.1 Menu and Toolbars .................................................................................. 7

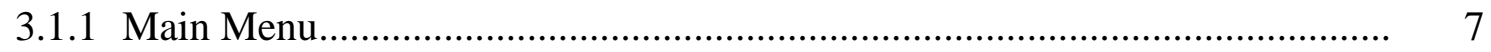

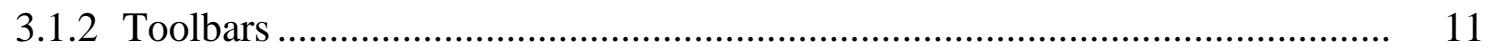

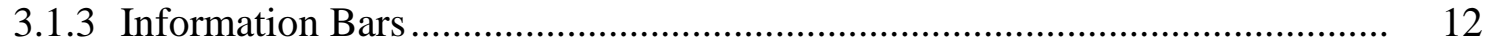

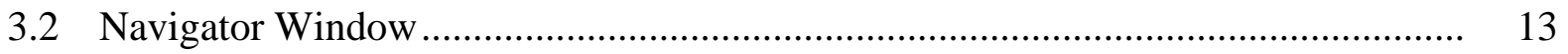

3.3 RESRAD DOS Emulator .......................................................................... 15

4 INPUT OF VARIABLES .............................................................................. 17

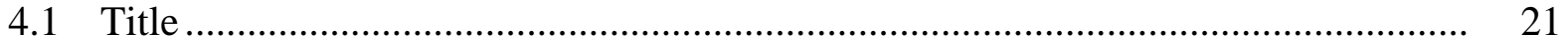

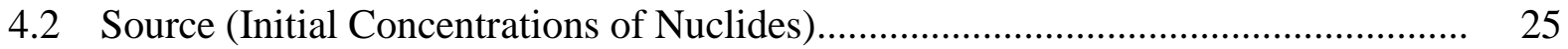

4.3 Radionuclide Transport Factors ........................................................................ 27

4.4 Calculation Parameters ................................................................................... 29

4.5 Contaminated Zone Parameters …..................................................................... 30

4.6 Cover and Contaminated Zone Hydrological Data............................................. 31

4.7 Saturated Zone Hydrological Data....................................................................... 33

4.8 Uncontaminated Unsaturated Zone Parameters ................................................. 35

4.9 Occupancy, Inhalation, and External Gamma Data .......................................... 36

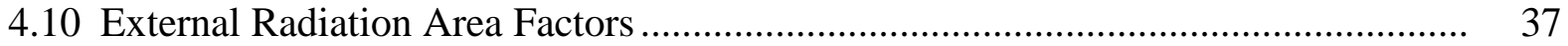

4.11 Ingestion Pathway, Dietary Data ..................................................................... 38

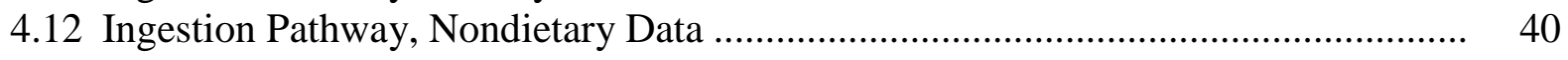

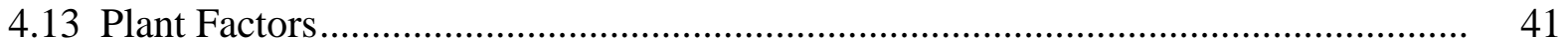

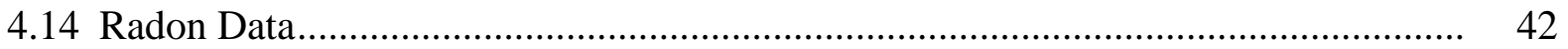

4.15 Storage Times before Use Data ..................................................................... 44

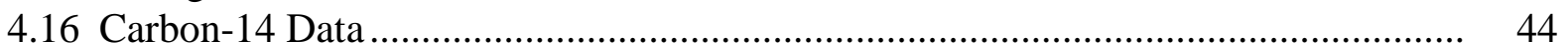

5 RESRAD Dose Conversion Factor Editor ............................................................. 46

5.1 Dose Coefficients ................................................................................................. 49

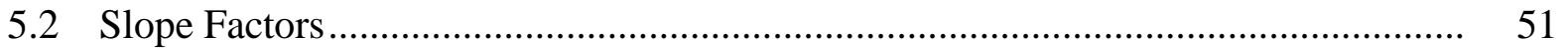

5.3 Risk and Dose Factors for Radon ............................................................... 51

5.4 Transfer Factors ........................................................................................... 53 


\section{CONTENTS (Cont.)}

5.5 Create New DCF Library ............................................................................... 54

5.6 Import and Export of DCF Library ………………………………………………... 56

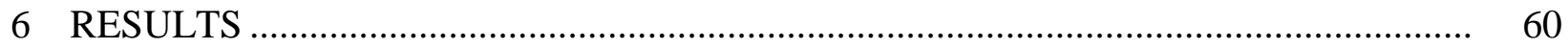

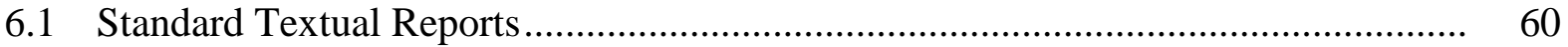

6.2 Report Viewer ...................................................................................................... 61

6.3 Graph Viewer .............................................................................................. 64

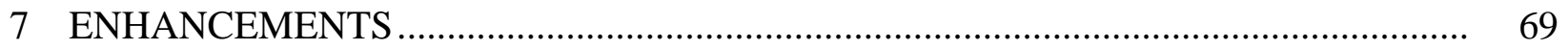

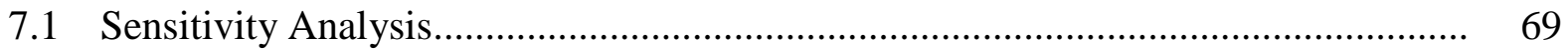

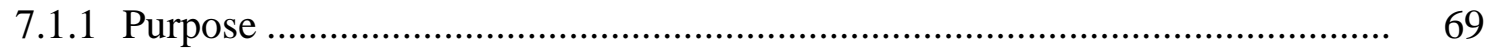

7.1.2 Getting to the Sensitivity Analysis ............................................................... 70

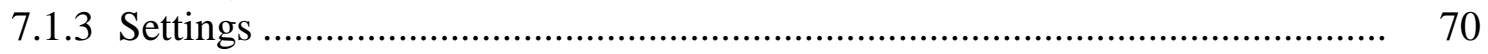

7.1.4 Output .......................................................................................... 71

7.2 Uncertainty/Probabilistic Analysis ....................................................................... 71

7.2.1 Procedures for Using Uncertainty/Probabilistic Analysis ............................... 72

7.2.2 Four Input Tabs for Uncertainty/Probabilistic Analysis................................... 72

7.2.3 Output Results ......................................................................................... 78

7.3 Soil Graphic Feedback ………………............................................................ 82

7.4 Radionuclide Transformation Databases ............................................................. 83

7.4.1 Radionuclide Transformation Databases ..................................................... 83

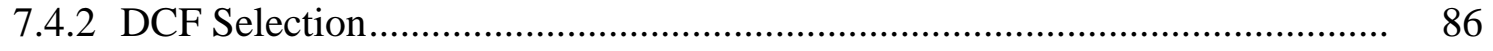

7.4.3 Dose Estimation Methodology …………………......................................... 86

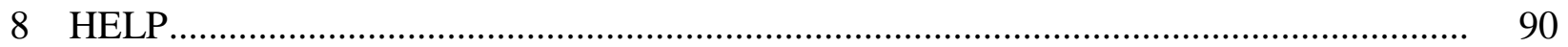

8.1 Application Help ....................................................................................... 90

8.2 Message Log …..................................................................................... 92

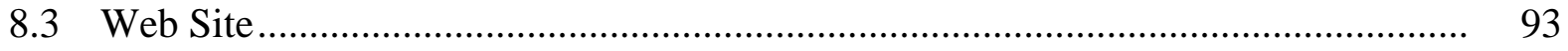

8.4 Documents ................................................................................................. 96

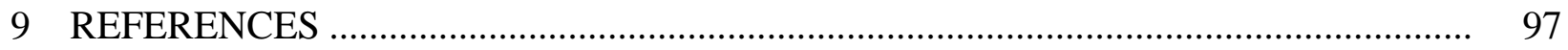

\section{FIGURES}

$1 \quad$ The Main Interface of RESRAD-ONSITE …………………………………................ 6

$2 \quad$ Main Menu and Submenus ......................................................................................... 7

$3 \quad$ The Primary Toolbar ............................................................................................... 11 


\section{FIGURES (Cont.)}

4 The Pathways Toolbar

5 The Interface with the Two Information Bars .......

6 Navigator

7 DOS Emulator Navigation

8 Title Form

9 Source Form.

10 Transport Factors Form.

11 Calculation Parameters Form.

12 Contaminated Zone Parameters Form

13 Cover and Contaminated Zone Hydrological Data Form.

$14 \quad$ Saturated Zone Hydrological Data Form ....................................................................... 33

15 Uncontaminated Unsaturated Zone Parameters Form ..................................................... 35

16 Occupancy, Inhalation, and External Gamma Data Form ............................................. 36

$17 \quad$ External Radiation Area Factors Form ………….................................................... 37

$18 \quad$ Ingestion Pathways, Dietary Data Form ………………………................................. 39

19 Ingestion Pathways, Nondietary Data Form ……................................................. 40

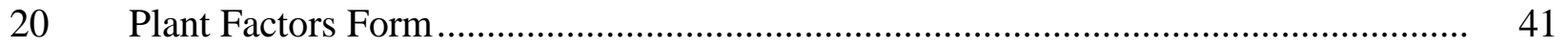

$21 \quad$ Radon Data Form .......................................................................................... 42

22 Storage Times Before Use Data Form ........................................................................ 44

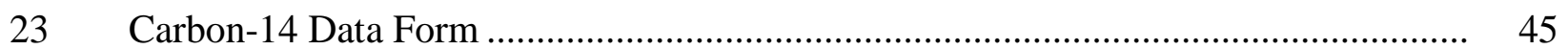

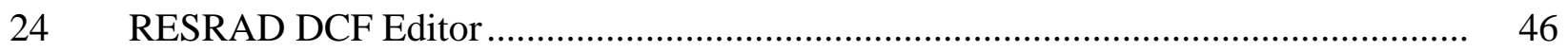

25 Available DCF Libraries in ICRP 38 Transformation Database .................................... 47

26 Available DCF Libraries in the ICRP 107 Transformation Database ........................... 48 


\section{FIGURES (Cont.)}

27 Dose Coefficients from a FGR-12-, FGR-11-, and FGR-13-based Library

28 External Pathway Adjustment Parameters from the FGR-12, FGR-11, and FGR-13 Library

29 FGR-13 based Morbidity Slope Factors

30 Radon Progeny Slope Factors and ICRP 26 Methodology-based Dose Coefficients

31 Radon Progeny Slope Factors and ICRP 60 Methodology-based Dose Coefficients

32 Transfer Factors

33 Xe-131m Default Dose Conversion Factors in the Database

$34 \quad$ Nuclide No Data Error Message ........................................................................ 55

35 Creating a New DCF Library ................................................................... 56

36 Export and Import Options in the DCF Editor.................................................. 57

$37 \quad$ Select the User Library for Export................................................................ 57

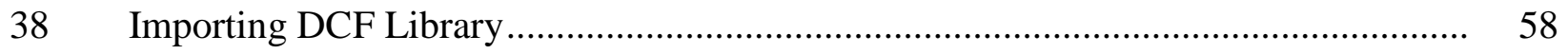

39 DCF Library File Duplication Message............................................................... 58

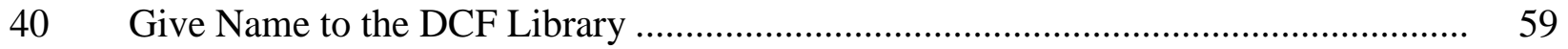

41 Imported File Available in the DCF Editor .................................................... 59

42 RESRAD-ONSITE Summary Report ......................................................... 62

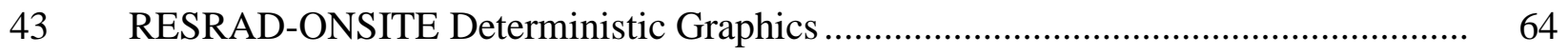

44 Menu Bar in RESRAD-ONSITE Deterministic Graphics ....................................... 66

45 Toolbar, Command Buttons, and Associated Functions in Deterministic

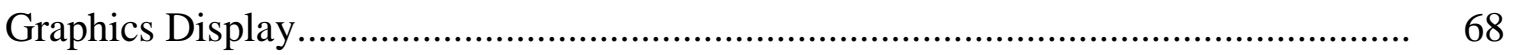

$46 \quad$ Sensitivity Analysis Setup Screen …...........................................................

47 Sensitivity Analysis Results........................................................................ 


\section{FIGURES (Cont.)}

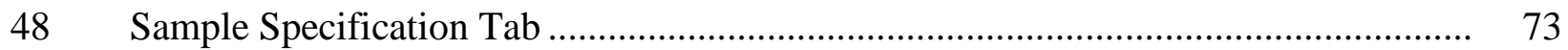

$49 \quad$ Parameter Distribution Tab...................................................................................... $\quad 75$

$50 \quad$ Help on Parameter Distribution .................................................................................. $\quad 76$

$51 \quad$ Input Rank Correlation Tab .....................................................................................

52 Output Specifications Tab................................................................................. $\quad 78$

$53 \quad$ RESRAD-ONSITE Uncertainty Report …………..................................................... 79

54 RESRAD-ONSITE Interactive Output Input Specification Tab ................................. 80

55 RESRAD-ONSITE Interactive Output Parameter Statistics Tab ................................. 80

56 RESRAD-ONSITE Interactive Output Results Tab ..................................................... 81

$57 \quad$ RESRAD-ONSITE Interactive Graphic Results ………………................................ 81

$58 \quad$ Soil Strata Parameters Window ………………….............................................. 82

$59 \quad$ First Unsaturated Zone Data Window …………........................................................ 83

60 Selection of ICRP 38 Radionuclide Transformation Database......................................... 85

61 Selection of ICRP 107 Radionuclide Transformation Database.................................... 86

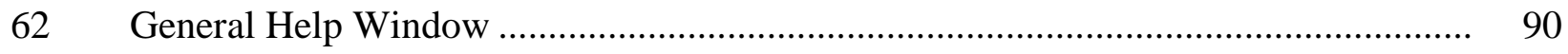

63 Parameter Descriptions in RESRAD-ONSITE Help ........................................................ 91

$64 \quad$ Message Log after RESRAD-ONSITE Run ............................................................. 92

$65 \quad$ RESRAD Family of Codes Home Page........................................................................ 94

$66 \quad$ RESRAD-ONSITE Code Home Page …………………………………..................... 95

67 Available General and RESRAD-ONSITE Documents on the Website ...................... 96 


\section{TABLES}

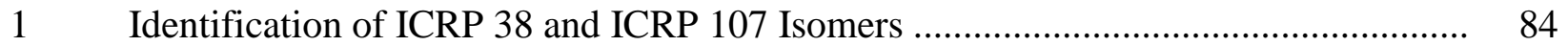

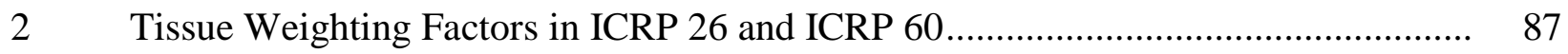

3 Quality Factors in ICRP 26 and Radiation Weighting Factors in ICRP 60............... 88

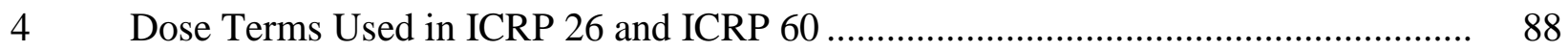




\section{ACKNOWLEDGEMENTS}

The authors would like to thank U.S. Department of Energy Program Managers Derek Favret, Amanda Anderson, Andy Szilagyi, and Andy Wallo for their guidance and encouragement throughout the project. We also like to thank Carlos Corredor for his detailed review of the report. We thank David LePoire, Jing-Jy Cheng, Cheng Wang, and Kevin Beckman for their contributions to the development and testing of RESRAD-ONSITE Version 7.2 and review of this report. Finally, we thank Vic Comello for editorial assistance. 
This page intentionally left blank. 


\section{INTRODUCTION}

The RESRAD-ONSITE code is equipped with a user-friendly interface that has many features to facilitate its use and comprehension. The design of the interface provides various navigation options, including entering data, performing calculations, and displaying the results of the calculations. General and context-specific help are available, offering information on editing and viewing the radionuclide database, the definitions of input parameters and their use in the calculations, and the selection and output of the results of the calculations into other applications. Two types of sensitivity analysis are supported by the code, deterministic and probabilistic, which can be used to study the influence of input parameters on the calculated results.

Version 7.2 of the RESRAD-ONSITE code has added several enhanced features since the User's Manual for Version 6 was published (Yu et al. 2001), including the incorporation of the International Commission on Radiological Protection (ICRP) 107 (ICRP 2008) radionuclide transformation dataset. The code allows the choice of newly available dose and cancer risk conversion factor libraries, variable cutoff half-lives, and radiological units for activity and dose. The code also permits consideration of a contaminated zone entirely or partially submerged under the groundwater table.

This user's guide provides instructions to users on how to install the RESRAD-ONSITE code, navigate the interface, and use the various features, including those discussed above, to set up a dose/risk analysis and to view/print the results as textual and graphical outputs. This updated user's guide supersedes and replaces the user's guide contained in Chapter 4 of the User's Manual for Version 6 (Yu et al. 2001). The entire user's manual for Version 6, which contains discussions of the theoretical basis and the equations implemented in the code, is available at the RESRAD website (http://resrad.evs.anl.gov) in Adobe PDF format.

This user's guide is divided in nine chapters:

1. Introduction

2. Installation: Discusses the installation and uninstallation procedures and system requirements.

3. Navigation: Presents instructions for moving around the interface to accomplish various tasks and to save inputs and outputs.

4. Input of Variables: Contains a description of each input form, information on how to use the forms, and descriptions of the parameters in the input forms.

5. RESRAD Dose Conversion Factor Editor: Contains information on using and accessing various database libraries.

6. Results: Shows how to find results as textual and graphical outputs. 
7. Enhancements: Explains the sensitivity and uncertainty/probabilistic analysis features.

8. Help: Provides several sources of help.

9. References 


\section{INSTALLATION}

The RESRAD family of codes, including RESRAD-ONSITE, Version 7.2, is distributed through the RESRAD website (http://resrad.evs.anl.gov). The code requires a Microsoft Windows 7 or newer operating system. A printer driver must be installed, but an actual printer does not need to be attached. The following sections describe the procedures for downloading and installing the code (Section 2.1), checking the installation (Section 2.2), and uninstalling the code (Section 2.3).

\subsection{INSTALLING FROM THE RESRAD WEBSITE}

- Connect to the RESRAD website at http://resrad.evs.anl.gov.

- Click on "Download.”

- Fill in the requested information and download the installation program. (Note: Administrative right to the computer is required to install the program.)

- When the installation program launches, follow the instructions to enter the information requested. (Note: It is suggested that first-time users accept the default selections.)

- If the default installation selections are used, the files needed to execute RESRAD-ONSITE Version 7.2 will be installed at C:IRESRAD_Family\ONSITE $\backslash 7.2 \backslash$, and the files to support the dose and risk calculations (e.g., dose coefficients, risk coefficients, etc.) will be installed at C:IRESRAD_Family\DCF\3.1.

The installation would also create the following subdirectories:

- C:\RESRAD_Family\ONSITE $\backslash 7.2 \backslash U$ serfiles $\backslash$, for saved input and output files.

- C:IRESRAD_Family\ONSITE \7.2\QAfiles $\backslash$, for saved quality assurance (QA) files.

- After installation, the program will be placed under the RESRAD Family group in the Start menu and a new RESRAD-ONSITE 7.2 icon will appear on the computer's desktop.

- Double-click the "RESRAD-ONSITE 7.2" icon to start RESRAD-ONSITE. (Note: If "Launch RESRAD-ONSITE” is selected before finishing the installation, the program will start automatically after the installation is complete.) 


\subsection{CHECKING THE INSTALLATION}

Two input files for quality assurance (QA) purposes are placed in the C:IRESRAD_Family $\backslash$ ONSITE $\backslash 7.2 \backslash Q$ QAfiles $\backslash$ subdirectory (hereafter referred to as the “... QQAfiles।” subdirectory) if the installation is successful. These two files can be used to run RESRAD-ONSITE to obtain output files for comparison with those generated by the code developers, which are placed in the C:IRESRAD_Family\ONSITE \7.2\QAfiles\ QAoutputforComparison $\backslash$ subdirectory (hereafter referred as the “... QQAoutputforComparisonl” subdirectory).

- Double-click the "RESRAD-ONSITE 7.2" icon on the computer desktop to start RESRAD-ONSITE.

- Click "File" in the menu bar at the top of the interface and open the “QUALITY ASSURANCE RESRAD ONSITE SI.RAD” input file in the “... QQAfiles” subdirectory.

- Click "File" in the menu bar and select "Title." In the "Title" input form and check "Save All files after each run" near the bottom. Then click "OK" to close the input form.

- Click "File" in the menu bar and then "Run RESRAD-ONSITE" to start the calculations. A message box appears informing you that the input file has been modified. Click "Yes" to save the modification to the input file. There are two other ways to run RESRAD-ONSITE. All three navigation options are presented in Chapter 3.

- When the calculations are completed, a "View" window showing the "SUMMARY.REP" output file appears. Click the " $X$ " icon to close the window.

- The text output files generated from the run will be saved in the “...।QAFiles।" subdirectory. They all will have the same file name, "QUALITY ASSURANCE RESRAD ONSITE SI," as the input file, but with different extensions, including “.con,” “.dau,” “.det,” “.int,” and “.sum,” representing the concentration, daughter dose, detailed, intake and risk, and summary reports, respectively.

- For comparison, open one of the text output files in the “...QQAFilesl” subdirectory and compare it with the corresponding output file in the “... QQAoutputforComparisonl” subdirectory that was generated by the code developers. The concentration, dose, risk, etc., results listed in the two output files should be the same, although the time and date listed in first line of each page will be different. The execution time will also likely be different. (Note: The output files can be opened with any word processor or automated file comparison software.) 
- Compare other output files generated from the run with the ones generated by the code developers.

- $\quad$ Run RESRAD-ONSITE with the other QA input files provided (if you wish), and compare the output files generated (in the “... (QAFiles〉” subdirectory) with the ones generated by the code developers. (Note: More QA files may be available at the User Center on the RESRAD website)

\subsection{UNINSTALLING}

When RESRAD-ONSITE 7.2 is installed, an “Uninstall RESRAD-ONSITE 7.2” option is also placed in the Windows Start menu under the RESRAD Family group RESRADONSITE 7.2 item. To uninstall RESRAD-ONSITE 7.2, click on the "Uninstall RESRADONSITE 7.2" option or use the Uninstall utility program in the Windows Control Panel. All files will be removed from the system in either case. 


\section{NAVIGATION}

Three navigation options are available to access input forms (the input forms are dialog boxes used to enter parameter values) and make selections through the RESRAD-ONSITE interface. The use of one navigation option does not exclude use of the other options. Figure 1 shows the designs of the main interface to facilitate the three navigation options:

- Menu and Toolbars: The menu and toolbar items are standard Windows tools to manipulate files, access input forms, make modeling selections, and retrieve calculated results. Shortcut keys are available for advanced users.

- Iconic Navigator Window: A tabbed window provides access to the input forms through graphical cues.

- DOS Emulator: Provides a set of textual command buttons, similar to those for a DOS interface.

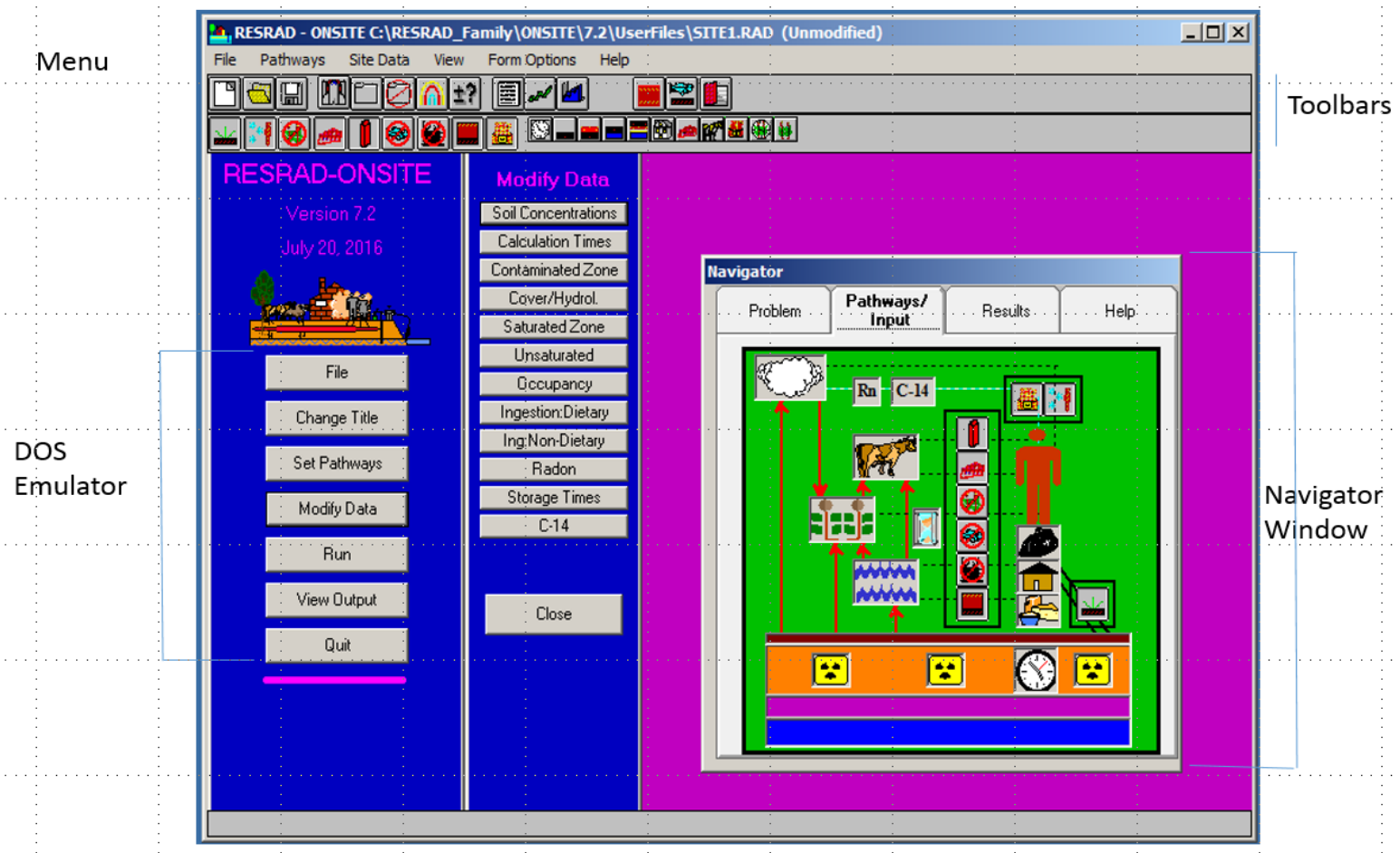

FIGURE 1 The Main Interface of RESRAD-ONSITE 


\subsection{MENU AND TOOLBARS}

\subsubsection{Main Menu}

The menu at the top of the main interface, i.e., the Main Menu, offers complete access to all of the input forms, operational functions, and features of the RESRAD-ONSITE code. The Main Menu and the submenus that branch from it are shown in Figure 2 and are described below.

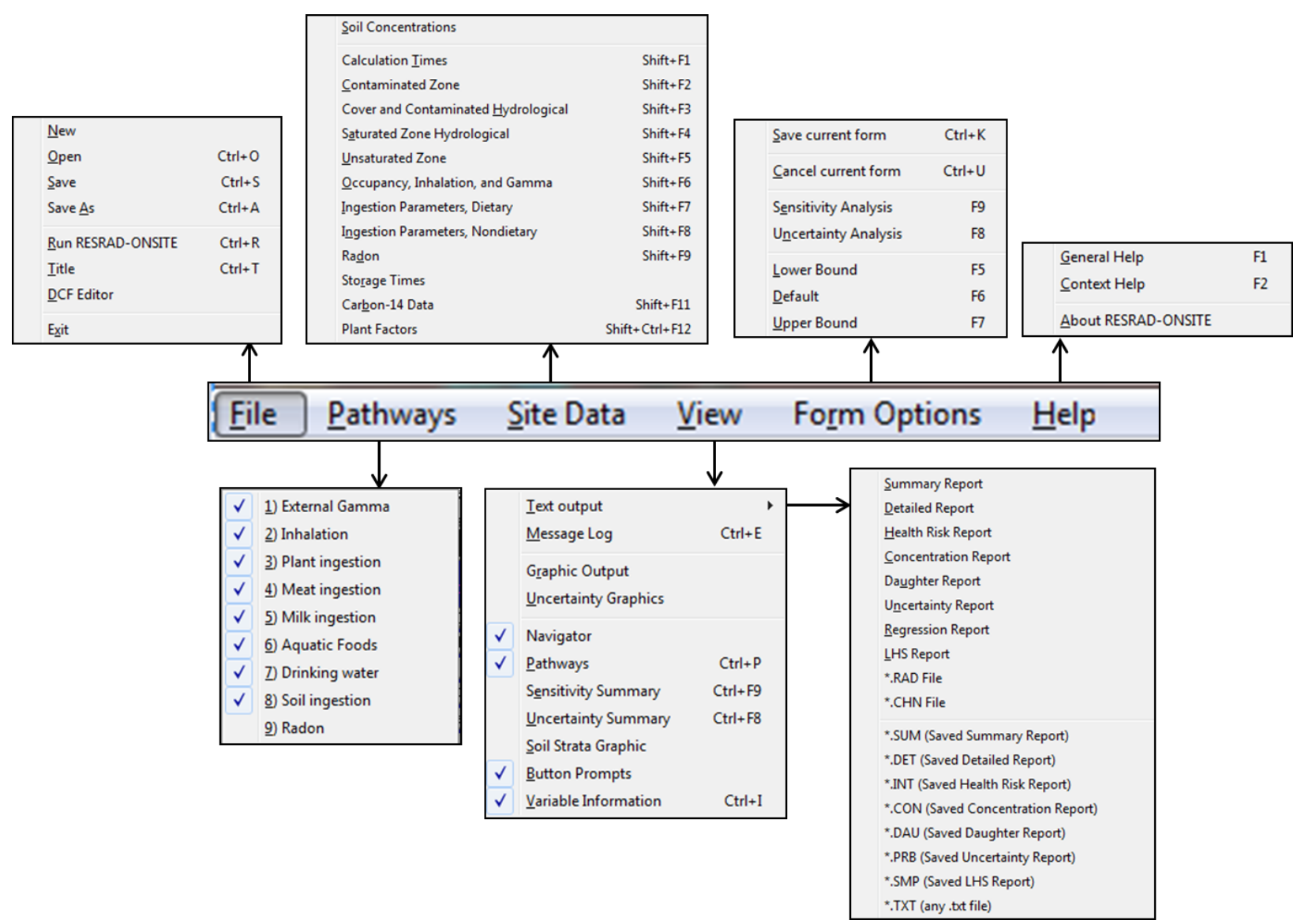

FIGURE 2 Main Menu and Submenus

The menu operations can be performed by activating the hot (underlined) keys when pressing the Alt-function key (Alt), or by using the shortcut keys shown next to the submenu commands. For example, the "save" operation can be performed by clicking "File" then "Save"; by entering the key sequence Alt followed by "F" followed by "S"; or by pressing down the Ctrlfunction key (Ctrl) and then hitting the "S" key.

File Submenu: The first block of four commands performs common file operations. The next three commands can be used to perform an analysis using the current inputs, access the "Title" 
input form, and launch the Dose Conversion Factor (DCF) Editor (DCF Editor), respectively. The last command terminates the navigation and exits the RESRAD-ONSITE code.

- New: Start afresh with a set of default or placeholder values for all the input parameters.

- Open: Bring up the dialogue box to open a previously saved input file.

- Save: Save the current input file.

- Save As: Bring up the dialogue box to save the current inputs under a different filename.

- Run RESRAD-ONSITE: Save the input file, generate all of the data files that are necessary to execute the computations, and launch the computations.

- Title: Display the "Title" input form.

- DCF Editor: Launch the Dose Conversion Factor Editor.

- Exit: Close the interface and exit.

Pathways Submenu: The submenu commands allow the user to toggle on and off the nine exposure pathways. A checkmark next to a pathway indicates that it is currently active.

Site Data Submenu: All but two variable or parameter input screens that are needed to specify the situation to be modeled are directly accessible from this submenu. The "External Radiation Area Factors" are accessible after selecting the "Occupancy, Inhalation, and External Gamma" site data option within this submenu; and the "Nuclide-dependent Transport Factors" are accessible after the nuclides have been selected under the "Soil Concentrations" option in this submenu. Any input options under this submenu that are currently open (i.e., being displayed) are indicated by a checkmark on the submenu, except for the "Soil Concentrations" option.

View Submenu: This submenu has two functions: (1) providing access to the various text reports generated and the graphics windows for results presentation, and (2) setting the display options for the Pathways Toolbar, the graphic input windows, and several feedback windows regarding input specifications.

- Text Output: Allow access to the text reports after successful completion of a RESRAD-ONSITE calculation.

- Message Log: Displays important messages regarding conditions encountered during the calculation that need attention. The user can check the "Message Log” after the calculation. 
- Graphic Output: Display the graphic output window for presenting the deterministic base case and sensitivity analysis results. Missing or not correctly registered *.ocx files will not display graphic output. The RESRAD website FAQ page contains information about correcting these problems.

- Uncertainty Graphics: Display the graphic output window for presenting the uncertainty analysis results, i.e., the results of the probabilistic analysis.

- Navigator: Display the iconic Navigator window for input specifications.

- Pathways: Display the Pathways Toolbar, which is the second toolbar under the Main Menu. This toolbar allows quick activation or deactivation of exposure pathways and quick access to the input forms.

- Sensitivity Summary: Display the gray bar at the bottom of the interface that summarizes the sensitivity analysis selections.

- Uncertainty Summary: Display the "Uncertainty Analysis Input Summary" window that shows the current input settings for a probabilistic analysis.

- Soil Strata Graphic: Display the "Soil Strata Parameters" graphic window. When selected, this window presents a cross section of the various zones with scaled thicknesses and allows access to the input form associated with each soil stratum. In order to no longer view the Soil Strata graphic, unselect this option from the "View" Submenu.

- Button Prompts: Display the information box associated with each button on the toolbars as the mouse moves over it.

- Variable Information: Display the gray bar near the bottom of the interface that shows the name, default value, and range of acceptable values for the input parameter that is currently highlighted.

Form Options Submenu: The first two commands on the "Form Options" submenu, "Save current form" and "Cancel current form," are used to save or cancel the changes made to an open input form and then close the form. The remaining five commands display specific input windows or set specific values associated with the highlighted parameter in an open input form, as described below:

- Sensitivity Analysis: Displays the sensitivity analysis input window for the highlighted parameter to allow the specification of a sensitivity analysis range.

- Uncertainty Analysis: Displays the uncertainty analysis input window to allow the specifications of distribution information for the highlighted parameter as well as its correlation with the other parameters that have been included in the uncertainty analysis. 
- Lower Bound: Sets the value of the highlighted parameter to the lowest value accepted by RESRAD-ONSITE. The lowest value may be a physical bound (i.e., the lowest value that is applicable for the parameter because of physical considerations) or simply a numerical bound imposed to prevent the code from crashing.

- Default: Sets the value of the highlighted parameter to the default value assigned in the RESRAD-ONSITE code. While most default values were determined after analyzing available literature data (e.g., ingestion rates, inhalation rates), some are merely placeholder values (e.g., field capacity).

- $\quad$ Upper Bound: Sets the value of the highlighted parameter to the highest value accepted by RESRAD-ONSITE. The highest value may be a physical bound (i.e., the highest value that is applicable for the parameter because of physical considerations) or simply a numerical bound imposed to prevent the code from crashing.

Help Submenu: The commands in this submenu allow access to general help, context-specific help for the currently highlighted input parameter, and information about the current version of the RESRAD-ONSITE code.

- General Help: Displays the help index, which is a list of topics concerning the features, designed use, and input parameters of the RESRAD-ONSITE code. Except for the "Input Parameters" topic, each topic is associated with an information screen, which will be displayed when the topic is selected. The "Input Parameters" topic is associated with a list of subtopics corresponding to the different categories of the input parameters. Each subtopic is associated with an information screen, which will be displayed when the subtopic is selected, or a list of input parameters each of which is associated with an information screen.

- Context Help: Displays the same help index as the "General Help” command. If the command is selected while an input parameter in an open form is highlighted, the information screen associated with the highlighted input parameter will be displayed.

- About RESRAD-ONSITE: Displays the "About RESRAD-ONSITE” window, which shows the version number and release date of the RESRADONSITE code installed on the computer and currently in use. In addition, the window contains information on the percentage of computer memory in use, the e-mail contact with the RESRAD team, and the link to the RESRAD program website. 


\subsubsection{Toolbars}

There are two toolbars located under the Main Menu - the Primary Toolbar and the Pathways Toolbar. These two toolbars contain command buttons that perform the same operations as the submenu commands that are associated with the Main Menu and were discussed in the previous section.

Primary Toolbar: Figure 3 shows the Primary Toolbar with the 14 command buttons it contains. These command buttons perform operations associated with files, input parameters, calculation results, and display. The specific operation performed by each button is described below:

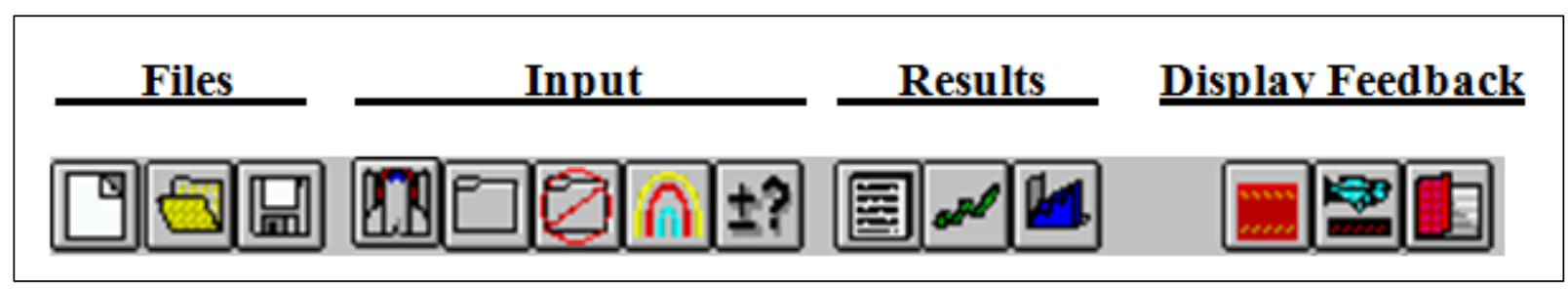

FIGURE 3 The Primary Toolbar

- Files

- Reset all input parameters to default values.

- Open an existing input file.

- Save data currently in all input forms to a file.

- Input

- Run the calculations.

- Save changes to the current input form.

- Cancel changes to the current input form.

- Perform the sensitivity analysis.

- Perform the uncertainty analysis on the current variable.

- Results

- View the latest summary report.

- View deterministic graphics (displays the graphic output window presenting the deterministic base case and sensitivity analysis results).

- View uncertainty/probabilistic graphics (displays the graphic output window presenting the uncertainty/probabilistic analysis results).

\section{- Display Feedback}

- Display/hide the soil strata graphic window.

- Display/hide the Pathway Toolbar. 
- Display/hide the gray bar at the bottom of the interface that summarizes the sensitivity analysis selections.

Pathways Toolbar: Figure 4 shows the 20 command buttons the Pathways Toolbar contains. The toolbar is displayed if the user preference is set to display it in the "View" submenu (Section 3.1.1). The first nine command buttons show the status of the nine exposure pathways, i.e., external radiation, inhalation, plant ingestion, meat ingestion, milk ingestion, aquatic food ingestion, drinking water ingestion, soil ingestion, and radon inhalation, respectively, considered in the RESRAD-ONSITE modeling. In Figure 4, the radon inhalation pathway is inactivated. Each pathway can be activated or inactivated by clicking the command buttons.

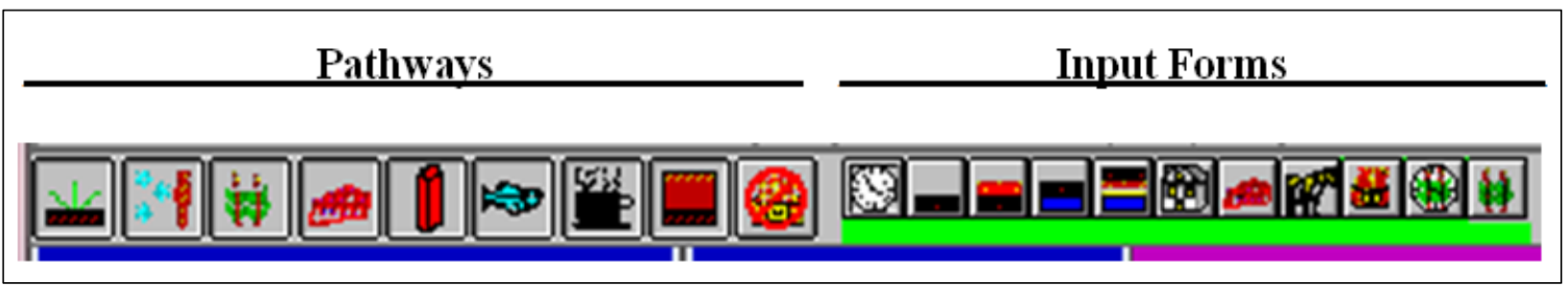

\section{FIGURE 4 The Pathways Toolbar}

The remaining 11 command buttons allow access to all but three input options, such as the "Site Data" submenu. The three variable input options that cannot be accessed with the command buttons are the "Soil Concentrations" option (accessible with the "Site Data" submenu), the "External Radiation Area Factors" (accessible from the "Occupancy, Inhalation, and External Gamma” data option), and the "Nuclide-dependent Transport Factors” option (accessible after the nuclides have been selected in the "Soil Concentrations" dialog box).

\subsubsection{Information Bars}

Two information bars are displayed at the bottom of the interface when they have been chosen from the "View" submenu. The "Sensitivity Analysis Summary Bar" (the lower gray bar in Figure 5) shows the number of input parameters selected for a sensitivity analysis and a button for each selected parameter. Each button shows the parameter name and the analysis range specified. Clicking on the button will display the "Set Sensitivity Analysis Range" input window in which the sensitivity analysis range can be changed or the input parameter can be deleted from the selection list. The "Variable Information Bar" (the upper gray bar in Figure 5) shows the name, default value, and range of acceptable values for the input parameter that is currently highlighted. 


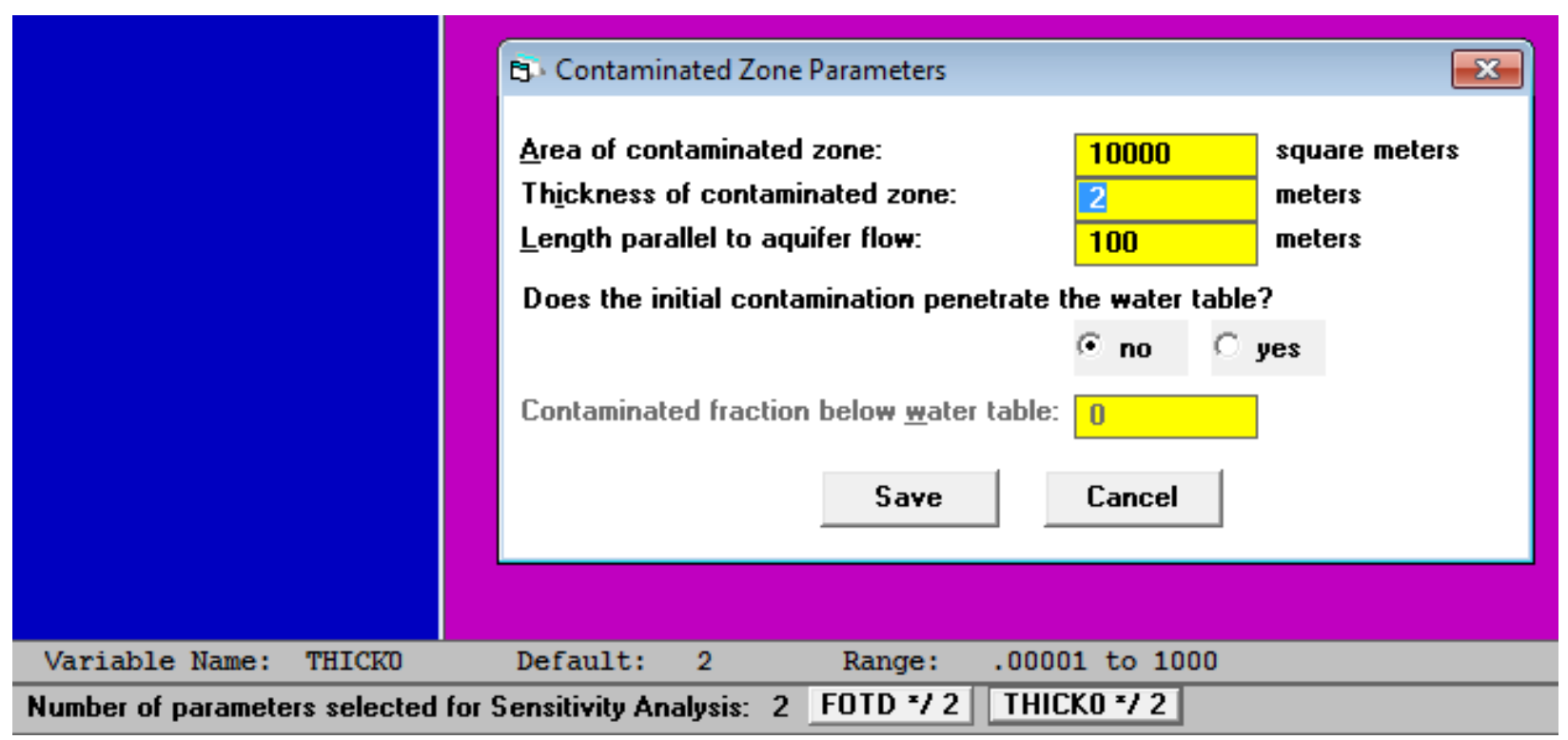

FIGURE 5 The Interface with the Two Information Bars

\subsection{NAVIGATOR WINDOW}

The Navigator window is displayed if the user has selected to display this window using the "View" submenu. The default preference is to display this window. This window has four tabs (Figure 6). The first tab, "Problem," shows the broad outline of the sequence to be adopted to perform the analysis. The second tab, "Pathways/Input," is for specifying the pathways and inputs for the site-specific scenario to be analyzed. The third tab, "Results," is for viewing the results after the analysis. The fourth tab, "Help," provides information on sources of help for the analysis. 

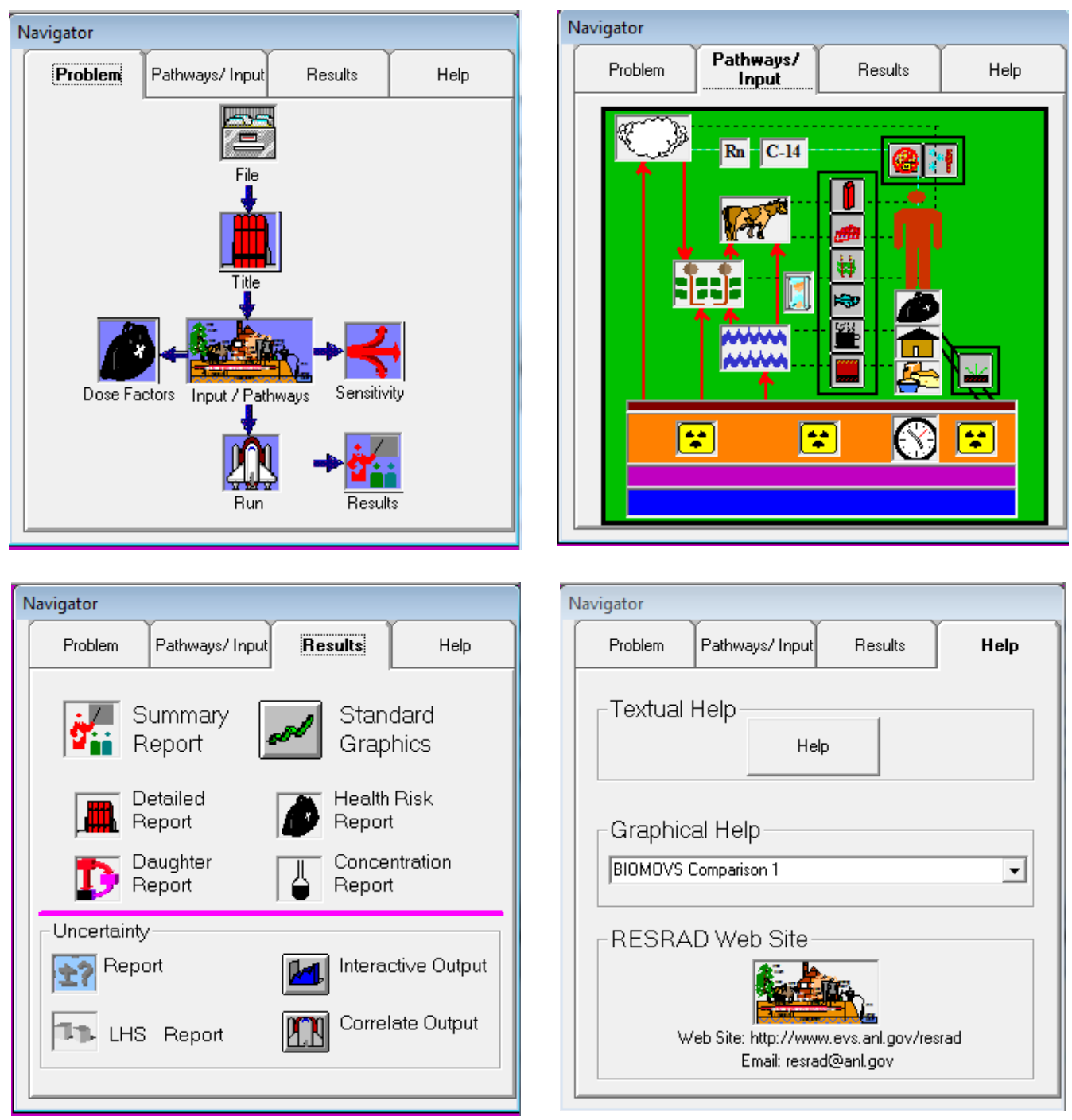

\section{FIGURE 6 Navigator}

Problem: The tab on this window can be used to set up a problem case in RESRAD-ONSITE. Each button will bring up a dialog box to continue the process of inputting additional parameters or variables.

Pathways/Input: The tab on this window can be used to view and set pathways activation. All pathway buttons are in the black boxes. Inhalation pathways are located above the person icon. Ingestion pathways are to the left. The single external pathway is at the lower right. Click the icons to access the input forms. If the "View/Button Prompts" option was selected from the Main Menu, prompts display what each icon represents.

Results: The top two buttons allow access to the main results in report and graphical forms. The next four buttons are for accessing the supplementary reports. If an uncertainty analysis was run, three more buttons appear below the line to access the two reports and a set of graphics. 
Help: The tab on this window can be used to access all help features, including parameter descriptions under textual help, selected slides from the RESRAD workshop under graphical help, and the RESRAD website.

\subsection{RESRAD DOS EMULATOR}

One way to approach a case is to follow the list of command buttons in the RESRAD DOS Emulator shown on the left side of the RESRAD-ONSITE main interface (see Figure 1). Figure 7 shows the navigation from the main DOS emulator column.

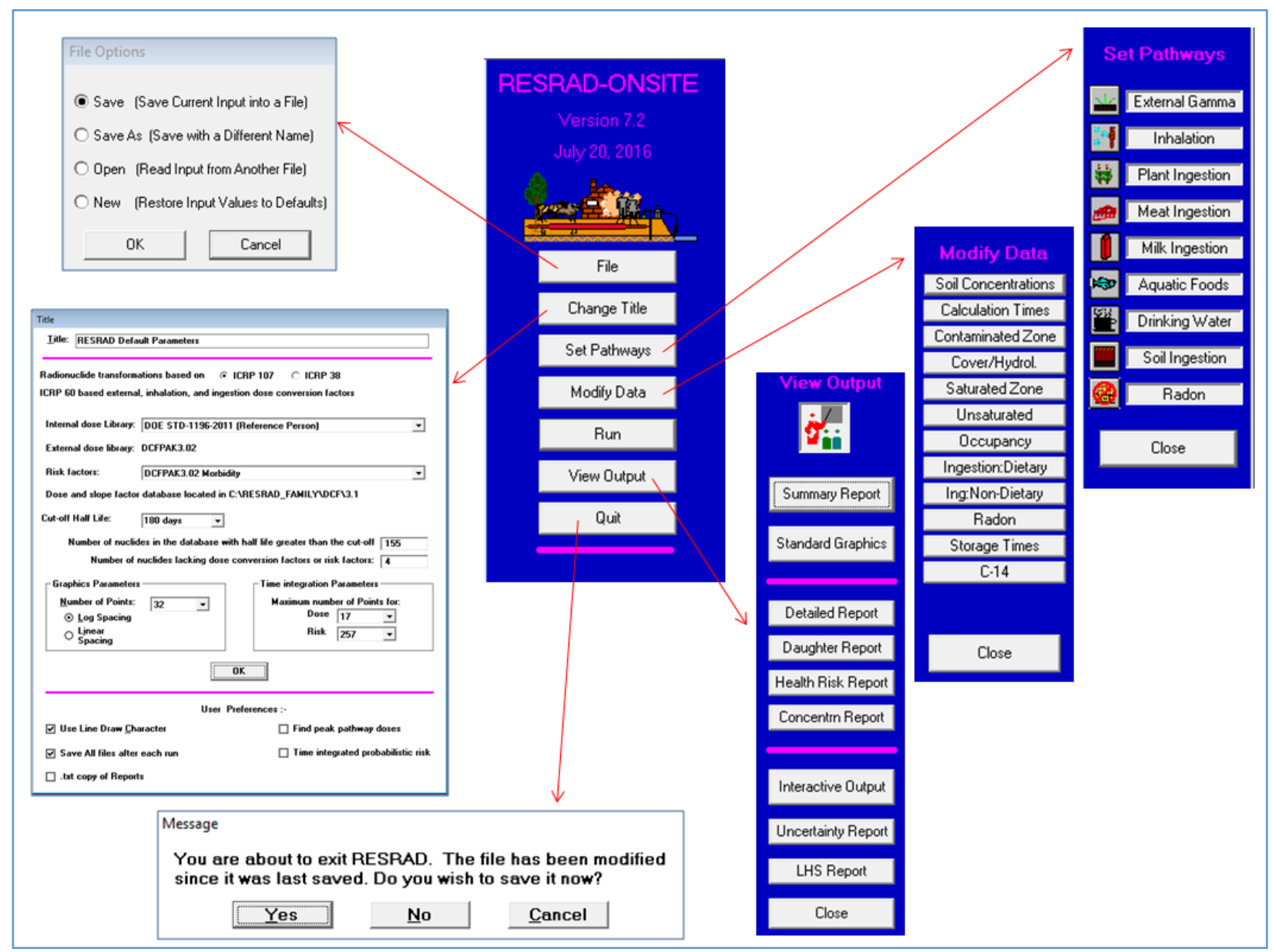

FIGURE 7 DOS Emulator Navigation

The description for each command button is presented below:

- File: Begin by bringing in an existing case or set the parameters to default values by selecting a new file. The current inputs selected can be saved into an existing file or to a different file. 
- Change Title: The window that appears after selecting this button includes other case-specific information besides the title. Generally, these other parameters can be kept at their default values. For more information, please refer to the description provided in this window (see Chapter 4).

- Set Pathways: Exposure pathways can be activated or deactivated depending on the land-use scenarios being modeled. For example, a residential farming scenario might include all pathways. An industrial scenario might rule out consideration of many ingestion pathways.

- Modify Data: When this button is clicked, a second column of buttons appears. Each button in this second column gives access to a group of data parameters for defining the case. After data in a window are changed, the data are saved in memory when the "Save" button is clicked.

- Run: After the case has been specified, the file is saved and the specified calculations are started. A window showing the progress of the calculations pops up. When the calculations are completed, a window allowing the user to view the output results report pops up.

- View Output: Although, by default, the output results report appears after a calculation, other reports and an interactive graphics window are also available. These can be chosen from the buttons on the column that appears to the right of the main column.

- Quit: Exit the RESRAD-ONSITE software by clicking this button. This action yields the same result as selecting "File/Exit" or clicking the close window button on the main RESRAD-ONSITE interface window.

To access the data input forms, click the buttons on the "Modify Data" column. 


\section{INPUT OF VARIABLES}

RESRAD-ONSITE has several ways to input variables or parameters or establish the proper pathways needed for a particular modeling scenario. In total, there are 16 input dialog boxes (forms) that can be selected through the previously mentioned buttons on the menu bar or menus on the left side of the software, and/or the Navigator dialog box (Figure 1). The dialog boxes or menus are:

1 Change Title: Accessible via the RESRAD-ONSITE radio buttons presented to the left of the open RESRAD-ONSITE software window (see Figure 1), or the Navigator button under the "Problem” tab as simply “Title” (see Figure 6).

2 Source: Accessible by clicking on the "Modify Data" radio button on left menu of the software (Figure 1). Under "Modify Data," select "Soil Concentrations.” You can also access the "Source" dialog box via the Navigator by clicking on the "Pathways/Input" tab and then hitting the boxes with the radioactive symbols (Figure 6). Finally you can access the "Source" parameters by going to the "Site Data" pulldown menu (Figure 2) and selecting "Soil Concentrations.”

3 Transport Factors: Can be accessed through the "Source" dialog previously mentioned above. The "Transport Factor" radio button is not accessible until after at least one nuclide has been selected. Probabilistic analysis on transfer factors is also not accessible until after at least one nuclide has been selected.

4 Calculation Times: This dialog box can be accessed in several ways. The first is via the "Modify Data” radio button. Under "Modify Data," select "Calculation Times” radio button (Figure 1). The second is by clicking on the clock icon shown on the pathways toolbar (when "Pathways" is selected in the pulldown "View" menu) (Figure 4), and the third is by clicking the clock icon in the "Pathways/Input" tab when the Navigator dialog box is open (Figure 1).

Finally, you can access the "Calculation Times" by clicking the "Site Data" on the top menu bar (Figure 1) and then selecting "Calculations Times” (Figure 2). You can also access the "Calculations Times” by using the shortcut Shift + F1.

5 Contaminated Zone Parameters: This dialog box also can be accessed several ways. First, via the "Modify Data” radio button. Under "Modify Data," select “Contaminated Zone” radio button (Figure 1). The second is by clicking on the "Contaminated Zone" icon (right of the clock icon) shown on the pathways toolbar (when "Pathways" is selected in the pulldown "View" menu [Figure 2]), and the third is by clicking on the orange zone layer of the soil representation in the "Pathways/Input" tab when the Navigator dialog box is open (Figure 6). As with the description of previous parameters, you can access the "Contaminated Zone" by clicking the "Site Data” on the top menu bar and then selecting "Contaminated Zone” (Figure 2) or by accessing it directly using the shortcut Shift + F2.

6 Cover and Contaminated Zone Hydrological Data: This dialog parameter or form can also be accessed by clicking the "Site Data" on the top menu bar and then selecting "Cover and 
Contaminated Hydrological" (Figure 2) or by using the shortcut Shift+F3. There are three other ways to access these parameters. First is via the "Modify Data" radio button. Under "Modify Data," select "Cover/Hydrol.” radio button. The second is by clicking on the "Cover/Hydrol." shown on the pathways toolbar and two icons to the right of the clock icon (when "Pathways" is selected in the pulldown "View" menu [Figure 2]), and the third is by clicking on the first top layer (burgundy) of the soil representation in the "Pathways/Input" tab when the Navigator dialog box is open (Figure 6).

7 Saturated Zone Hydrological Data: The saturated zone hydrological data is also available in five different ways. Just like the previous parameters, the saturated zone parameters are easy to get to under the "Modify Data" menu. Under this toolbox menu, click on the "Saturated Zone" radio button (Figure 1). The second way to access is through the pathways toolbar by clicking on the third icon to the right of the clock icon. The third method for arriving at these parameter settings for the saturated zone is through the Navigator dialog box, by clicking the "Pathways/Input" tab and then clicking the last blue layer of the graphical representation of soil (Figure 6). Finally, two more ways involve selecting "Saturated Zone Hydrological” on the "Site Data” menu or using the shortcut Shift+F4.

8 Unsaturated Zone Parameters: The first way to access these parameters is by clicking on the "Modify Data" icon, which is presented at the left side of the main interface (Figure 1). Then under the "Modify Data" menu, select the "Unsaturated" radio button. The second way is by clicking on the fourth button to the right of the clock icon on the menu in the pathways toolbar, and finally via the Navigator dialog box, by clicking the "Pathways/Input" tab and then clicking on the purple layer of the graphical representation of soil (Figure 6). You can edit the parameters by selecting "Unsaturated Zone" on the "Site Data” menu or using the shortcut Shift+F5.

9 Occupancy, Inhalation, and External Gamma Data: The first way to access these parameters is by clicking on the "Modify Data" icon, which is presented at the left side of the main interface (Figure 1). Then under the "Modify Data" menu, select the "Occupancy" radio button. The second way is through the Navigator dialog box, by clicking the "Pathways/Input" tab and then clicking either on the large "cloud" icon represented on the upper left side of the dialog tab or the "house" icon shown on the right side of the dialog tab. The third way is the "house" icon on the Pathways Toolbar (Figure 4). You can also access this parameter dialog box by going to the "Site Data" pulldown menu on the menu bar and select "Occupancy, Inhalation, and Gamma” (Figure 2) or use the shortcut Shift+F6.

10 External Radiation Area Factors: The external radiation area factor is a submenu of the "Occupancy" dialog box. Access the "Occupancy" form via one of the various ways presented above and then click on the "Shape" radio button after selecting the non-circular area.

11 Ingestion Pathway, Dietary Data: Information to edit the dietary ingestion parameters can be performed by going through the "Modify Data" menu and clicking on the "Ing:Dietary" radio button. These parameters are also accessible via the Pathway buttons on the pathways toolbar (fifth icon from right to left), via the "Site Data" dropdown menu and selecting the "Ingestion Parameters, dietary" radio button, or by using the shortcut Shift+F7. Another way of accessing 
this data for editing is via the "Pathway/Input" tab in the Navigator dialog box by clicking on the icon below the "house" icon on the lower right side of the graphical menu.

12 Ingestion Pathway, Nondietary Data: Nondietary data for ingestion pathways can be entered by going through the "Modify Data” radio button. Under "Modify Data” select "Ing:Nondietary" radio button (Figure 1). These parameters are also accessible via the buttons on the pathways toolbar (fourth icon from right to left), via the "Site Data" dropdown menu and selecting the "Ingestion Parameters, nondietary" radio button, or by using the shortcut Shift+F8. It is also accessible through the Navigator using the "Pathways/Input" tab and clicking on the "cow" icon, the "agriculture" icon, or the "water" icon.

13 Plant Factors: The plant factor is a submenu of the "Ingestion Pathway, Nondietary Data" dialog box. Access the "Ingestion Pathway Nondietary Data” form using one of the various ways presented above and then click on the "Plant Factor" radio button.

14 Radon Data: Radon data parameters can be accessed in multiple ways, as well. The first method is via the "Modify Data" button and then selecting the "Radon" button under the "Modify Data" menu (Figure 1). You can also access the radon parameters dialog box (form) via the buttons on the pathways toolbar (third icon from right to left), or via the "Site Data" dropdown menu and selecting the "Radon" radio button, or by using the shortcut Shift+F9. Another way of accessing this data for editing is via the "Pathway/Input" tab in the Navigator dialog box by clicking the "Rn" icon just to the right of the "cloud" icon (Figure 6).

15 Storage Times before Use Data: Under the “Modify Data” select “Storage Times” (Figure 1). You can also access "storage times before use data" by clicking on the second icon from right to left on the pathways toolbar (if "Pathways" is previously selected under the "View" menu). "Storage Times" is also accessible via the "Site Data” dropdown menu. Finally, "Storage Data" can be accessed through the Navigator dialog box and selecting the "hourglass" icon in the middle of the "Pathways/Input” tab (Figure 6).

16 Carbon-14 Data: The parameter dialog box (form) only opens if you have selected C-14 as one of your sources under the soil concentration initial setup. If you do not select C-14, you will see the following message: "C-14 is not a contaminant." If you do select C-14 as one of your sources of concern, then there are several ways to arrive at the different variables or parameters. The first, like some of the previous parameters, is via the "Modify Data" menu and clicking on the "C-14" radio button (Figure 1). The "C-14" parameter dialog box can also be accessed by clicking on the first icon from right to left on the pathways toolbar (if "Pathways" is previously selected under the "View" menu). "C-14" is also selectable via the "Site Data” dropdown menu or by using the shortcut Shift+F11. Finally, "C-14" can be accessed through the Navigator dialog box and selecting the "C-14" icon in the upper middle of the "Pathways/Input" tab (Figure 6). The following features are common to all data input forms (dialog boxes).

Saving Information to Memory: Two levels of saved information are available in RESRADONSITE. Temporarily saving information to memory is the first level and can be executed with any of the following commands: 
- Function Keys: Press the F10 function key to save, the ESC key to cancel.

- Form: Press the "Save" button to save, the "Cancel" button to cancel.

- Menu: Select "Form Options/Save current form” from the Main Menu to save, "Form Options/Cancel current form) to cancel (see Figure 2).

- Primary Toolbar: Press the "Folder" button to save, the "Canceled Folder" button to cancel.

Saving Information to File: Saving the settings to a file is the second level and can be executed with any of the following commands.

- Window: Press the "File" button in the DOS Emulator or Navigator.

- Menu: Select "File/Save” or "Save As".

- Toolbar: Press the "Disk" button.

- Run: The file must be saved to disk before a run. Follow the prompts to save in the desired place.

Numerical Entries: (Some entry boxes may be grayed out because they are not applicable to the current case.)

- Defaults: To set the selected parameter back to its default value, either select "Form Options/Default" from the Main Menu or press the F6 function key.

- Bounds: To set the selected parameter to its upper or lower bound, either select the "Form Options" from the Main Menu bar and select "Upper Bound" (or function key F7) or "Lower Bound" (or function key F5).

- Help: Context-specific help will be shown anytime the F2 function key is pressed. For further sources of help, see Chapter 8.

Selecting a Parameter for Sensitivity Analysis: Input parameters can be selected for oneparameter-at-a-time sensitivity analysis by pressing the F9 key while the cursor is in the input box for that parameter (see Section 7.1 on Sensitivity Analysis). Some parameters are ineligible for sensitivity analysis, because it does not make sense to perform a sensitivity analysis on those parameters.

Selecting a Parameter for Uncertainty/Probabilistic Analysis: Input parameters can be selected for inclusion in an uncertainty/probabilistic analysis by pressing the F8 key while the cursor is in the input box for that parameter (see Section 7.2 on Uncertainty/Probabilistic Analysis). Some parameters are ineligible for uncertainty analysis, either because it does not 
make sense to perform the analysis on those parameters, or because of unmanageable constraints imposed by interrelationships with other parameters.

The subsections that follow describe each screen in detail. Most input is through numerical entry into boxes, although some selections are through standard Windows list boxes, check boxes, and option boxes. Access to dose conversion factors ${ }^{1}$, slope/risk factors, and transfer factors is available through the DCF Editor (see Chapter 5).

\subsection{TITLE}

The "Title" form shown in Figure 8 does not have a cancel feature. Any changes made to this form can be reversed only by inputting the original values again. None of the parameters in this form is eligible for uncertainty or sensitivity analysis.

1 The dose conversion factor is a multiplier used to convert radionuclide concentration to dose. The two terms, dose conversion factor or dose coefficient, are used interchangeably in this document. 


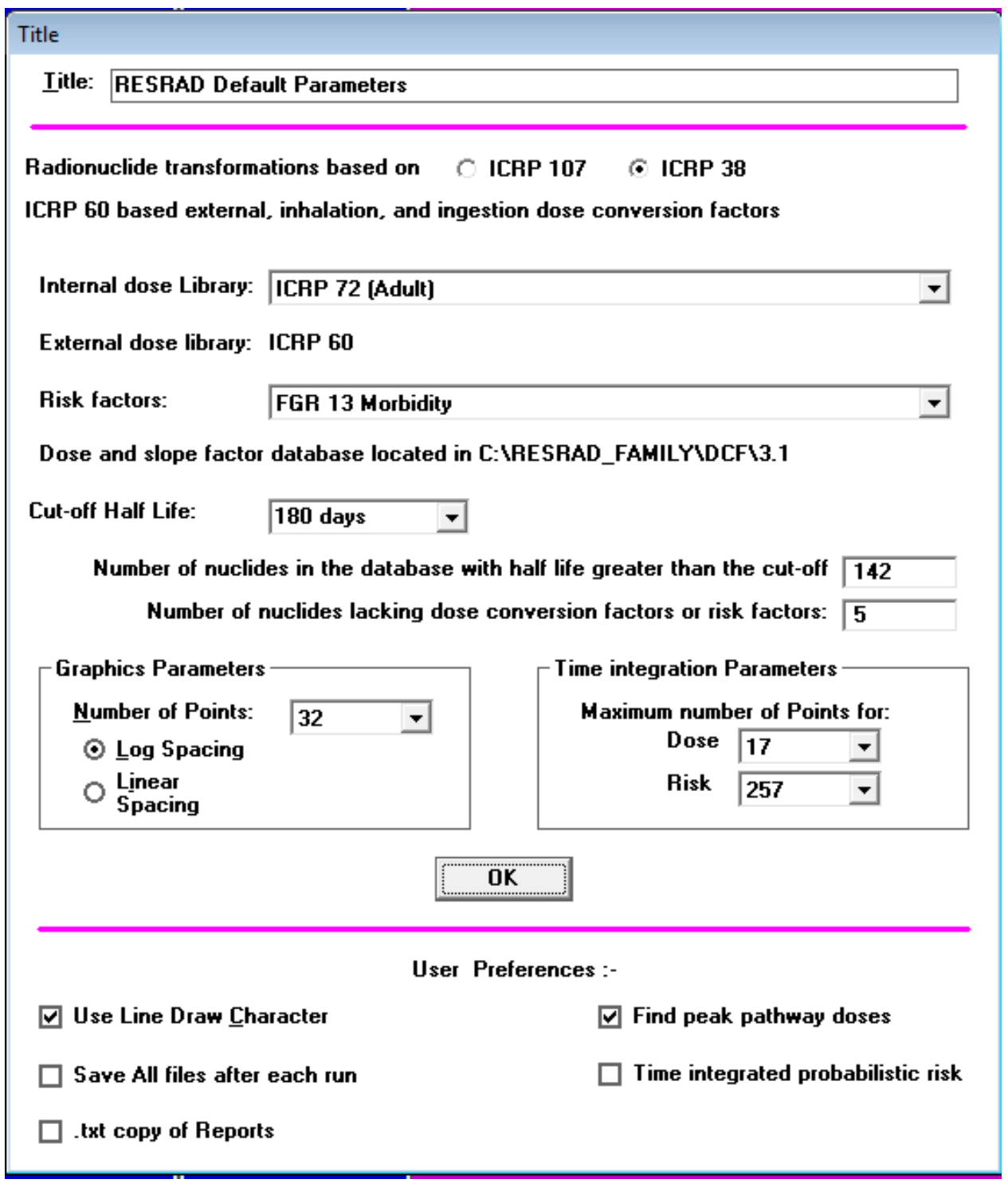

\section{FIGURE 8 Title Form}


Title: This box is used to enter text that describes the problem being modeled. This text will appear at the top of each report page. Note that the apostrophe character (') cannot be used in the “Title” box or RESRAD-ONSITE will crash.

Radionuclide Transformation based on: The user has an option to select the ICRP 107 (ICRP 2008)-based or ICRP 38 (ICRP 1983)-based radionuclide transformation database. If the ICRP 107 radionuclide transformation database is selected, only ICRP 60 (ICRP 1991)-based external, inhalation, and ingestion dose coefficients are available. If the ICRP 38 radionuclide transformation database is selected, the ICRP 26 (ICRP 1977)-based external, inhalation, and ingestion dose coefficients are also available.

Internal Dose Library: The user selects the set of internal dose coefficients to use. If the ICRP 107 radionuclide transformation database is selected, the DCFPAK 3.02 internal dose coefficients library for any age group among Adult, Age 15, Age 10, Age 5, Age 1, and Infant or those for a reference person (Chapter 5 ) can be selected for the analysis. If the ICRP 38 radionuclide transformation database is selected, the Federal Guidance Report 11 (FGR-11) (Eckerman et al., 1988) dose coefficient library or age-dependent ICRP 72 (ICRP 1996) libraries can be selected for the analysis. FGR-11 internal dose coefficients are based on the ICRP 26 methodology, and ICRP 72 internal dose coefficients are based on the ICRP 60 methodology. Section 7.4 discusses the ICRP 26 and ICRP 60 methodologies. These libraries of dose coefficients can be viewed by using the DCF Editor, which is a standalone utility program common to the RESRAD family of codes. Users can also create their own dose coefficient libraries starting with the base libraries available in the DCF Editor.

External Dose Library: The external dose coefficient library is automatically selected based on the internal dose library selection. For example, if the FGR-11 internal dose library is chosen, the external dose library used is FGR-12 (Eckerman et al., 1993). Both the internal and external dose libraries will come from the user-created library when a user-created library is selected.

Risk Factors: Users select the set of slope (risk) factors to use. Libraries of risk factors can be set up by using the DCF Editor. If the ICRP 107 radionuclide transformation database is selected, the DCFPAK 3.02 morbidity or mortality risk factor libraries can be selected for the analysis. If the ICRP 38 radionuclide transformation database is selected, the standard FGR-13 morbidity or mortality risk factor library (Eckerman et al. 1999) or the Environmental Protection Agency’s (EPA’s) Health Effects Assessment Summary Tables (HEAST) 2001 morbidity (EPA 2001) slope factor libraries can be selected for the analysis. Users can also create their own risk factor libraries, and those can be selected for the analysis.

If the default installation selections are used, the files to support the dose and risk factor libraries are located at C:IRESRAD_Family $\backslash D C F \backslash 3.1$.

Cutoff Half-Life: This indicates the assumption about secular equilibrium for principal and associated radionuclides. The fate and transport of radionuclides with half-lives greater than the specified half-life are modeled explicitly by the code. Progeny radionuclides with half-lives shorter than the specified value are assumed to be in secular equilibrium with their immediate 
parent. The user can select from the values in the list (180, 30, 7, or 1 day[s]) or type in a value that is not less than 10 minutes.

Informational Boxes: There are two informational boxes on this form. The first shows the number of radionuclides in the currently chosen ICRP 38 or ICRP 107 database that have a halflife greater than or equal to the current cutoff half-life. The second shows the number of such radionuclides that are lacking one or more dose coefficients or slope factors.

\section{Graphics Parameters}

Number of Points: This specifies the number of times, including the user-specified evaluation times, that will be used to generate smoother data plots. A higher number means higher graphic resolution but also longer execution times. The choices are limited to 32, 64, 128, 256, 512, and 1,024 points. When the user selects 7 times in the calculation time form, then 8 times (including time zero) will be part of the graphical time points. If 32 graphical points are selected, then the code will generate 24 more time points. A greater number of points is required, if the rate of release of a radionuclide changes rapidly over time. For most of the radionuclides, 32 or 64 points should give results of sufficient accuracy.

Spacing: The spacing shows the manner in which the numbers of time points are distributed over the time horizon. In RESRAD-ONSITE, the time horizon is the sum of the maximum userspecified reporting time (Section 4.4) and the exposure duration (Section 4.9). The spacing can be linear or log.

- Log: If the log option is chosen, the time points are spaced in a geometric sequence (uniformly on a logarithmic scale) between the smallest and the largest.

- Linear: If the linear option is chosen, the time points are spaced uniformly (in an arithmetic sequence) between 0 and the time horizon.

\section{Time Integration Parameters}

- Dose Integration over Time: Specifies the maximum number of integration points for the time integration of dose. Up to 17 points may be used over a one-year period.

- $\quad$ Risk Integration over Time: Specifies the maximum number of integration points for the time integration of risk. Up to 513 points may be used over the exposure duration.

\section{User Preferences}

- Use Line Draw Character: It is recommended that the MS Line Draw font be used for the reports because it produces well-formatted tables and quality lines. 
- Find Peak Pathway Doses: To include the pathway-specific peaks in the calculation, check this box. If it is unchecked, only the total dose peak will be found.

- Save All Files after Each Run: By default, all output files have a fixed name, and therefore are overwritten for each run. When this option is checked, the output files have the input file's base name with a descriptive extension. The output files are saved in the same location as the input .rad file.

- Time Integrated Probabilistic Risk: By default, the probabilistic risk is not time-integrated (the probabilistic dose is time-integrated). When this option is checked, the probabilistic risk will be time-integrated, and the calculations will take longer to complete.

- .txt Copy of Reports: By default, the text copy of reports is not generated. When this option is checked, a text copy of reports is also generated.

\subsection{SOURCE (INITIAL CONCENTRATIONS OF NUCLIDES)}

Source is also referenced in the software as "radionuclides" or "soil concentrations." The "Source" form (Figure 9), which can be selected under "soil concentrations" or the radioactive tri-foil within the Navigator menu, does not have a cancel feature. Any changes made to this form can be reversed only by re-entering the values. 


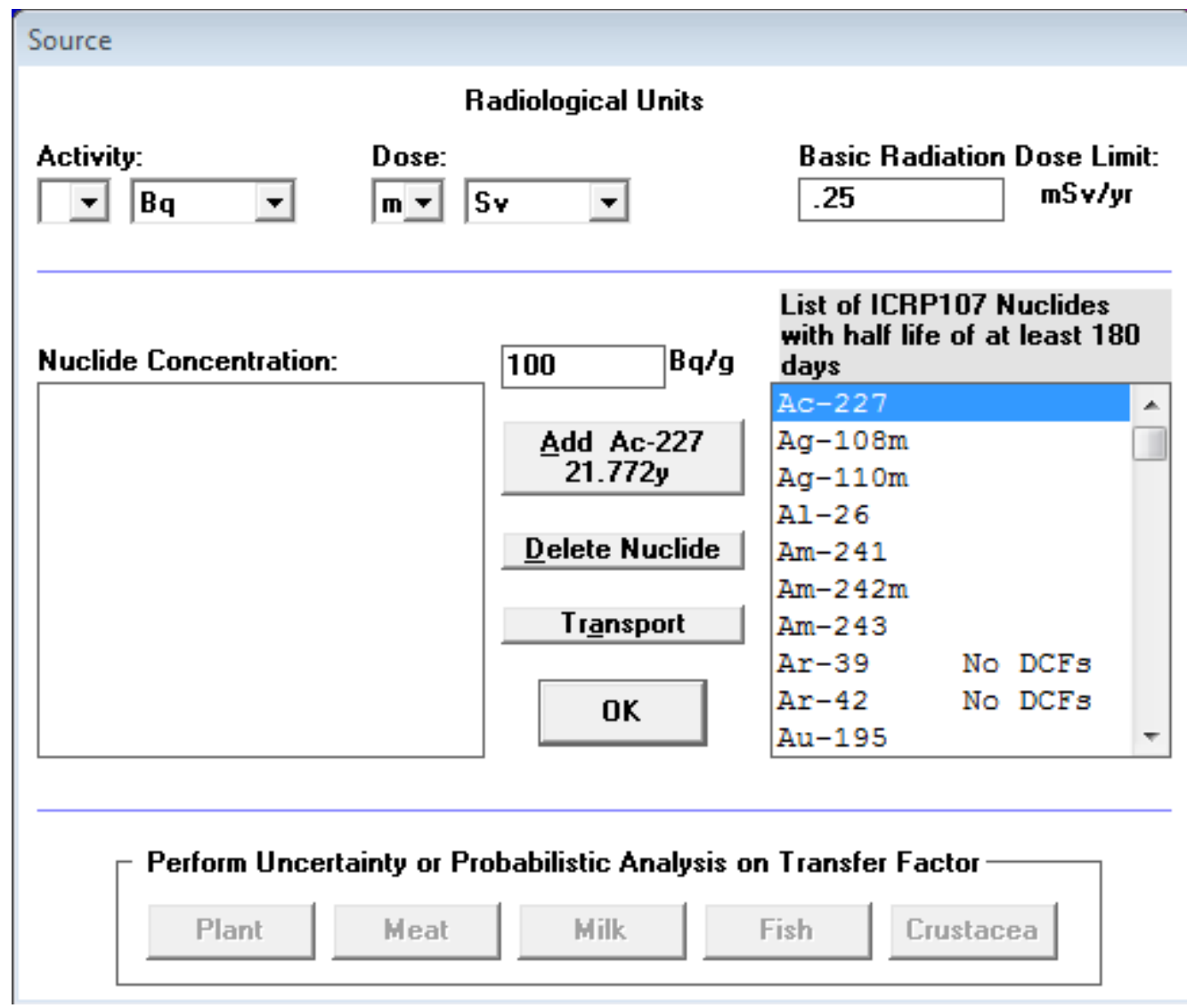

FIGURE 9 Source Form

Radiological Units: The dropdown boxes allow the user to select the prefix and desired unit of Activity and Dose.

1. Activity: Available choices are Curie (Ci), Becquerel (Bq), disintegration per second (dps), and disintegration per minute (dpm). The $\mathrm{Ci}$ and $\mathrm{Bq}$ can be combined with metric prefixes ranging from atto $\left(10^{-18}\right)$ through exa $\left(10^{18}\right)$.

2. Dose: Available choices are Roentgen equivalent man (rem) and Sievert (Sv); these be combined with metric prefixes ranging from atto $\left(10^{-18}\right)$ through exa $\left(10^{18}\right)$.

Basic Radiation Dose Limit: This is the annual dose limit to be used for soil guidelines.

List of Nuclides in Database: This list (in the right scroll box) shows all of the radionuclides in the database selected that have a half-life greater than the cutoff half-life selected in the "Title" form. See Section 3.1 in the RESRAD-ONSITE Manual Version 6 (Yu et al. 2001) for a discussion on associated radionuclides. Any radionuclides lacking one or more dose coefficients or slope factors are flagged with a "No DCFs" comment on the side. This notifies the user that 
these radionuclides cannot be analyzed unless a library with a dose coefficient and slope factors is selected.

To Add a Radionuclide: To add a radionuclide, either click the radionuclide name in the right scroll box and then click on the "Addd Nuclide" button, or just double-click the radionuclide name. The radionuclide will appear in the left scroll box with a concentration that is specified in the top-center input box. All potential decay products will be added to the left scroll box; the decay products will have a default concentration of 0 , if they are not already present in the scroll box.

To Delete a Radionuclide: To delete a radionuclide, click on the radionuclide name on the left scroll box and then click the "Delete Nuclide" button. All potential decay products that arise only from the deleted radionuclide and that have a zero initial concentration also will be automatically deleted. You can delete the highlighted radionuclide by using the shortcut Alt+D.

Nuclide Concentration: This is the radionuclide concentration averaged over an appropriate depth and area. See Section 3.3 of the RESRAD-ONSITE Manual Version 6 (Yu et al. 2001) and RESRAD Data Collection Handbook (Yu et al. 2015) for more details.

- To Change an Existing Radionuclide Concentration: Click on the radionuclide in the left scroll box and enter the concentration.

- To Change the Default Concentration When Adding New Radionuclides: Click on the right scroll box and enter the concentration in the top-center box. To add radionuclides with this concentration, see the instructions above.

To View or Edit Transport Parameters: To view or edit transport parameters (Section 4.3), click on the radionuclide name on the left scroll box and then click the "Transport” button.

Perform Uncertainty or Probabilistic Analysis on Transfer Factor: To perform uncertainty or probabilistic analysis on transfer factors, highlight a nuclide in the contaminant box on the left and then click a button to set the probabilistic analysis parameters for the transfer factor (Section 7.2).

Note: The single radionuclide soil guidelines do not depend on the soil concentration; the mixture sum, however, does depend on the soil concentration. Thus, calculated mixture sum values are valid only if the concentrations are known.

\subsection{RADIONUCLIDE TRANSPORT FACTORS}

Figure 10 shows the “Transport Factors” form. 


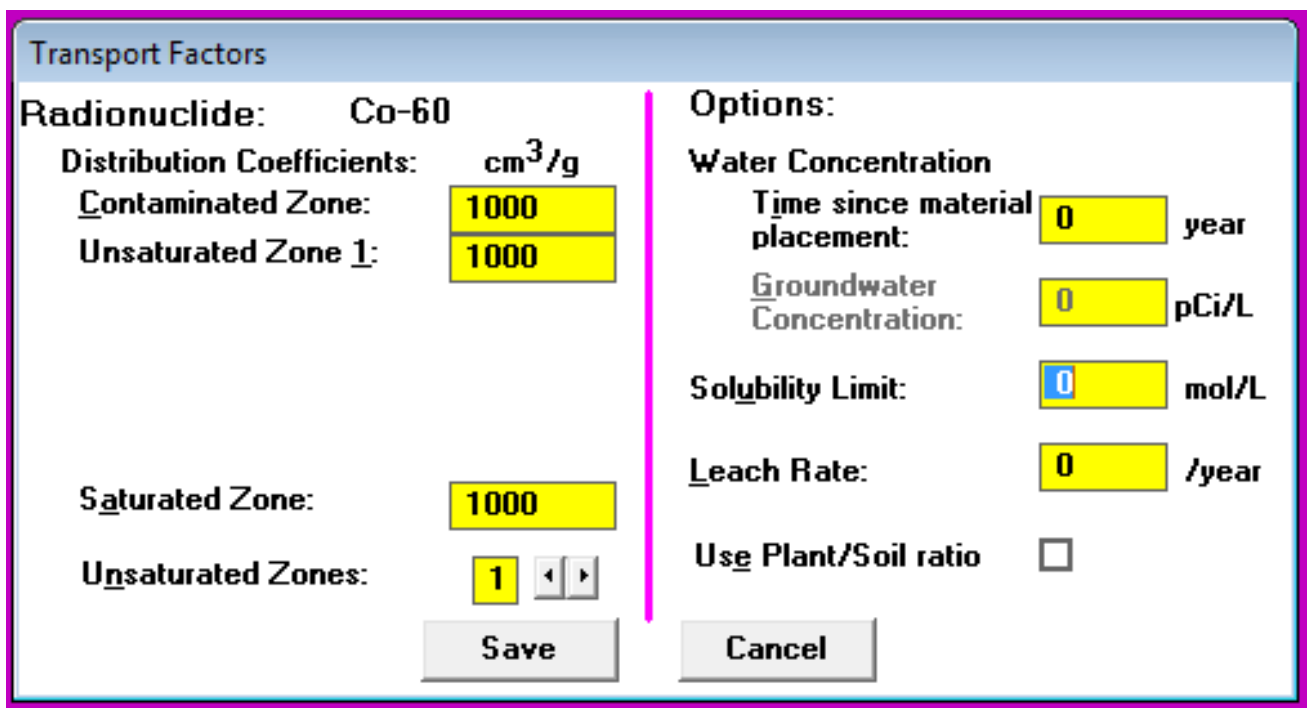

FIGURE 10 Transport Factors Form

Distribution Coefficients: The distribution coefficient is the ratio of the mass of solute adsorbed or precipitated on the soil (per unit of dry mass) to the solute concentration in the liquid. Defaults are provided for each radionuclide; however, site-specific values can vary over many orders of magnitude, depending on the chemical form, soil type, $\mathrm{pH}$, redox potential, and presence of other ions. Therefore, the use of site-specific distribution coefficients is highly recommended. Uncertainty and sensitivity analysis can be performed on the distribution coefficients.

Contaminated Zone: The contaminated zone distribution coefficient is used to estimate the leach rate.

Unsaturated and Saturated Zone: The distribution coefficients in the unsaturated and saturated zone are used to compute the radionuclide transport rate for the groundwater transport calculations.

Unsaturated Zones: This is the number of partially saturated layers between the primary contamination and the saturated zone. The code has provisions for up to five different horizontal strata.

Options: Values for the distribution coefficients can be directly entered; in addition, four options are available for non-direct estimation. The distribution coefficient will be set for all zones. Some estimates might give unrealistic (negative) values. The first valid value from the ordered list is used in the calculations.

Use of Water Concentrations: A distribution coefficient will be estimated based on the consistency of the soil concentration, water concentration, and time since placement. This option can be used when both the time since placement and the water concentration are nonzero. For nuclides in a chain, the parent radionuclide distribution coefficients should be determined before their progeny. 
Use of Solubility Limit: See Appendix J in RESRAD-ONSITE Version 6 User's Manual. This option can be used when the solubility limit is nonzero.

Use of Leach Rate: The distribution coefficient will be set for all zones to the value from Equation E.3 in Appendix E of the RESRAD-ONSITE User's Manual. This option can be used when a nonzero leach rate is entered.

Use of Plant/Soil Ratios: Relates to derived distribution coefficients. This option is used when the "Use Plant/Soil Ratio" check box is checked. See Appendix D, Table D.3, Plant/Soil Concentrations for Root Uptake Ratio in the RESRAD-ONSITE User’s Manual.

Direct Input of Distribution Coefficient: If none of the four options were applied or given a valid value, then the entered value should be used.

\subsection{CALCULATION PARAMETERS}

Also referenced within the software as "Calculation Times" or "Evaluation Times," none of the inputs on the "Calculation Parameters" form (Figure 11) is eligible for sensitivity or uncertainty analysis.

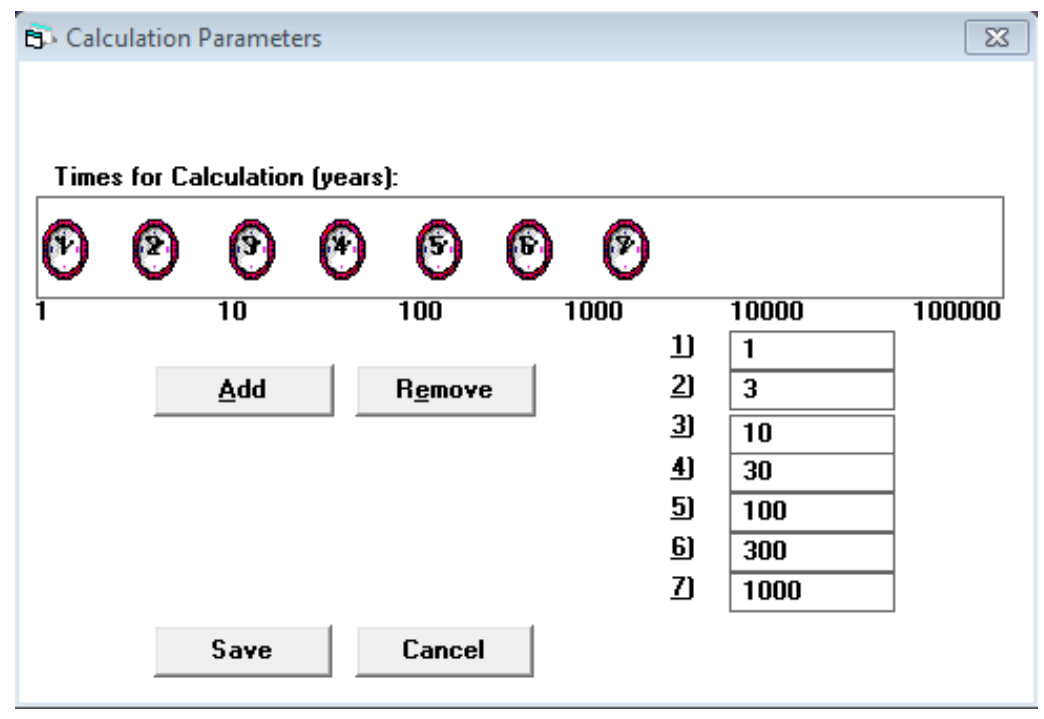

\section{FIGURE 11 Calculation Parameters Form}

Times for Calculation: These are the times following the radiological survey at which text results will be generated. Graphical output will supply intermediate values between the first and last user-specified times for log spacing. Under the linear spacing, the graphical output will supply intermediate values between time zero and the last user-specified time. A time horizon of 1,000 years is commonly used; however, calculations can be carried out to longer periods to identify potential problems from delayed contributions from the groundwater or other pathways. 
Results are always calculated for year 0 . The results are generated for a maximum of nine userspecified times.

Add: Use this button to add a time:

- Click on the “Add” button. A new clock icon and a time box will appear. Set the time following the change time procedure, or

- $\quad$ Click the right mouse button while in the frame containing the clock icons.

Remove: Use this button to remove a time:

- Click the appropriate time box or click the clock icon, then press the “Remove” button.

\section{To Change a Time:}

- $\quad$ Click the appropriate time box and enter the new value, or

- Click the appropriate clock icon and drag to the desired time location.

\subsection{CONTAMINATED ZONE PARAMETERS}

Figure 12 shows the “Contaminated Zone Parameters” form.

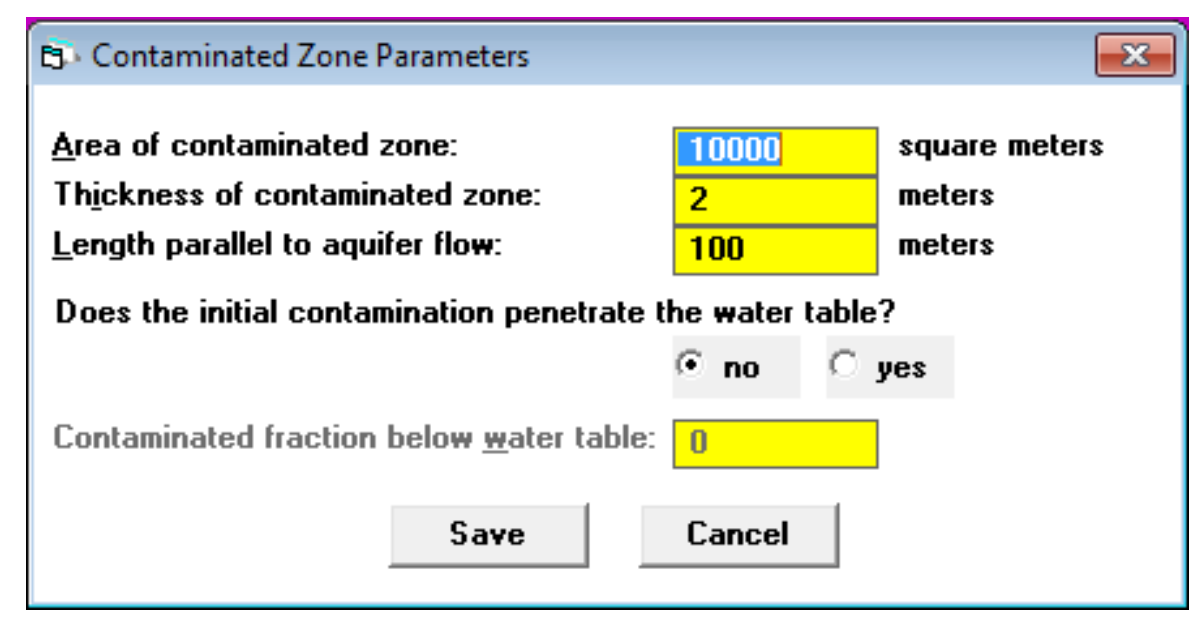

FIGURE 12 Contaminated Zone Parameters Form

Area of Contaminated Zone: The area of the contaminated zone is a compact area that contains the locations of all soil samples with radionuclide concentrations that are clearly (two standard deviations) above background.

Thickness of Contaminated Zone: The thickness of the contaminated zone is the distance between the shallowest and the deepest depths of contamination. 
Length Parallel to Aquifer Flow: The length parallel to aquifer flow is the distance between two parallel lines perpendicular to the direction of the aquifer flow; one is at the upgradient edge of the contaminated zone, and the other is at the downgradient edge.

Does the Initial Contamination Penetrate the Water Table: The user has an option to model contamination that is within the water table. If the "no" check box is clicked, all primary contamination is assumed to be above the water table. Checking the "yes" check box will allow the user to input a contaminated fraction that is below the water table, and, in this situation, the unsaturated zone thickness is set to zero.

Contaminated Fraction below Water Table: The contaminated fraction below the water table is a fraction of contamination that is saturated (i.e., below the water table). This parameter is required only if the "yes" check box is selected above.

\subsection{COVER AND CONTAMINATED ZONE HYDROLOGICAL DATA}

Uncertainty and sensitivity analysis can be performed on any parameter selected on the “Cover and Contaminated Zone Hydrological Data” form (Figure 13).

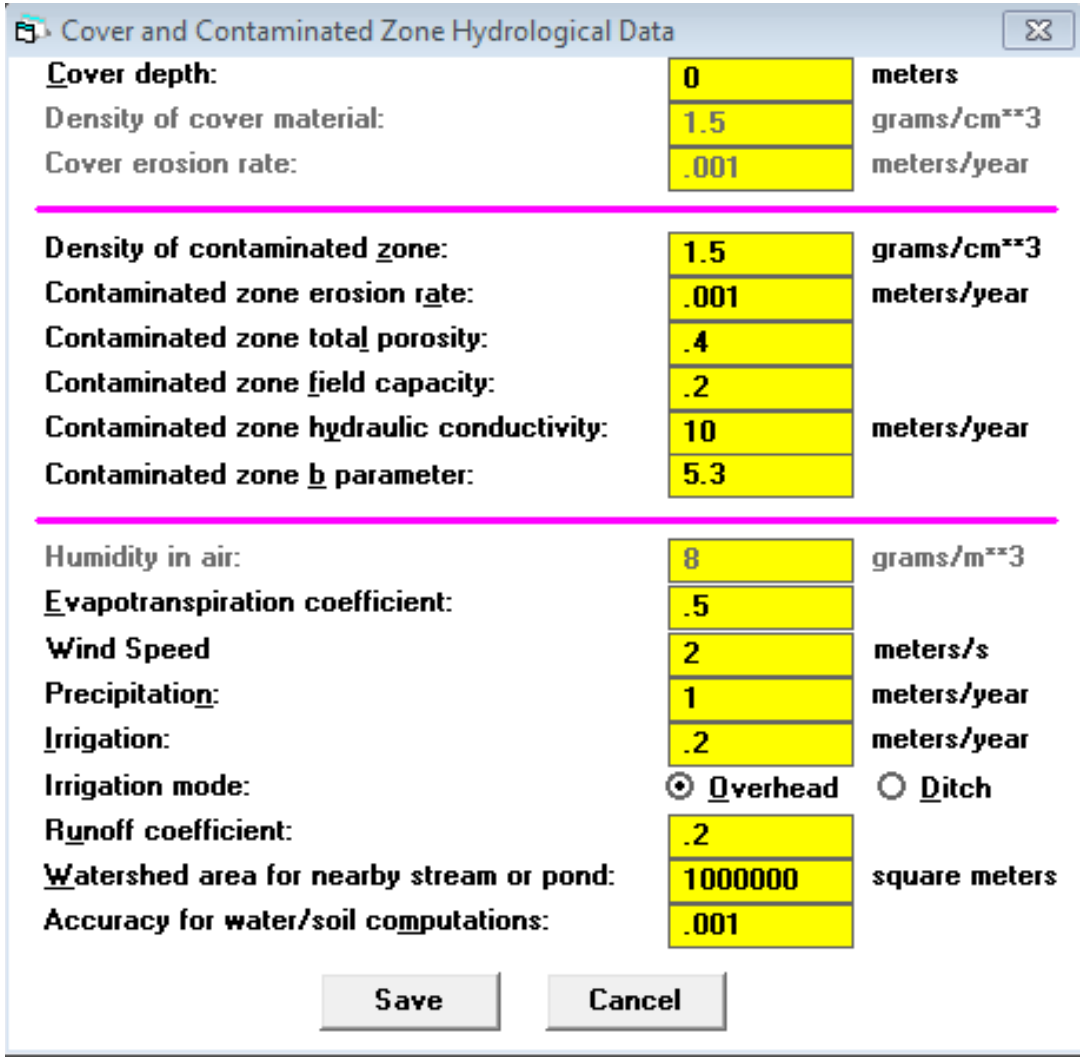

FIGURE 13 Cover and Contaminated Zone Hydrological Data Form 
Cover Depth: Cover depth is the distance from the ground surface to the location of the uppermost soil sample with radionuclide concentrations that are clearly above background. If nonzero cover depth is input, the user is required to input the density of cover material and the cover erosion rate.

Density (of Clean Cover and Soil in the Contaminated Zone): This is the mass of (dry) solids in a unit volume of material in the respective layers of material. This parameter is used to compute the exposure to external radiation. The density in the contaminated zone is also used to compute the release of activity to groundwater.

Erosion Rate: The erosion rate is the rate at which soil is removed by erosion. The rate can be estimated by means of the universal soil-loss equation described in Appendix A of the RESRADONSITE User's Manual. The contaminated zone erosion rate is only significant if and when the cover depth becomes zero. The cover erosion rate is only required when nonzero cover thickness is input.

Total Porosity (of Contaminated Zone): This is the fraction of soil (by volume) that is occupied by liquid and gaseous phases in the contaminated zone.

Field Capacity (of Contaminated Zone): This is the volumetric moisture content of soil at which (free) gravity drainage ceases. This is the amount of moisture that will be retained in a column of soil against the force of gravity.

Hydraulic Conductivity (of Contaminated Zone): This is the apparent flow velocity through the contaminated zone under a unit hydraulic gradient.

b Parameter (of Contaminated Zone): The soil-specific exponential b parameter relates the hydraulic conductivity of partially saturated soil to its moisture content.

Humidity in Air: Humidity in air is used only for the tritium model discussed in Appendix L of the RESRAD-ONSITE User's Manual, which also contains a map of average U.S. humidity values.

Evapotranspiration Coefficient: This is the fraction of precipitation and irrigation water that penetrates the topsoil which is lost to the atmosphere by evaporation and by transpiration by vegetation.

Wind Speed: The annual average wind speed is used to calculate the area factor for inhalation and foliar deposition (Appendixes B and D of RESRAD-ONSITE Users' Manual). It is also used for the radon pathway (Appendix C of the RESRAD-ONSITE User's Manual) and in the tritium and carbon-14 models (Appendix L of RESRAD-ONSITE User's Manual).

Precipitation: This is the annual average value of precipitation at the site. It is used to compute the infiltration rate in the primary contamination and the evapotranspiration of tritium. 
Irrigation: This is the amount of irrigation water that is applied over a period of 1 year per unit area of land. The irrigation can be applied by two methods: (1) overhead irrigation, and (2) ditch irrigation. The user can select either of these two irrigation modes.

Runoff Coefficient: This is the fraction of precipitation that does not penetrate the topsoil, and instead leaves the area of concern as surface runoff.

Watershed Area for Nearby Stream or Pond: This parameter is the total area from where the water runoff contributes to the nearby stream or pond. This parameter is used to estimate the dilution factor for a surface water pathway.

Accuracy for water/soil Computations: This is the fractional accuracy desired (conversion criterion) in the Romberg integration used to obtain water/soil concentration ratios.

Some of these parameters are discussed in Appendix E of RESRAD-ONSITE User's Manual, including typical values for various soil materials.

\subsection{SATURATED ZONE HYDROLOGICAL DATA}

Uncertainty and sensitivity analysis can be performed on any parameter whose value can be input on the "Saturated Zone Hydrological Data" form (Figure 14).

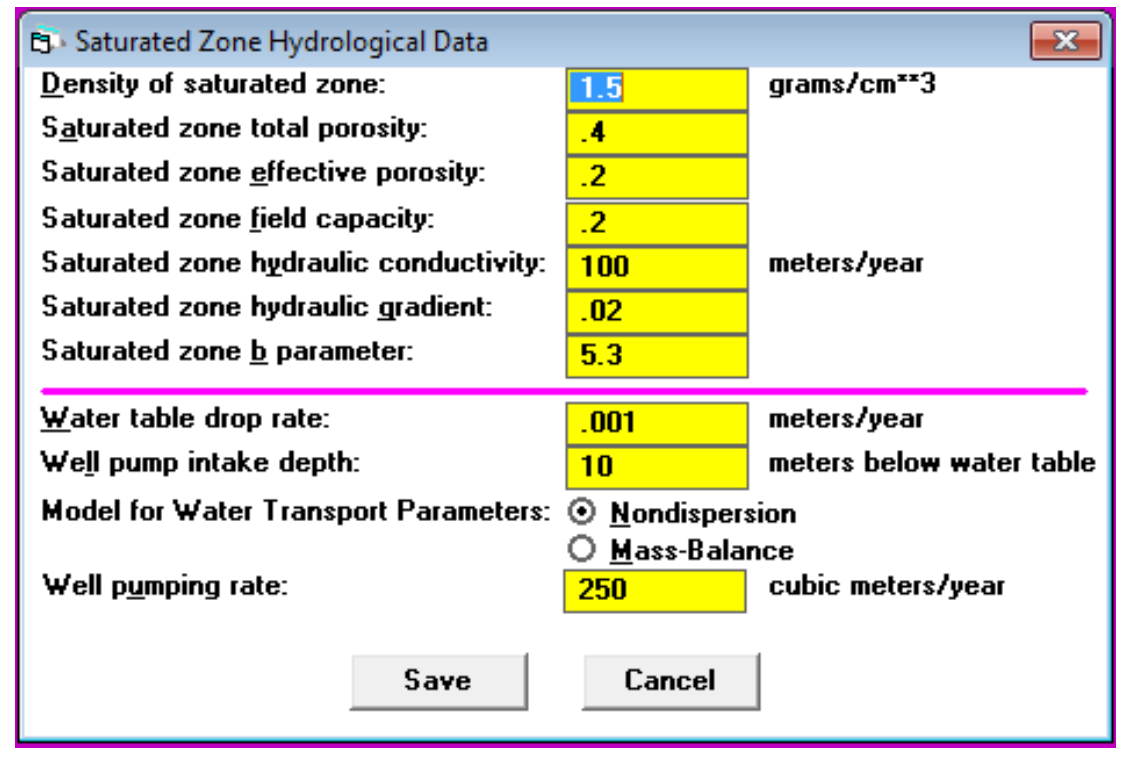

FIGURE 14 Saturated Zone Hydrological Data Form

Density of Saturated Zone: This is the density of the saturated zone. For the definition of density, see Section 4.6. 
Saturated Zone Total Porosity: This is the total porosity of the saturated zone. For the definition of porosity, see Section 4.6.

Saturated Zone Effective Porosity: This is the fraction of soil (by volume) through which water flows. Part of the soil moisture may not contribute to the movement of moisture and contaminants.

Saturated Zone Field Capacity: This is the field capacity of the saturated zone. For the definition of field capacity, see Section 4.6.

Saturated Zone Hydraulic Conductivity: This is the hydraulic conductivity of the saturated zone. For the definition of hydraulic conductivity, see Section 4.6.

Saturated Zone Hydraulic Gradient: This is the slope of the surface of the water table.

Saturated Zone b Parameter: This is the b parameter of the saturated zone. For the definition of the b parameter, see Section 4.6. The b parameter for the saturated zone is used only if the water table drop rate is greater than 0 .

Water Table Drop Rate: This parameter is the rate, in meters per year, that the water table decreases. If the water table drop rate is not zero, the unsaturated zone thickness will be created or increased.

Well Pump Intake Depth: This parameter is the number of meters below the water table for an on-site well intake.

Model for Water Transport Parameters: To model water transport in RESRAD-ONSITE code, two options are available: (1) nondispersion and (2) mass-balance. The user can select one option in modeling groundwater transport.

Nondispersion Option: The well water radionuclide concentration is derived by using a dilution factor based on a more complicated geometry. This option is normally for large contaminated areas $>1,000 \mathrm{~m}^{2}$. For more details on this model, see Appendix E in RESRAD-ONSITE User's Manual.

Mass-Balance Option: All radionuclides released from the contaminated zone are withdrawn through the well. This option can be used for small contaminated areas. For more details on this model, see Appendix E in the RESRAD-ONSITE User's Manual.

Well Pumping Rate: This is the rate at which water is extracted from the well. The well pumping rate should meet the water use demand for a given scenario. 


\subsection{UNCONTAMINATED UNSATURATED ZONE PARAMETERS}

Uncertainty and sensitivity analysis can be performed on any parameter whose value can be input on the "Uncontaminated Unsaturated Zone Parameters" form (Figure 15).

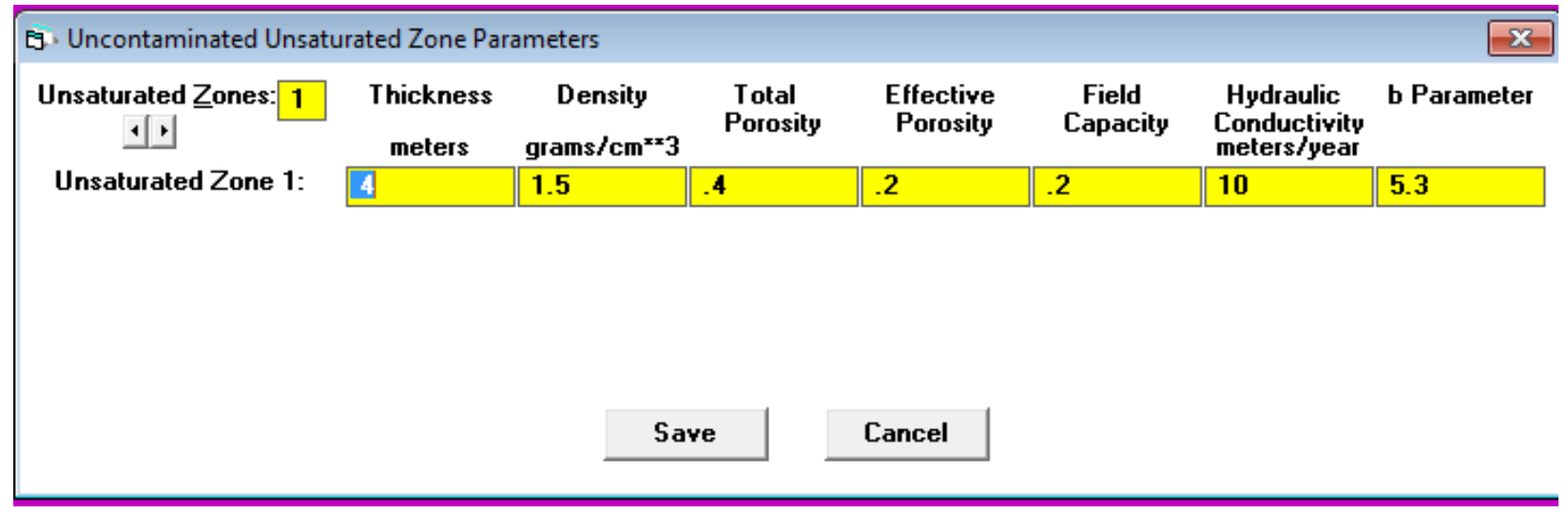

FIGURE 15 Uncontaminated Unsaturated Zone Parameters Form

Unsaturated Zone: This is the portion of the uncontaminated zone that lies below the contaminated zone and above the groundwater table.

Number of Unsaturated Zones: The code has provisions for up to five different horizontal strata.

Thickness: This is the thickness of the unsaturated zone.

Density: This is the density of the unsaturated zone. For the definition of density, see Section 4.6.

Total Porosity: This is the total porosity of the unsaturated zone. For the definition of porosity, see Section 4.6.

Effective Porosity: This is the effective porosity of the unsaturated zone. For the definition of effective porosity, see Section 4.7.

Field Capacity: This is the field capacity of the unsaturated zone. For the definition of field capacity, see Section 4.6 .

Hydraulic Conductivity: This is the hydraulic conductivity of the unsaturated zone. For the definition of hydraulic conductivity, see Section 4.6.

b Parameter: This is the b parameter of the unsaturated zone. For the definition of the b parameter, see Section 4.6. 


\subsection{OCCUPANCY, INHALATION, AND EXTERNAL GAMMA DATA}

Uncertainty and sensitivity analysis can be performed on any parameter on the “Occupancy, Inhalation, and External Gamma Data” form (Figure 16).

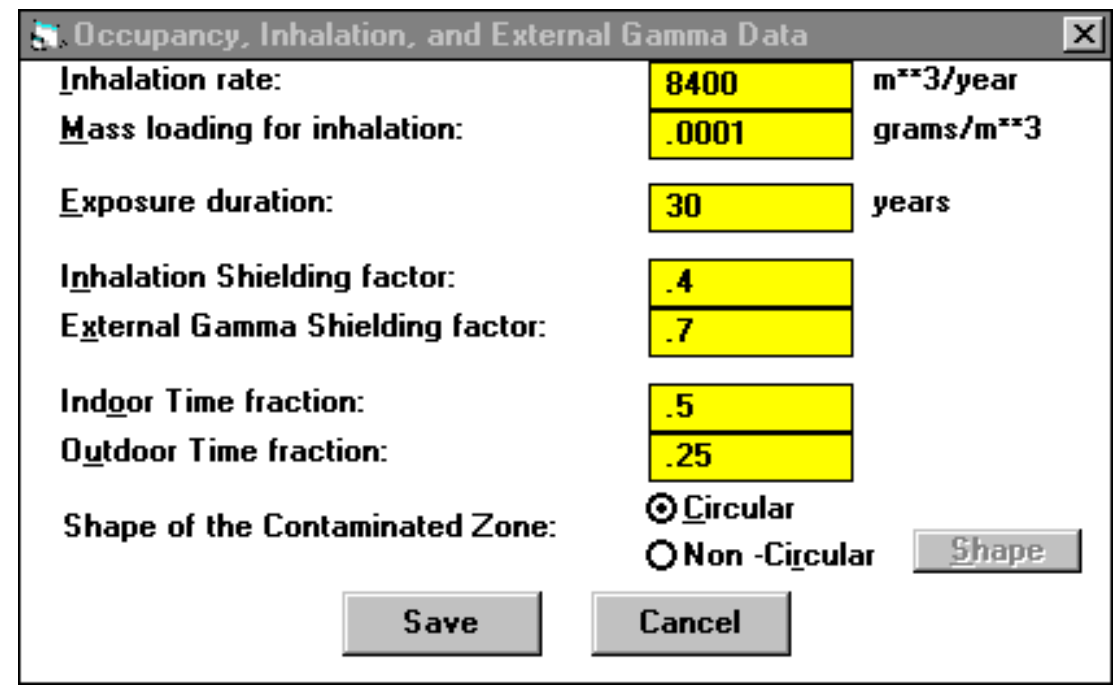

FIGURE 16 Occupancy, Inhalation, and External Gamma Data Form

Inhalation Rate: This is the average annual air intake rate.

Mass Loading for Inhalation: This is the average mass of respirable particulates in a unit volume of air when humans are present at the site (includes the effects of human activity). It is used in the inhalation pathway computations.

Exposure Duration: This is the length of time the receptor is exposed. This parameter is used only for risk calculations, not for dose calculations. The risk will be estimated by using up to a 513-point integral over the exposure duration. However, using more time integration points increases the computation time.

Inhalation Shielding Factor: This accounts for the effect of the building structure on the level of contaminated dust that exists indoors. It is the fraction of outdoor contaminated dust that is present indoors.

External Gamma Shielding Factor: This factor accounts for the effect of the building structure on the level of gamma radiation that exists indoors. It is the fraction of outdoor gamma radiation that penetrates the building.

Indoor Time Fraction: The fraction of the year the receptor spends in a building situated on top of the contaminated zone. 
Outdoor Time Fraction: The fraction of the year the receptor spends outside on top of the contaminated zone.

Shape of the Contaminated Zone: By default, the receptor is assumed to be placed in the middle of a circularly shaped contaminated zone for purposes of the external gamma exposure. If the receptor is not in the middle, or if the contaminated area is not circular, the "Noncircular" option can be selected. Then the receptor location and contamination shape can be set by clicking on the "Shape" button.

\subsection{EXTERNAL RADIATION AREA FACTORS}

For a noncircular contaminated area, the user can draw the shape of the contaminated area and place the receptor at any location within the contaminated area using the "External Radiation Area Factors” form (Figure 17).

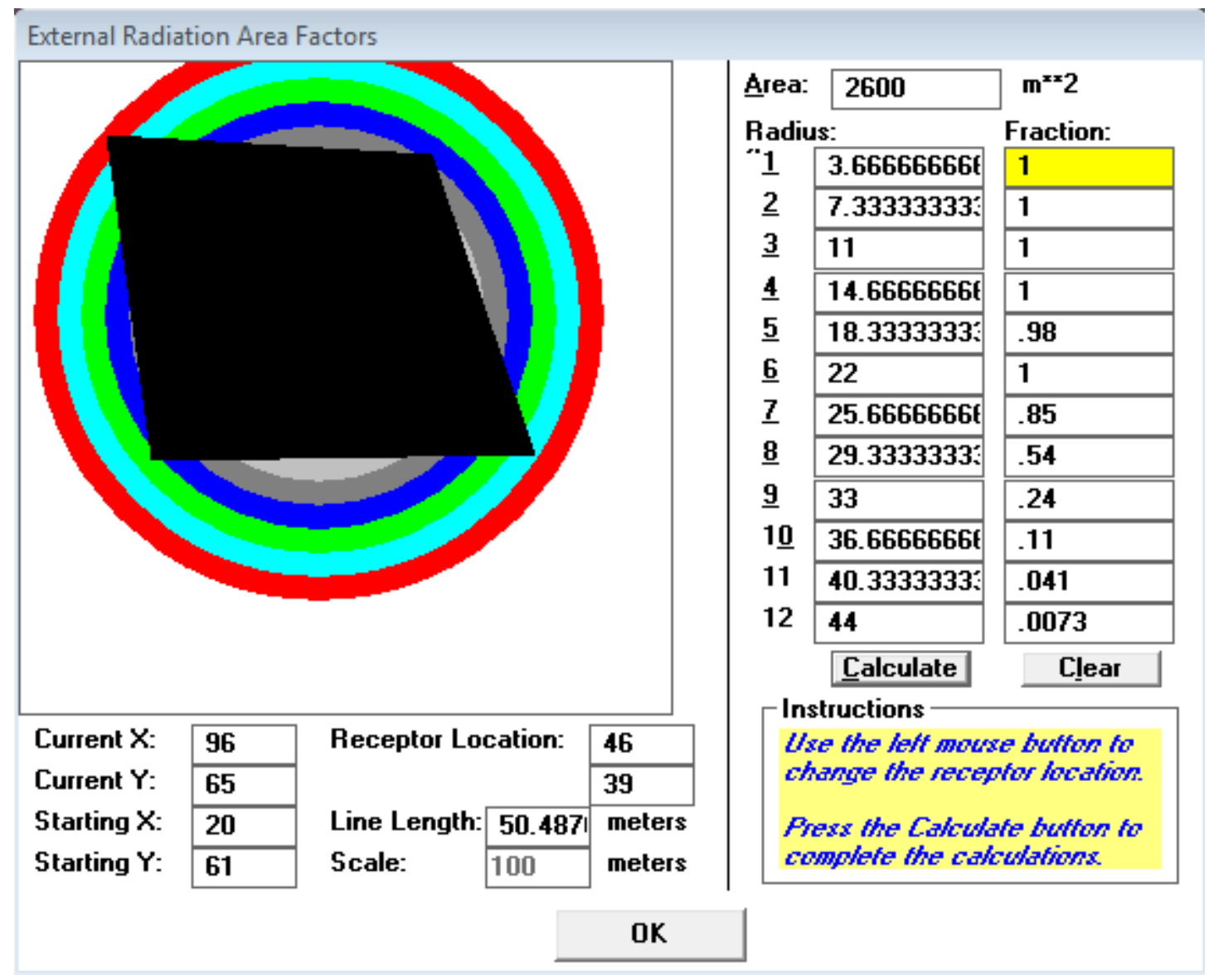

FIGURE 17 External Radiation Area Factors Form 
To set Contaminated Area Shape and Receptor Location, follow these steps:

- Set Scale: Enter the dimension of the graphic square in the central bottom part of the window.

- Draw Contaminated Area: To draw the contaminated area, click the topmost left corner of the contamination with the left mouse button. The starting $\mathrm{X}$ and $\mathrm{Y}$ location of the contamination will show in the boxes on the lower left corner of the form (you will notice that the current $\mathrm{X}$ and $\mathrm{Y}$ values are the same as the starting location, and the line length is zero). Now, keep drawing the contaminated area until you have circled the entire contaminated area and then click the right mouse button. (While drawing the contaminated area you can follow the instructions in the lower right box.) You indicate the vertices with the left mouse button and click the right mouse button to specify the last vertex.

- Specify the Receptor Location: To specify the receptor location, place the cursor at the desired receptor location and click the left mouse button. Follow the same procedure, if you want to change the receptor location. Receptor coordinates will show in the boxes next to the "Receptor Location."

- Calculate the Area Fractions: Press the "Calculate" button to complete the calculations for the contaminated fractions of the 12 annular regions.

Note: The form initially will open with nothing in the graphic square, the current and starting $X$ and $Y$ boxes, and the "Line Length" box. The form will have default receptor locations, areas, and contaminated fractions for the 12 annular regions.

Save the Setup: Press the "Save Form" button on the toolbar or use the menu selections "Form Options/Save Current Form" or the click the "OK" command button on the form.

\subsection{INGESTION PATHWAY, DIETARY DATA}

Uncertainty and sensitivity analysis can be performed on any consumption rate and intake parameter on the "Ingestion Pathway, Dietary Data" form (Figure 18). 


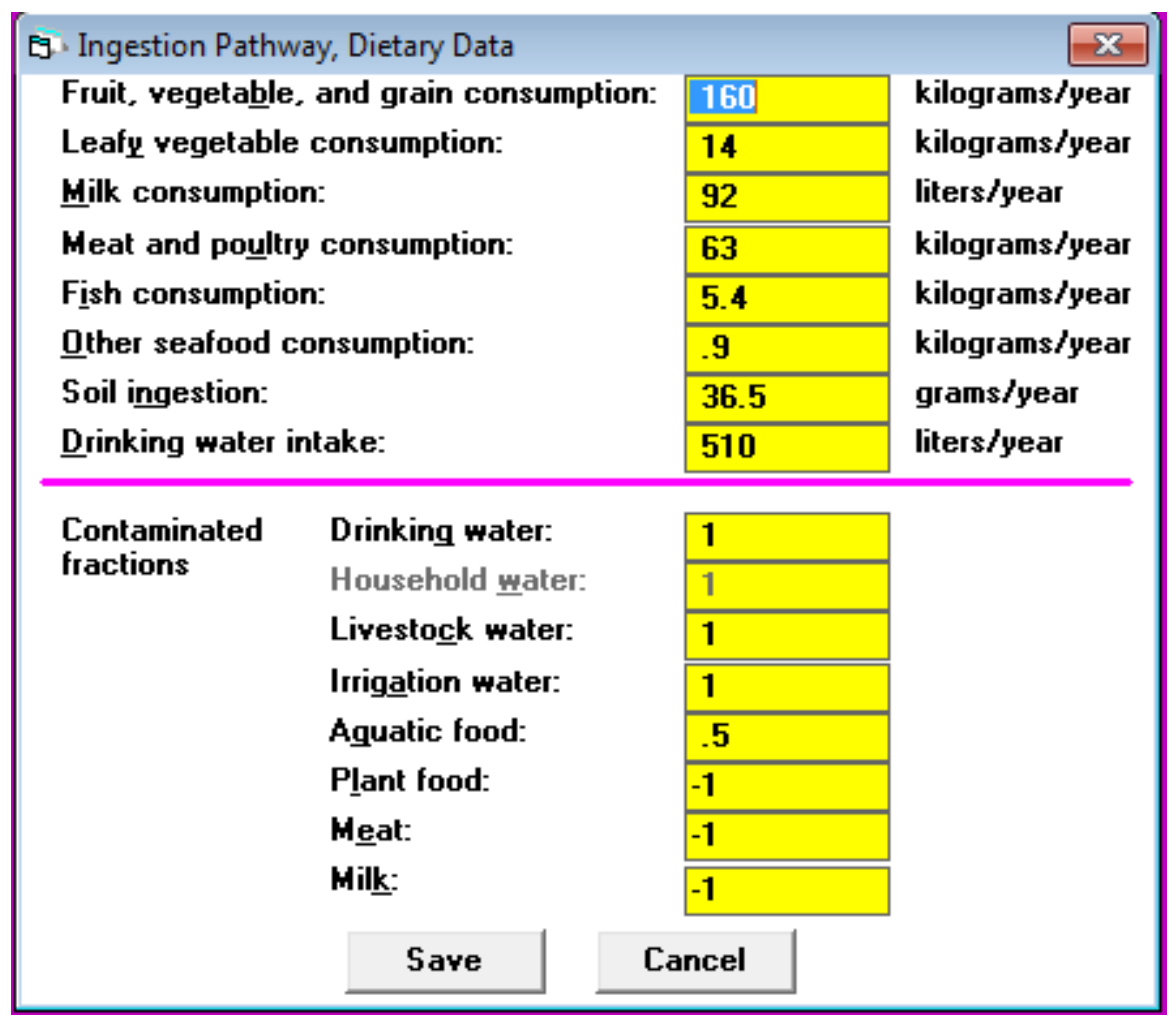

FIGURE 18 Ingestion Pathway, Dietary Data Form

Parameters in Top Half of Window: National averages that are usually site-independent. Adjustments for regional differences in diet may sometimes be appropriate. The consumption rate for different food categories that are required for RESRAD-ONSITE code include fruit, vegetable, and grain consumption; leafy vegetable consumption; milk consumption; meat and poultry consumption; fish consumption; and other seafood consumption. The soil intake and drinking water intake are also required.

Contaminated Fractions of Foodstuffs: All the water used and food consumed may not be contaminated. The contaminated fractions that originate from the contaminated site are required.

Drinking, Household, Livestock, and Irrigation Water: The fraction of water used that originates from the contaminated site. No mass balance is maintained between these parameters and the well pumping rate.

Aquatic: The fraction of the aquatic food that is contaminated.

Plant, Meat, and Milk: The -1 default value indicates that the area factor method discussed in Appendix D, Section D.2.1.2, of the RESRAD-ONSITE User's Manual will be used. 


\subsection{INGESTION PATHWAY, NONDIETARY DATA}

Uncertainty and sensitivity analysis can be performed on any intake rate parameter on the “Ingestion Pathway, Nondietary Data” form (Figure 19).

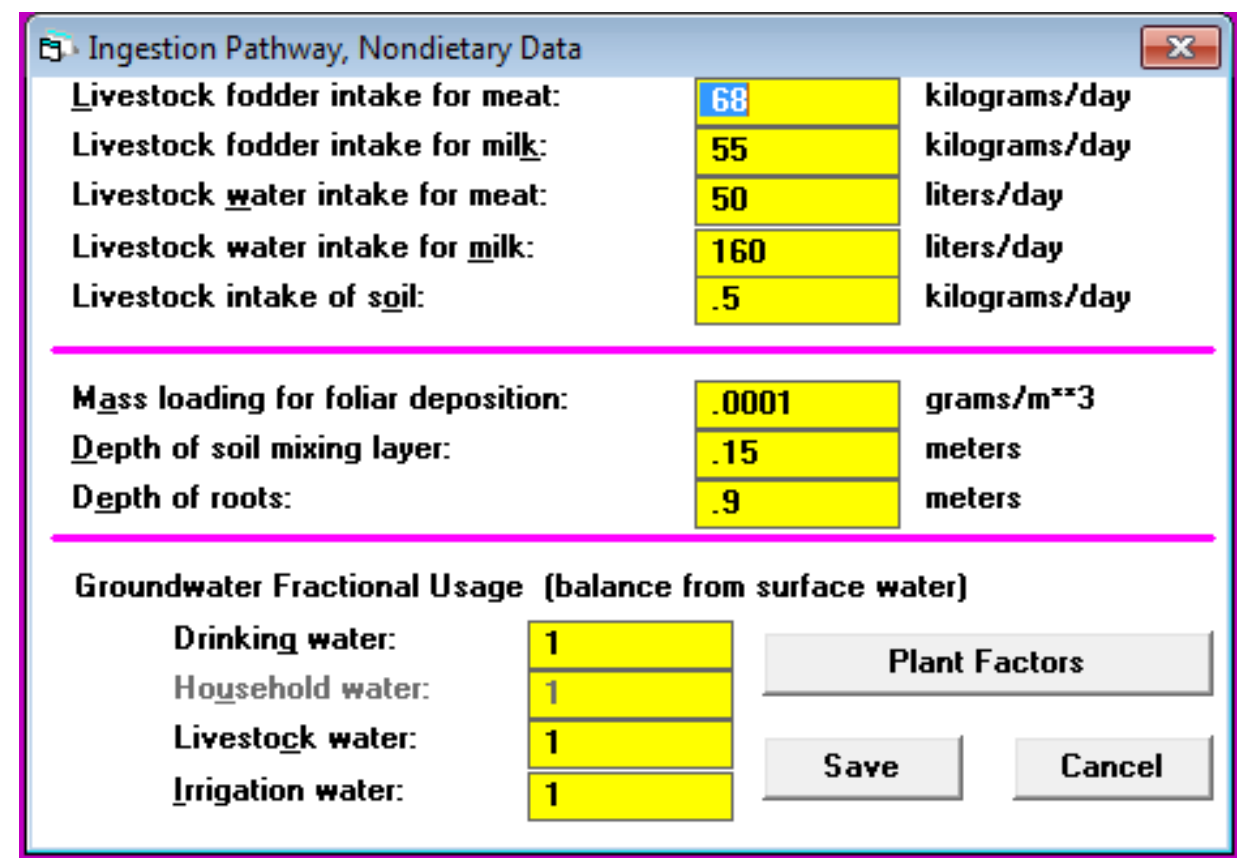

FIGURE 19 Ingestion Pathway, Nondietary Data Form

Parameters in Top Window: Livestock intake rates are national averages that are usually siteindependent. The fodder and water intake for meat cows and milk cows are input separately. Adjustments for regional differences in farming practices may sometimes be appropriate.

Mass Loading for Foliar Deposition: Mass loading for foliar deposition is the average mass loading of airborne contaminated soil particles in a garden/farm during the growing season.

Depth of Soil Mixing Layer: Depth of the soil mixing layer is the thickness of the layer in which mixing of the soil will occur. This parameter is used in calculating the depth factor for the dust inhalation and soil ingestion pathways and for foliar deposition for the ingestion pathway.

Depth of Roots: Depth of roots is the maximum plant root depth below the ground surface.

Groundwater Fractional Usage Parameters: Indicate the fraction of contaminated water from groundwater (well or spring). The remainder of the contaminated water is from surface water (pond or river). This is not to be confused with the contaminated fractions of foodstuffs discussed in Section 4.11. For example, selecting a drinking water contaminated fraction of 0.6 and a groundwater fractional usage of 0.5 would result in $40 \%$ of the drinking water coming 
from an uncontaminated source, 30\% from an on-site well or spring, and 30\% from an on-site pond or river.

Plant Factors: Clicking on the "Plant Factors" box will open the "Plant Factors" form (Figure 20).

\subsection{PLANT FACTORS}

Plant factors are related to growth and contaminant transfer. They depend on the mix of crops and regional farming practices. Uncertainty and sensitivity analysis can be performed on any parameter that is an input on this form (Figure 20).

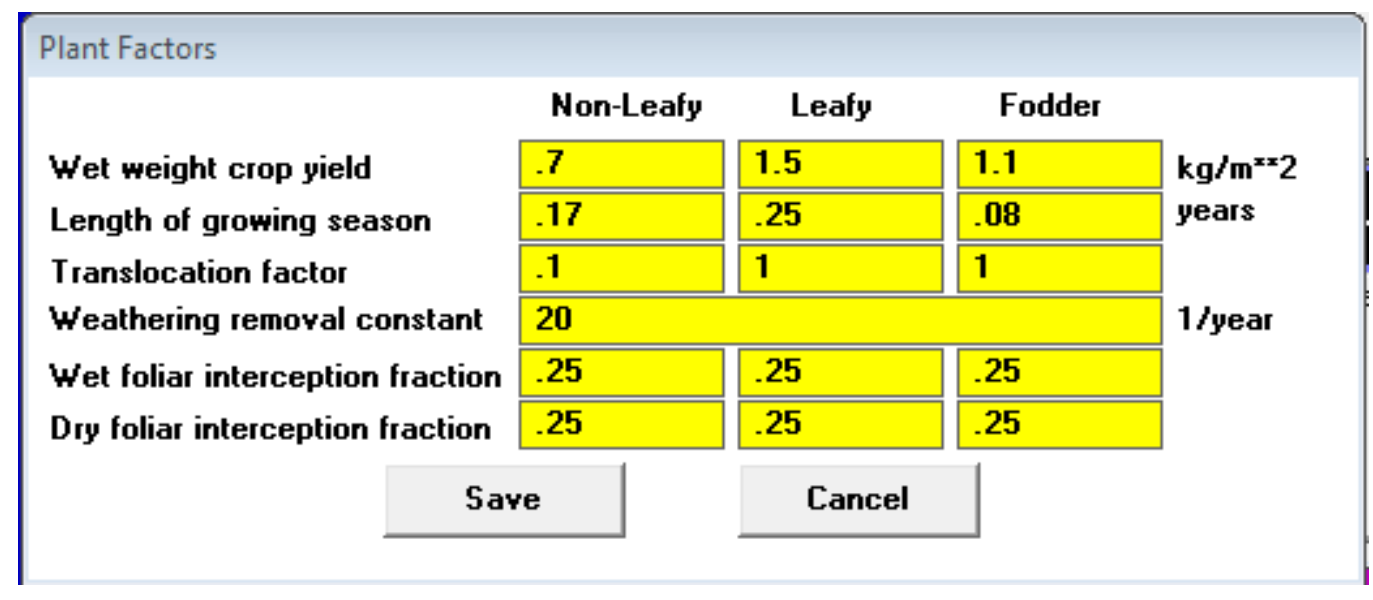

FIGURE 20 Plant Factors Form

Wet Crop Yield: Wet crop yield is the weight of the edible portion of plant food produced per unit land area for different food classes. The code has wet weight crop yield for non-leafy, leafy, and fodder. The non-leafy (includes non-leafy vegetables, fruits, and grains) and leafy vegetables are for human consumption and fodder for animals.

Length of Growing Season: The length of the growing season is the exposure time to contamination for the plant food during the growing season. The contamination can reach the edible portion of the plant food through foliar deposition, root uptake, and water irrigation. The code has the length of the growing season for non-leafy vegetables, leafy vegetables, and fodder.

Translocation Factor: The translocation factor is the fraction of contamination that is retained on the foliage that is transferred to the edible portion of the plant. The code has three food categories: non-leafy (includes non-leafy vegetables, fruits, and grains) and leafy vegetables for human consumption and fodder for animals. 
Weathering Removal Constant: The weathering process would remove contaminants from the foliage of plant food. The process is characterized by a removal constant and reduces the amount of contaminants on foliage exponentially during the exposure period.

Wet Foliar Interception Fraction: The wet foliar interception fraction is the fraction of deposited radionuclides that is retained on the foliage of the plant food from irrigation. The code has foliar interception fractions for non-leafy and leafy (for human consumption) and fodder (for animal consumption).

Dry Foliar Interception Fraction: The dry foliar interception fraction is the fraction of deposited radionuclides that is retained on the foliage of the plant food from airborne particulates. The code has foliar interception fractions for non-leafy and leafy (for human consumption) and fodder (for animal consumption).

\subsection{RADON DATA}

Uncertainty and sensitivity analysis can be performed on any parameter on the "Radon Data” form (Figure 21).

\begin{tabular}{|c|c|c|c|}
\hline \multicolumn{3}{|l|}{ E]. Radon Data } & $x$ \\
\hline \multirow{2}{*}{\multicolumn{2}{|c|}{$\begin{array}{l}\text { Cover total porosity: } \\
\text { Cover volumetric water content: }\end{array}$}} & .4 & \multirow{7}{*}{$\begin{array}{l}\mathrm{m}^{x \times} 2 / \mathrm{s} \\
\text { meters } \\
\mathrm{g} / \mathrm{cm}^{x \times 3}\end{array}$} \\
\hline & & .05 & \\
\hline \multirow{2}{*}{\multicolumn{2}{|c|}{$\begin{array}{l}\text { Cover radon diffusion coefficient: } \\
\text { Bldg foundation thickness: }\end{array}$}} & .000002 & \\
\hline & .15 & \\
\hline & & 2.4 & \\
\hline \multicolumn{2}{|l|}{ Bldg foundation total porosity: } & .1 & \\
\hline \multirow{2}{*}{\multicolumn{2}{|c|}{$\begin{array}{l}\text { Bldg foundation volumetric water content: } \\
\text { Bldg foundation radon diffusion coefficient: }\end{array}$}} & .03 & \\
\hline & & .0000003 & \multirow{5}{*}{$\begin{array}{l}\mathrm{m}^{\mathrm{xx}} 2 / \mathrm{s} \\
\mathrm{m}^{\mathrm{x}} 2 / \mathrm{s} \\
\text { meters } \\
1 / \mathrm{hr} \\
\text { meters }\end{array}$} \\
\hline \multirow{2}{*}{\multicolumn{2}{|c|}{$\begin{array}{l}\text { Contaminated radon diffusion coefficient: } \\
\text { Radon vertical dimension of mixing: }\end{array}$}} & .000002 & \\
\hline & & 2 & \\
\hline \multirow{2}{*}{\multicolumn{2}{|c|}{$\begin{array}{l}\text { Building air exchange rate: } \\
\text { Building room height: }\end{array}$}} & .5 & \\
\hline & & 2.5 & \\
\hline \multicolumn{2}{|l|}{ Building indoor area factor: } & $\mathbf{0}$ & \multirow{5}{*}{ meters } \\
\hline \multirow{3}{*}{\multicolumn{2}{|c|}{ 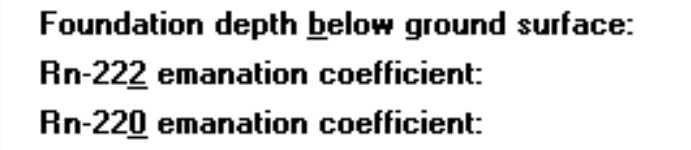 }} & -1 & \\
\hline & & .25 & \\
\hline & & .15 & \\
\hline Save & \multicolumn{2}{|c|}{ Cancel } & \\
\hline
\end{tabular}

FIGURE 21 Radon Data Form 
Radon Pathway: Radon pathway is discussed in detail in Appendix C of the RESRAD-ONSITE User's Manual. The radon pathway parameters are only used when a radon parent for either Rn-222 or Rn-220 is present as a contaminant. The wind speed found on the "Cover and Contaminated Zone Hydrological Data” window is also used for the outdoor radon dose component calculation.

Total Porosity (Cover, Building Foundation): This is the total porosity of the material. For the definition of porosity, see Section 4.6.

Building Foundation Thickness: This is the average thickness of the building structure in the subsurface of the soil.

Building Foundation Density: This is the density of the building foundation material. For the definition of density, see Section 4.6.

Volumetric Water Content (Cover, Building Foundation): This is the volume fraction of soil that is occupied by water.

Radon Diffusion Coefficient (Cover, Building Foundation, and Contaminated Zone): The effective (or interstitial) radon diffusion coefficient is the ratio of the diffusive flux density of radon activity across the pore area to the gradient of the radon activity concentration in the pore space. Entering -1 for any diffusion coefficient will cause the code to calculate the diffusion coefficient based on the porosity and water content of the medium.

Radon Vertical Dimension of Mixing: This is the height into which the plume of radon is uniformly mixed in the outdoor air.

Building Air Exchange Rate: This is the number of the total volumes of air contained in the building being exchanged with outside air per unit of time.

Building Room Height: This is the average height of rooms in the building.

Building Indoor Area Factor: This is the fraction of the floor area built on the contaminated area. Values greater than 1.0 indicate a contribution from walls penetrating the contaminated zone. The default value 0 indicates that the time-dependent area factor is derived from an assumed floor area of $100 \mathrm{~m}^{2}$ and the amount of wall extending into the contaminated zone.

Foundation Depth below Ground Surface: This is the depth from the surface to the basement slab bottom. The default -1 indicates that the slab will be placed directly on top of the contaminated zone.

Emanation Coefficient (Rn-222, Rn-220): This is the fraction of the total radon generated by radium decay that escapes soil. This parameter depends on other parameters such as porosity, particle size distribution, mineralogy, and moisture content. 


\subsection{STORAGE TIMES BEFORE USE DATA}

Storage times are the times during which foodstuffs and feeds are stored, thus allowing for radionuclide decay and ingrowth before consumption (Figure 22). The smallest graphical time point or the user-specified calculation time cannot be less than the largest cumulative storage time for any food. For meat (storage time 20 days), the meat cow consumes fodder (storage time 45 days), which will be irrigated with water (storage time 1 day), so the smallest graphical time point cannot be less than the cumulative storage time of 66 days $(20+45+1=66)$. These parameters usually have minor effects on results. See Appendix D of RESRAD-ONSITE User's Manual for more details. Uncertainty and sensitivity analysis can be performed on the storage times.

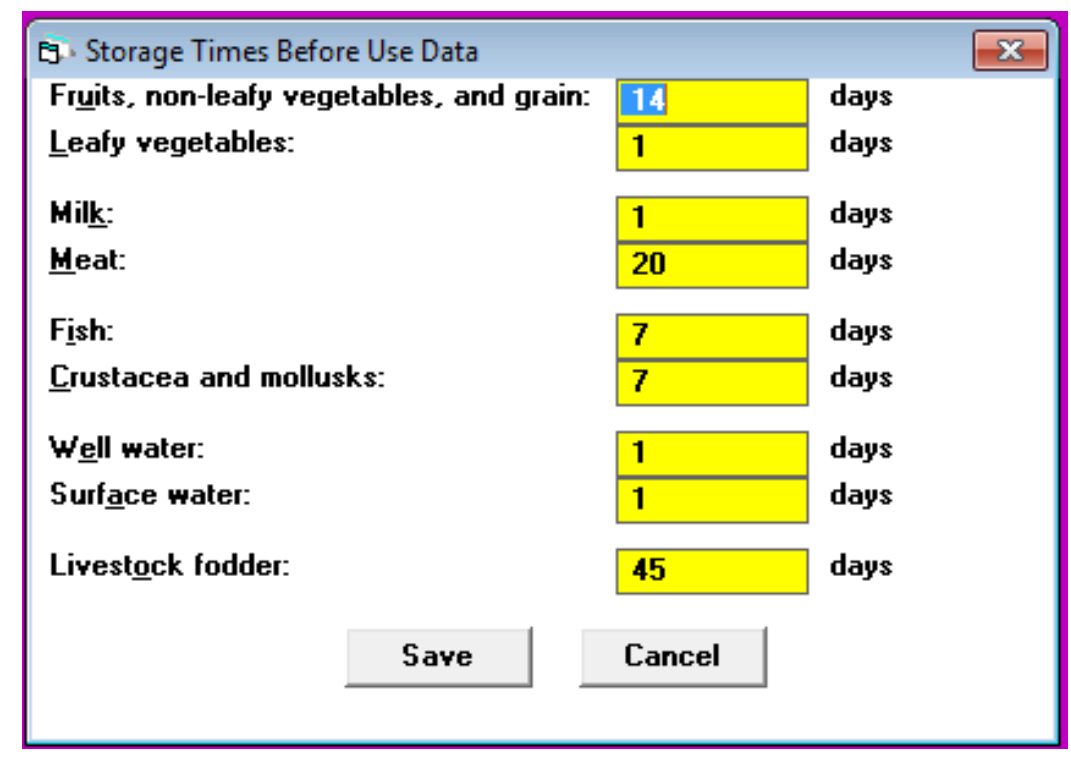

FIGURE 22 Storage Times Before Use Data Form

\subsection{CARBON-14 DATA}

The carbon-14 pathway model is discussed in detail in Appendix L of the RESRADONSITE User's Manual. Uncertainty and sensitivity analysis can be performed on any parameter on the "Carbon-14 Data" form (Figure 23). 


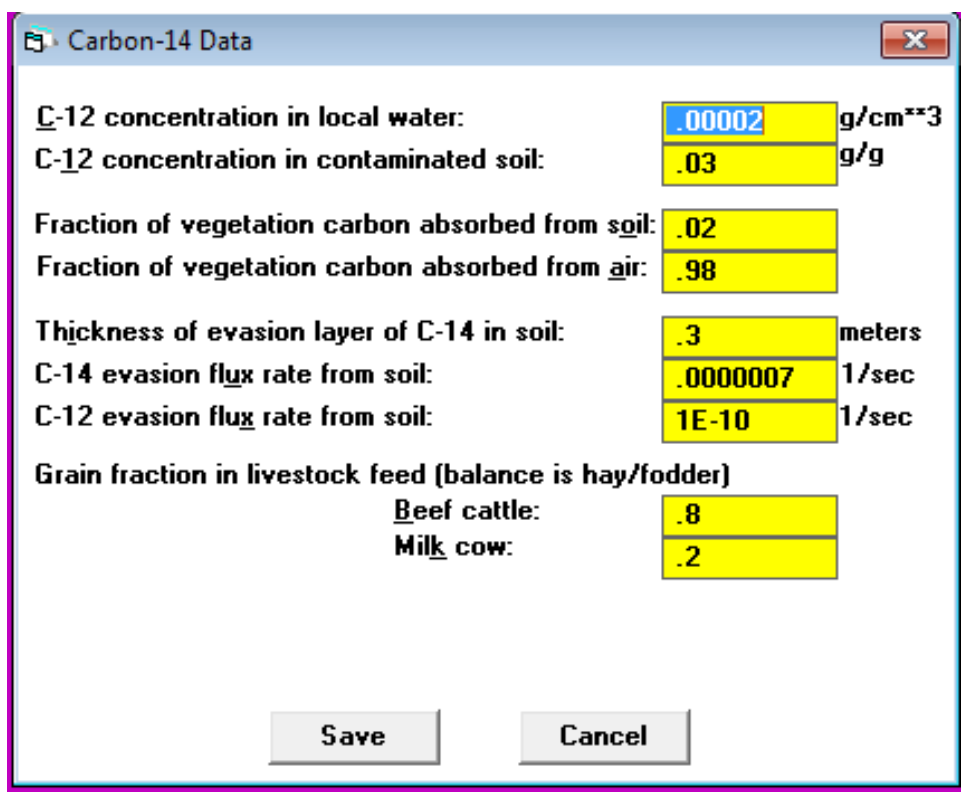

FIGURE 23 Carbon-14 Data Form

C-12 Concentration in Local Water: This is the stable carbon concentration in water.

C-12 Concentration in Contaminated Soil: This is the fraction of the soil that is stable carbon.

Fraction of Vegetation Carbon Absorbed from Soil: This is the fraction of total vegetation carbon obtained by direct root uptake from soil.

Fraction of Vegetation Carbon Absorbed from Air: This is the fraction of total vegetation carbon assimilated from the atmosphere through photosynthesis.

C-14 Evasion Layer Thickness: This is the maximum thickness through which C-14 can escape to the air by conversion to carbon dioxide. C-14 below this depth is assumed to be trapped.

C-14 Evasion Flux Rate from Soil: This is the fraction of soil inventory of C-14 within the evasion layer that is lost to the atmosphere per unit time.

C-12 Evasion Flux Rate from Soil: This is the fraction of soil inventory of C-12 within the evasion layer that is lost to the atmosphere per unit time.

Grain Fraction in Beef Cattle Feed: This is the fraction of grain in the beef cattle diet. The balance is assumed to be hay or fodder.

Grain Fraction in Milk Cow Feed: This is the fraction of grain in the milk cow diet. The balance is assumed to be hay or fodder. 


\section{RESRAD DOSE CONVERSION FACTOR EDITOR}

The RESRAD Dose Conversion Factor (DCF) Editor is a standalone utility program used to develop and edit the user-specific dose coefficient, transfer factor, and slope factor libraries for use in the RESRAD family of codes. Figure 24 shows the RESRAD DCF Editor welcome page.

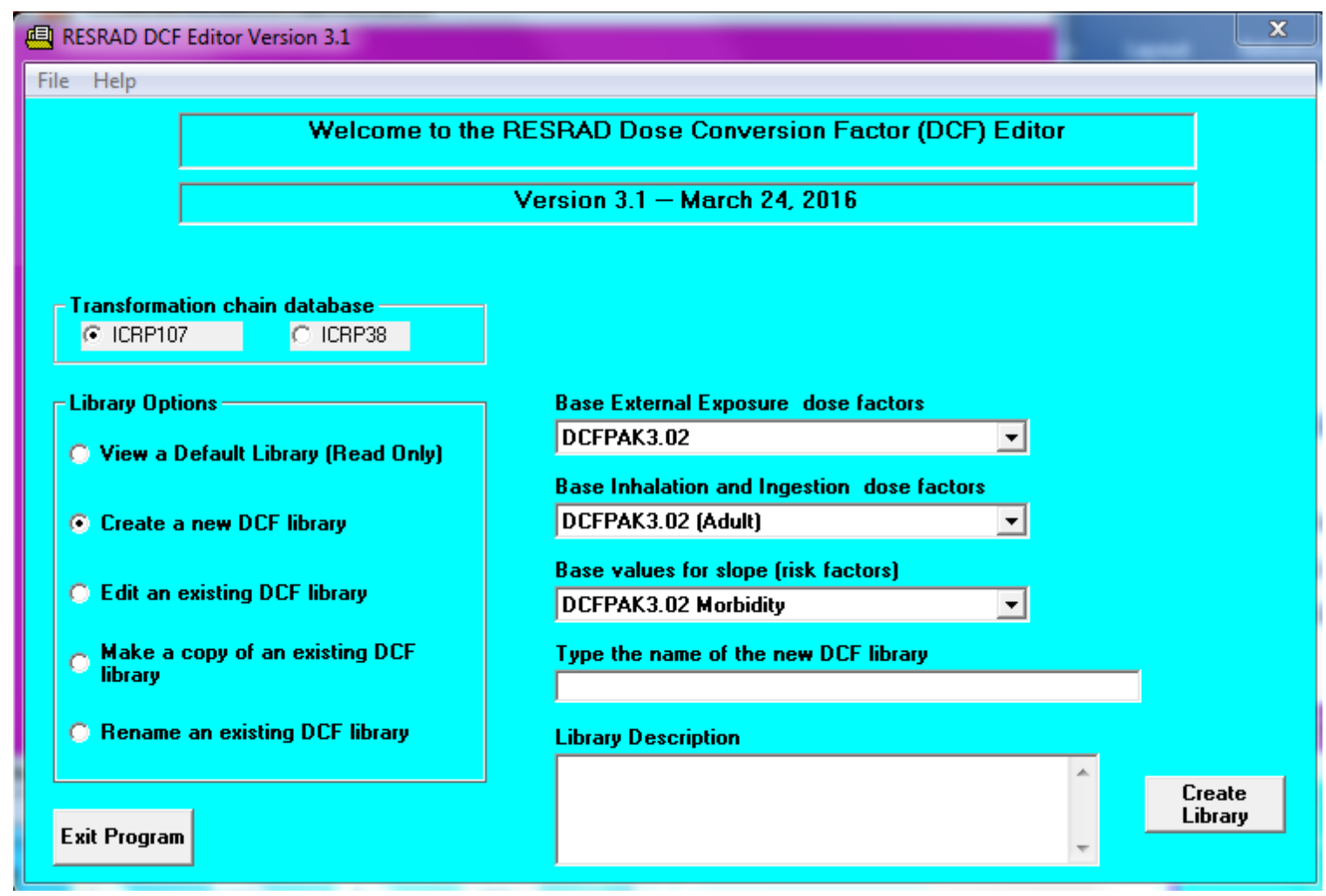

\section{FIGURE 24 RESRAD DCF Editor}

Transformation Chain Database: The user has an option to select the ICRP 107-based or ICRP-38-based radionuclide transformation database. Multiple default libraries are available for ICRP 38 and ICRP 107; a dropdown box shows all of the libraries available for a selected transformation database. Figure 25 shows the partial list of the libraries available for the ICRP 38 transformation database. The library description provides information on the default dose and risk factors associated with the selected default library. 


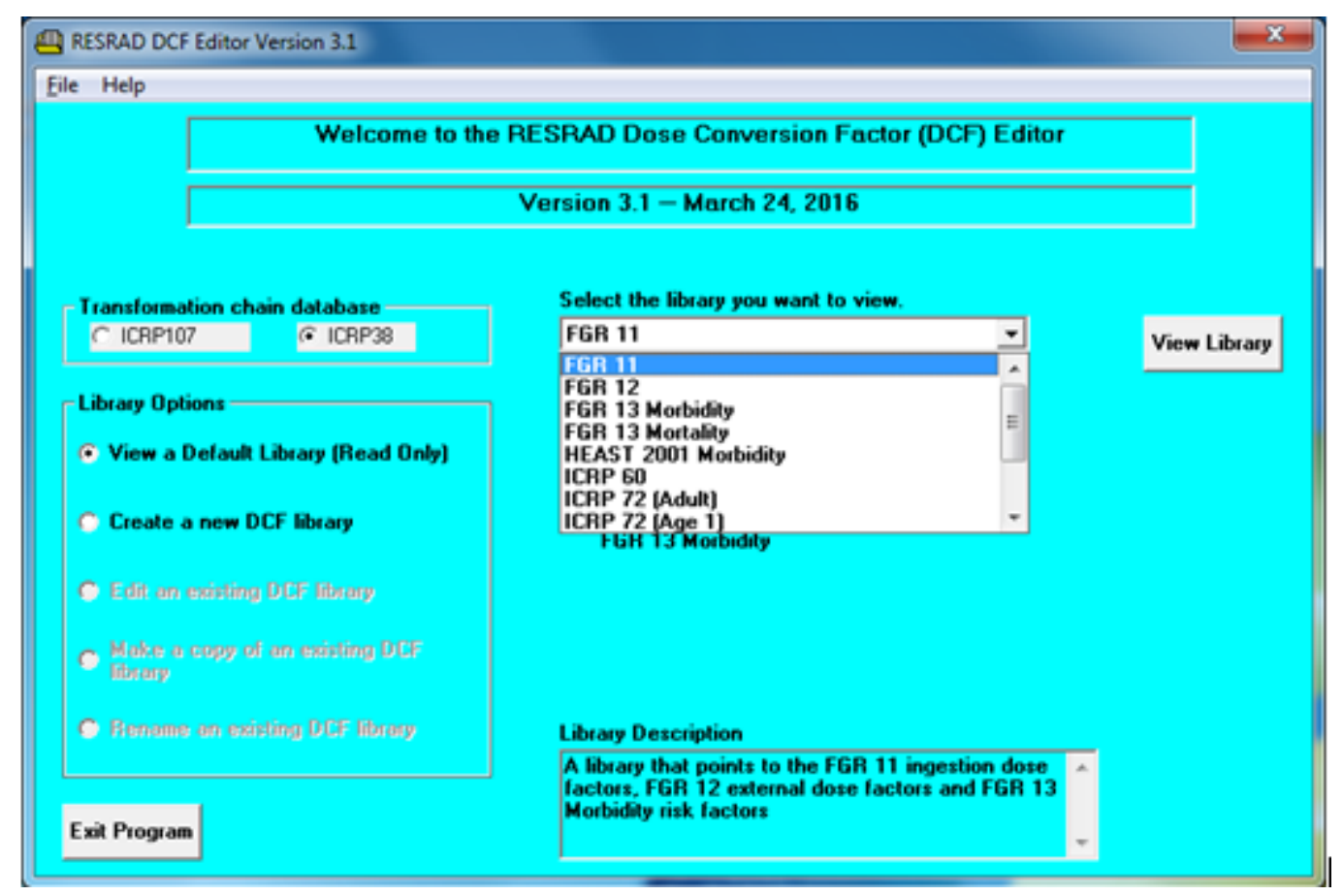

FIGURE 25 Available DCF Libraries in ICRP 38 Transformation Database

Figure 26 shows the multiple DCF libraries available when the ICRP 107 transformation database is selected. RESRAD-ONSITE code also has a Reference Person DCF library. The reference person is defined as a hypothetical aggregation of human (male and female) physical and physiological characteristics arrived at by international consensus for standardizing radiation dose calculations. The reference person dose coefficients are derived using age-specific dose coefficients coupled with information on the age and gender structure of the U.S. population in 2000 census data and age- and gender-specific intakes (DOE 2011). 


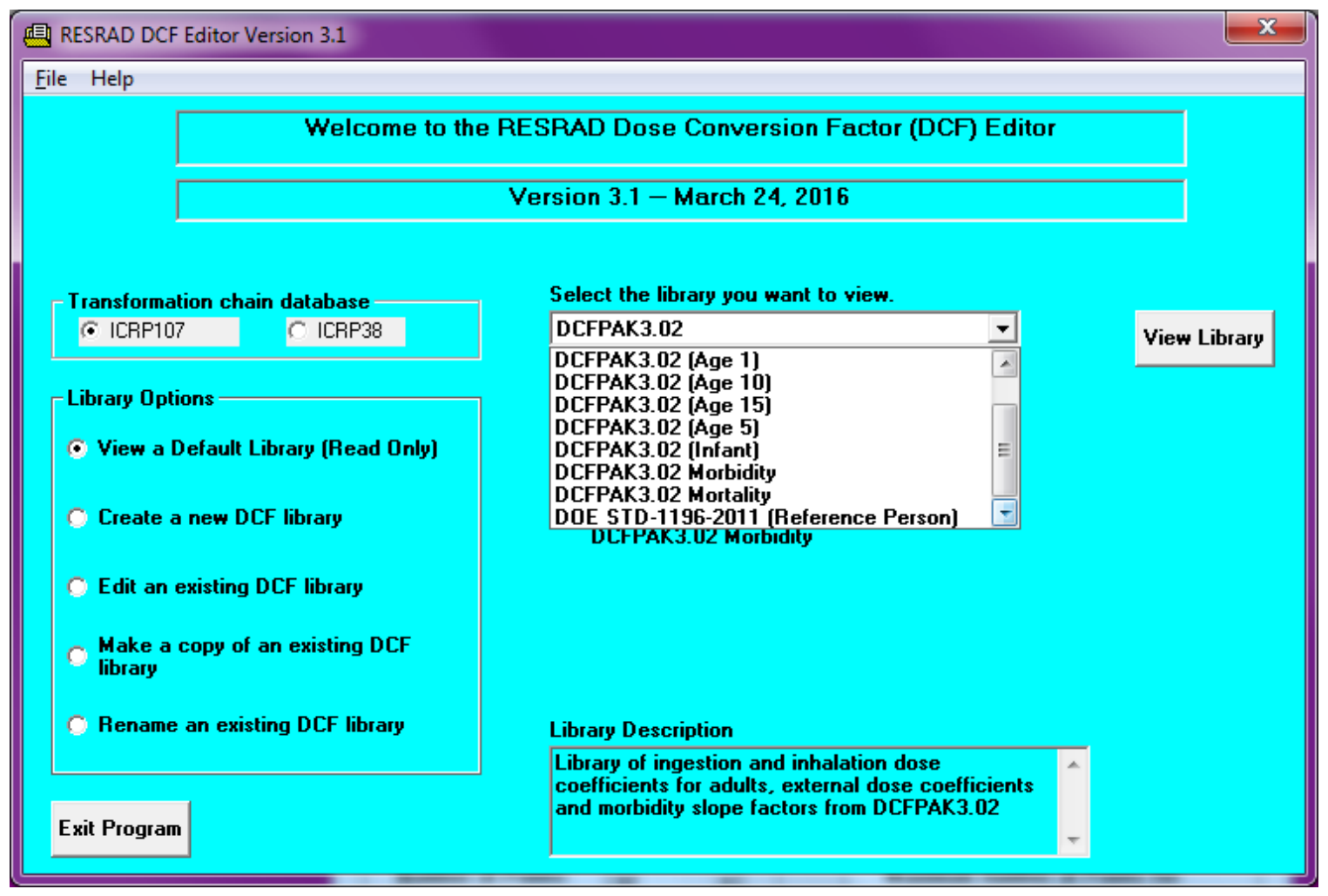

FIGURE 26 Available DCF Libraries in the ICRP 107 Transformation Database

Library Options: The user has multiple library options: view a default library, create a new library, edit an existing DCF library, make a copy of an existing DCF library, or rename an existing DCF library.

To View a Default Library (Read Only): Select this option to view the default dose conversion, food transfer, and slope factors. The default values are contained in default libraries, which users cannot modify. New libraries created by the user automatically use data from one of the default libraries as a starting point. To view a default library, select the library you want to view and click "View Library."

To Create a New DCF Library: Select this option to create a new DCF library based on the default values. You need to select base external, inhalation and ingestion dose factor, and risk factor libraries. You must provide a name for the new library. You can also enter a description of the library. The description may contain references or other helpful information. After entering the name and description, click the "Create Library” button to continue.

To Edit an Existing DCF Library: Select this option to edit a previously created DCF library (or one imported into the database). To edit an existing DCF library, select the library from the dropdown list. Edit the library description, if necessary, and click the "Edit Library" button. 
To Make a Copy of an Existing DCF Library: Select this option to make a copy of an already existing DCF library. This option is similar to the "Create a New DCF Library" option. This feature is used to create a new DCF library based on another user-defined library. To copy an existing library, select the existing library from the dropdown list and enter the name of the new library in the text box. Then press the "Copy Library" button to copy the dose conversion, transfer, and risk factors from the existing library to the new library.

To Rename an Existing DCF Library: Select this option to rename an existing DCF library. Select an existing DCF library from the dropdown list, type the name of the new library in the text box, and click the "Rename Library" button.

\subsection{DOSE COEFFICIENTS}

As mentioned before, multiple DCF libraries are available in the ICRP 38 and ICRP 107 transformation databases. Figure 27 shows the FGR-11 internal dose conversion factors and FGR-12 external dose conversion factors, using the ICRP 38 transformation database.

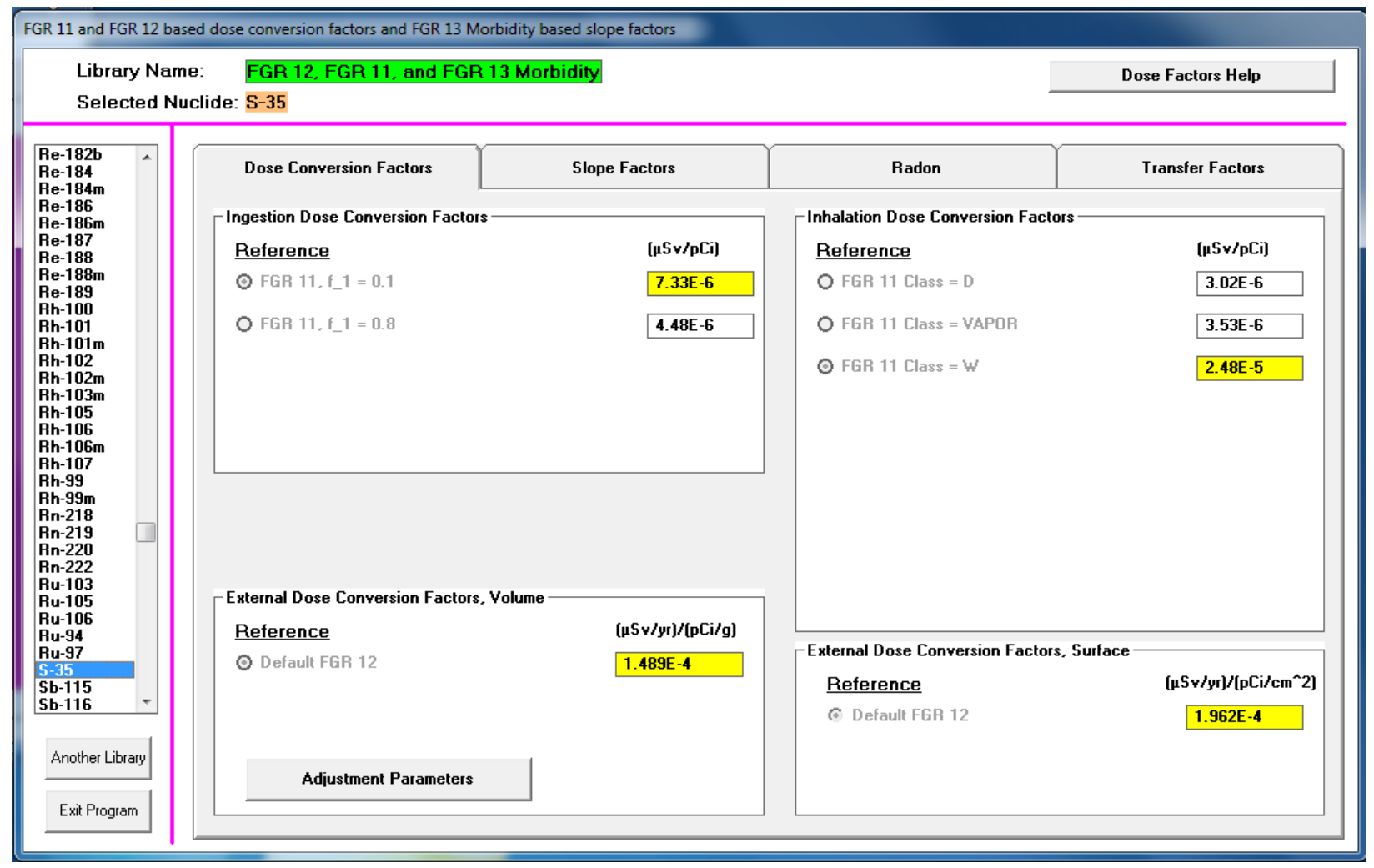

FIGURE 27 Dose Coefficients from a FGR-12-, FGR-11-, and FGR-13-based Library 
Ingestion Dose Coefficients: FGR-11 (Eckerman et al. 1988) dose coefficients for various GI tract fractions are shown for S-35 in Figure 27. The maximum value is selected as the default. When one selects “Create a New DCF Library" or "Edit an Existing DCF Library” option, one can select another DCF by clicking the option button for the DCF or enter a user-specific value. If a user-specific value is entered, a reference can be inserted into the text box.

Inhalation Dose Coefficients: FGR-11 dose coefficients for various lung clearance classes are shown for S-35 in Figure 27. The maximum value is selected as the default. When user selects "Create a New DCF Library" or "Edit an Existing DCF Library" library option, one can select another DCF by clicking the option button for the DCF or enter a user-specific value. If a userspecific value is entered, a reference can be inserted into the text box.

External Dose Coefficients: External dose coefficients from EPA FGR-12 (Eckerman and Ryman 1993) for S-35 are shown in Figure 27. The values are listed for volume and surface sources. When one selects a "Create a New DCF Library" or "Edit an Existing DCF Library" library options, one can enter a user-specific value. If a user-specific value is entered, a reference can be inserted into the text box. For volume sources, “Adjustment Parameters” (Figure 28) are also specified that include depth- and cover-fitted parameters and area- and shape-fitted parameters for each radionuclide. The adjustment parameters are used to calculate external dose coefficients for any size volume source. The adjustment parameter values cannot be changed by a user.

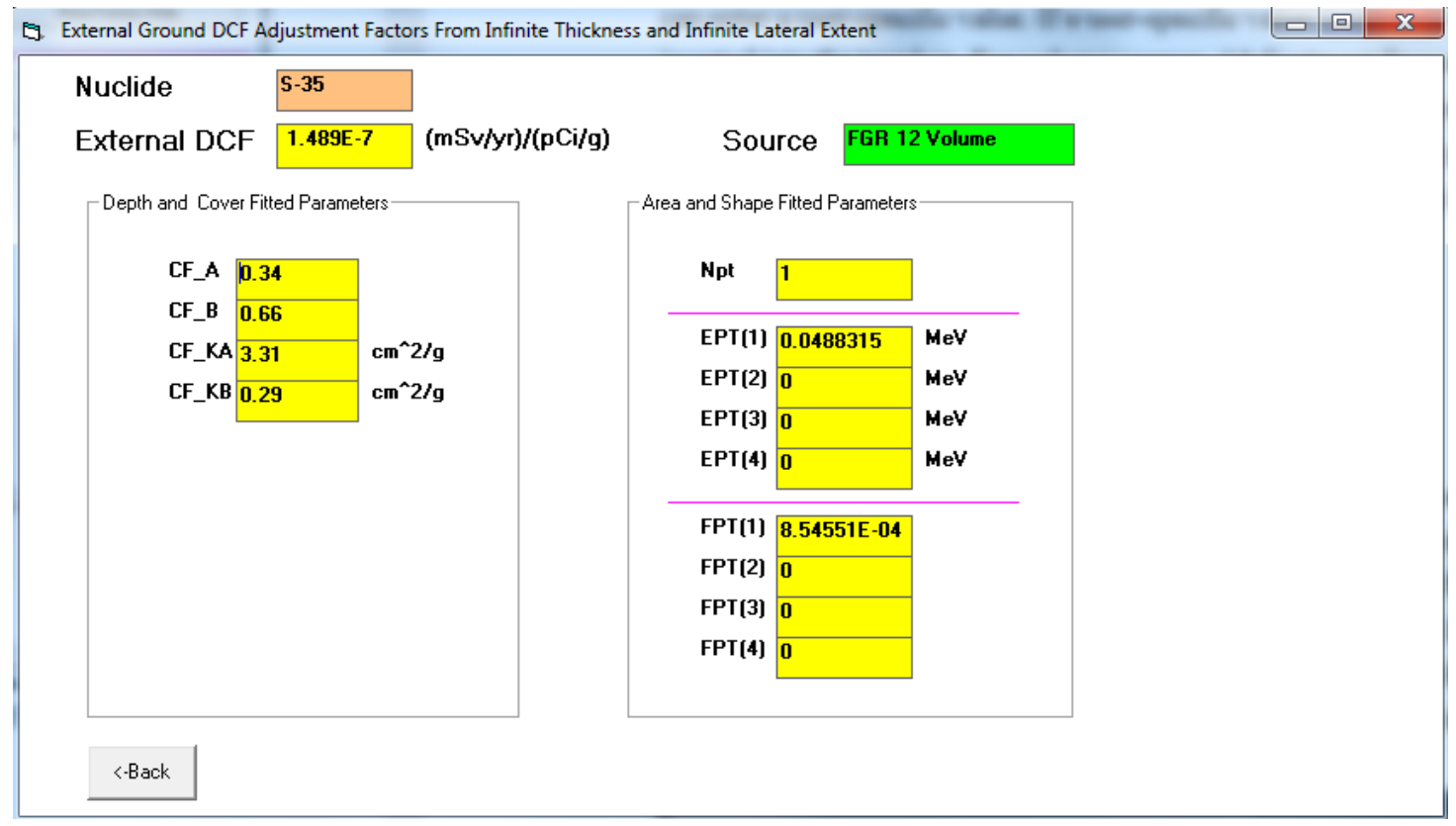

FIGURE 28 External Pathway Adjustment Parameters from the FGR-12, FGR-11, and FGR-13 Library

To view dose coefficients for another nuclide, select that radionuclide. Section 4.1 discusses the other DCF libraries available. 


\subsection{SLOPE FACTORS}

Clicking on the "Slope Factors" tab provides slope factor values in the selected library. Figure 29 shows the FGR-13-based morbidity slope factor for S-35. Section 4.1 discusses the other slope/risk factor libraries available. The slope factors are available for the ingestion, inhalation, and external exposure pathways. The slope factor values shown are from the FGR-13 report (Eckerman et al. 1999). When the user selects a "Create a New DCF Library" or "Edit an Existing DCF Library" library option, the user can enter a user-specific value. If a user-specific value is entered, a reference can be inserted into the text box.

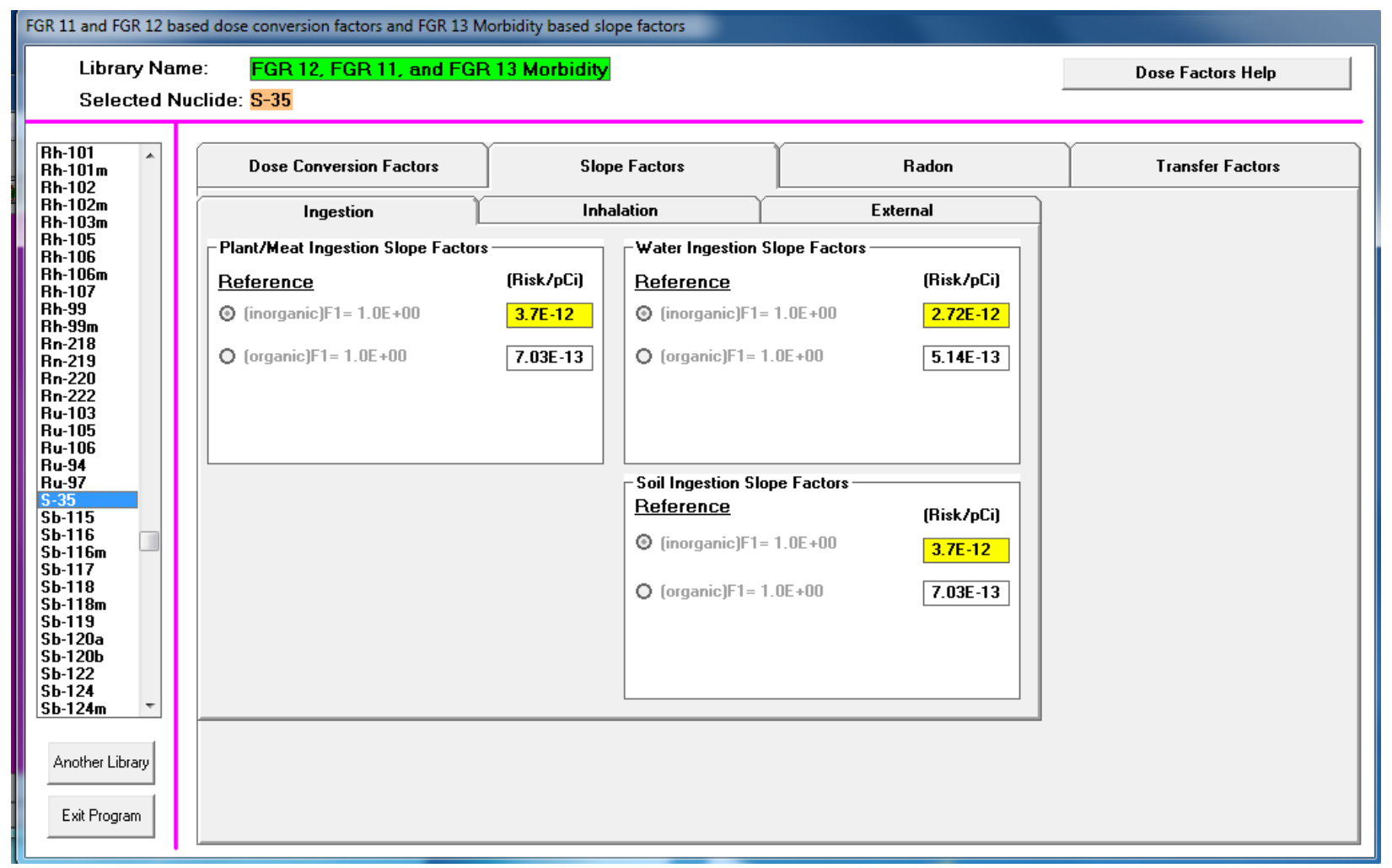

FIGURE 29 FGR-13 based Morbidity Slope Factors

\subsection{RISK AND DOSE FACTORS FOR RADON}

Clicking on the "Radon" tab on the top provides the radon progeny slope factors and the radon dose coefficients in the selected library (Figure 30). Two sets of radon dose coefficients are available. One is based on the ICRP 26 methodology, and the other is based on the ICRP 60 methodology (Section 7.4.3). For ICRP 26 methodology-based libraries, the ICRP 26 methodology-based radon dose coefficients are used; and for ICRP 60 methodology-based libraries the ICRP 60 methodology-based radon dose coefficients are used. Figure 31 shows the radon dose coefficients based on the ICRP 60 methodology. 


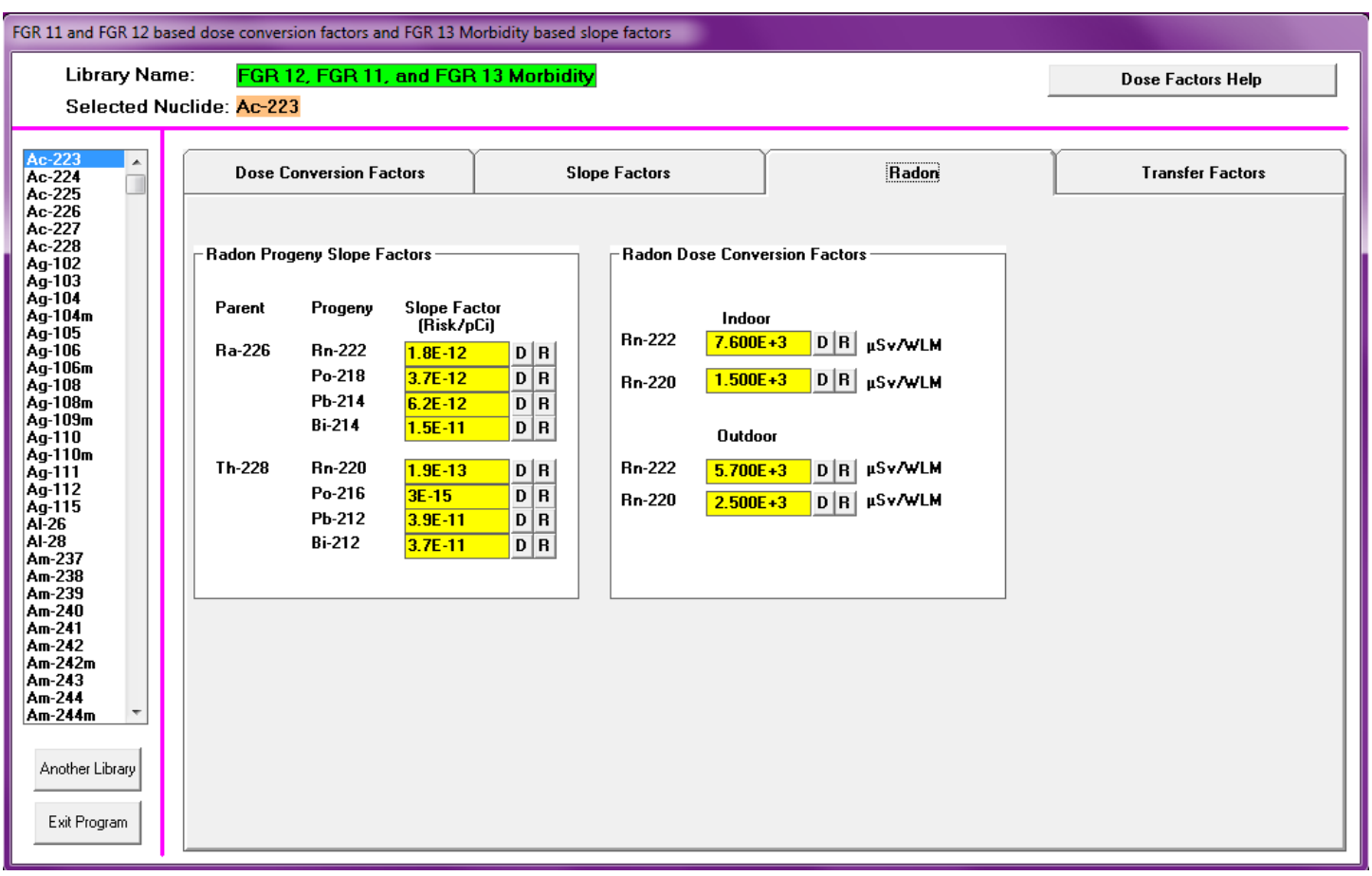

FIGURE 30 Radon Progeny Slope Factors and ICRP 26 Methodology-based Dose Coefficients

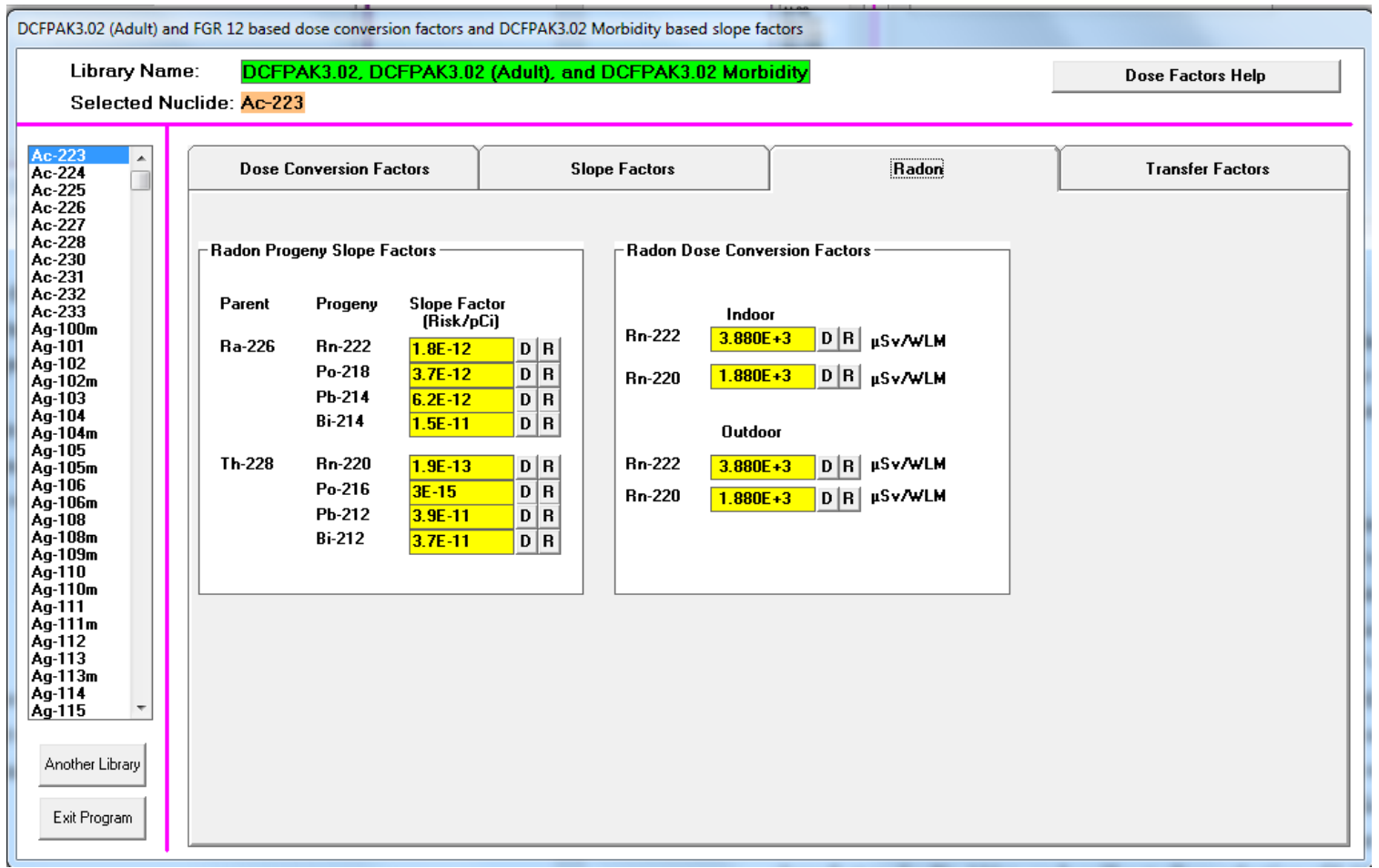

FIGURE 31 Radon Progeny Slope Factors and ICRP 60 Methodology-based Dose Coefficients 
Radon Progeny Slope Factors: The values are from the EPA HEAST report (EPA 1994). When one selects a "Create a New DCF Library" or "Edit an Existing DCF Library" option, one can enter a user-specific value. To change the default values, enter a new value in the text box. To select the default value, click the " $\mathrm{D}$ " button; to enter references for user-specific values, click the "R" button.

Radon Dose Coefficients: Two sets of radon dose coefficients are available (Figure 30 and Figure 31). See discussion in Appendix C of the RESRAD-ONSITE User's Manual for use (Yu et al. 2001). When a user selects a "Create a New DCF Library" or "Edit an Existing DCF Library" option, the user can enter a user-specific value. To change default values, enter a new value in the text box. To select the default value, click the " $\mathrm{D}$ " button; to enter references for user-specific values, click the " $\mathrm{R}$ " button.

\subsection{TRANSFER FACTORS}

Clicking on the "Transfer Factors" tab provides transfer factors in the selected library (Figure 32). Transfer factors are element-dependent. The transfer factors are provided for different food types (plant, meat, milk, fish, and crustacea).

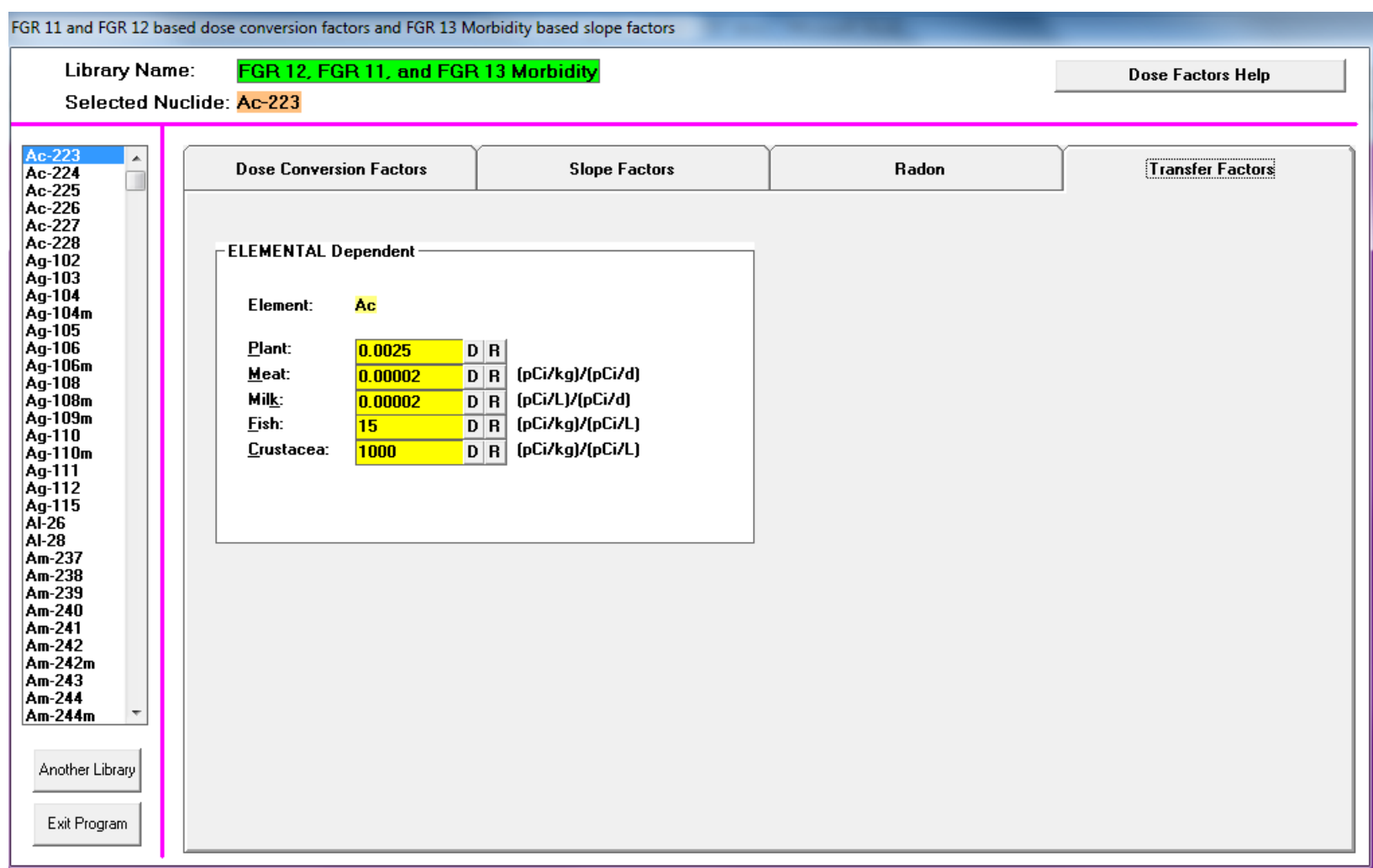

FIGURE 32 Transfer Factors 
Transfer Factors: See the detailed discussion in Appendix D of the RESRAD-ONSITE User's Manual. When a user selects a "Create a New DCF Library" or "Edit an Existing DCF Library" option, the user can enter a user-specific value in the text box. To select the default value, click the " $\mathrm{D}$ " button; to enter references for user-specific values, click the " $\mathrm{R}$ " button.

\subsection{CREATE NEW DCF LIBRARY}

For radionuclides that lack dose conversion or slope factors, a value of -1 or -2 is assigned. The value -2 is assigned when the half-life is $<10$ minutes, and a value of -1 is assigned when the radionuclide half-life is greater than 10 minutes. For a radionuclide with an assigned value of -2 , a zero value for the dose conversion and slope factor is used at run time. For a radionuclide with an assigned value of -1 for the dose conversion and slope factor, the code will not run and will tell the user that the DCF or slope factor is missing and ask the user to provide the missing data in the private dose factor library. For example, Xe-131m does not have internal dose conversion and slope factors (see Figure 33). When the user selects I-131 as a principal radionuclide, the daughter Xe-131m DCF and slope factors are required. Because the database does not have internal DCFs and slope factors for Xe-131m, the code will not allow selection of I-131 in the "Source Form" and will request that a new DCF library that has internal DCFs and slope factors be created (see Figure 34) for Xe-131m. The following are the steps for creating and using the new DCF library:

- Select "DCF Editor" under the "File" menu.

- In the DCF Editor, select “Create a new DCF Library” (see Figure 35).

- Give a name to the new DCF library such as "User I-131"; make sure the base library is the one you want to use for all other radionuclides (see Figure 35). Note that there is 20 character limit in the library name.

- Click on the "Create Library" button, then select "Xe-131m" and click the circle in front of the blank box (it is right under the line with the value " -1 " (see Figure 35).

- Enter a value such as “0” in the value box (see Figure 35).

- Make sure you do this for both the "Dose Conversion Factors" and "Slope Factors" tabs. Note that there are multiple tabs under the "Slope Factors" tab; remember to enter values there.

- Exit the DCF Editor program.

- Open "Change Title” in the main (DOS Emulator) menu.

- Select the new created DCF library - "User I-131" in the example. Note that this library is now used for internal dose, external dose, and risk factors.

Now I-131 can be selected in the "Source Form" and the code will run and use the Xe-131m user-defined internal DCFs and slope factors. 


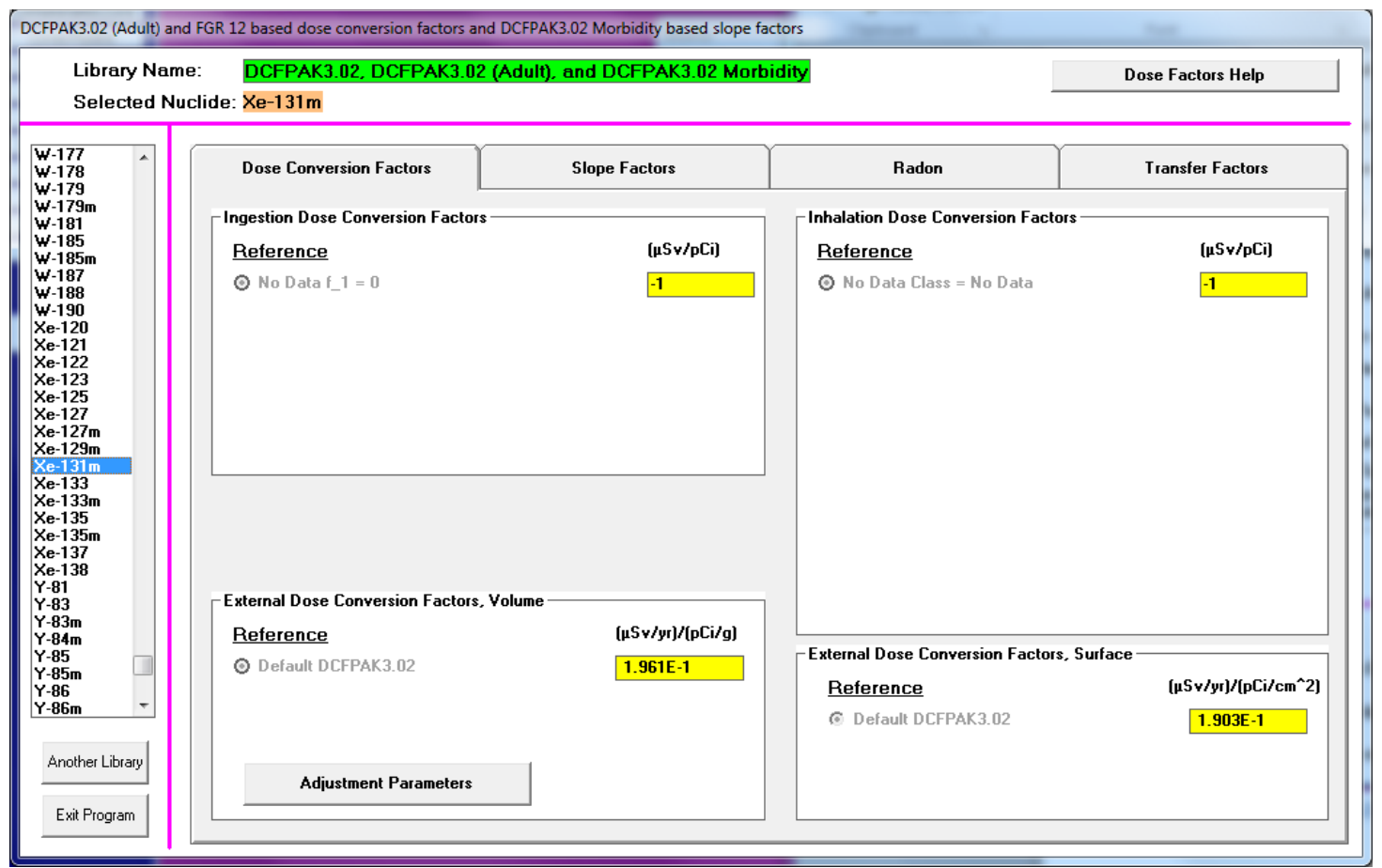

FIGURE 33 Xe-131m Default Dose Conversion Factors in the Database

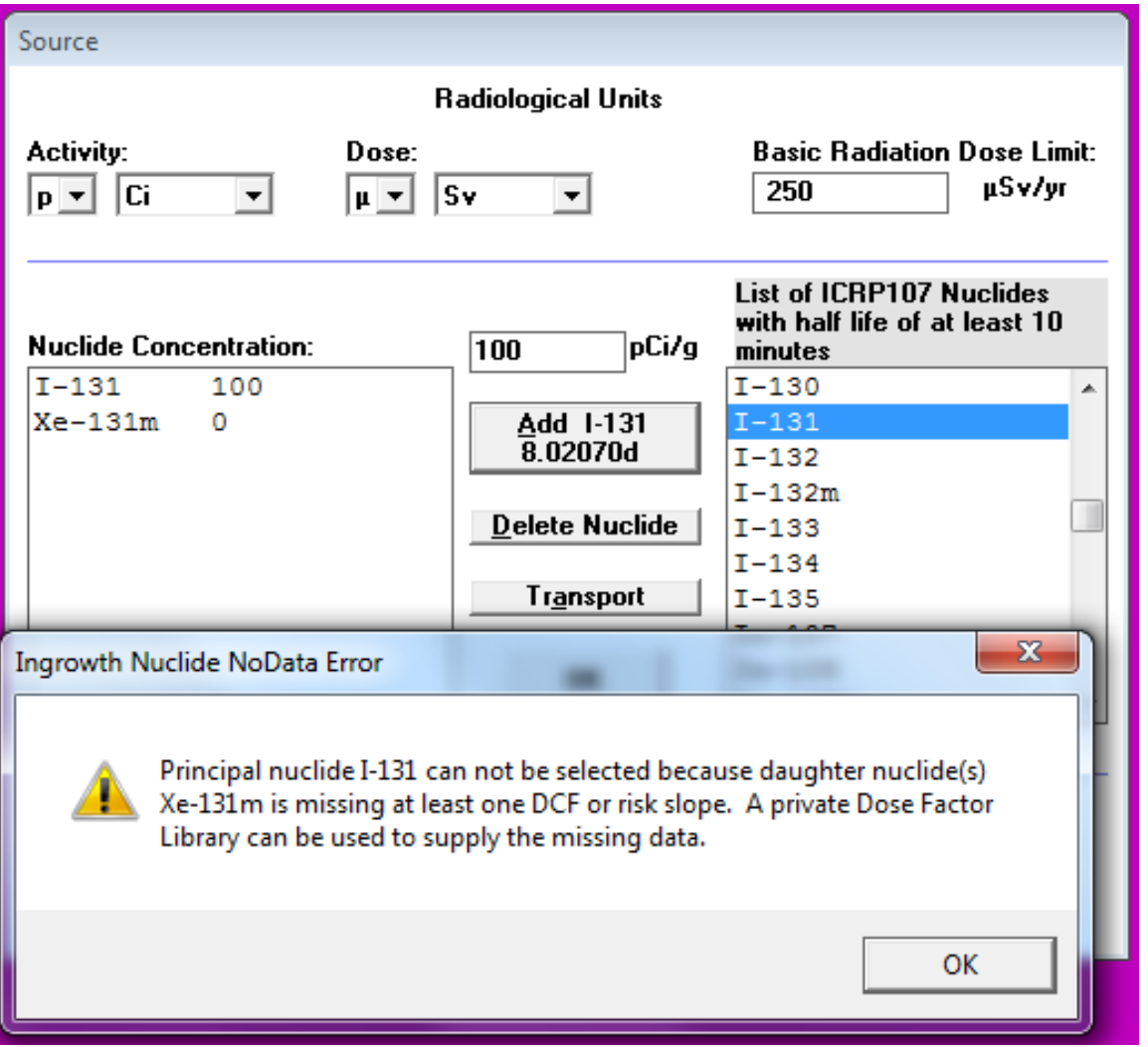

FIGURE 34 Nuclide No Data Error Message 


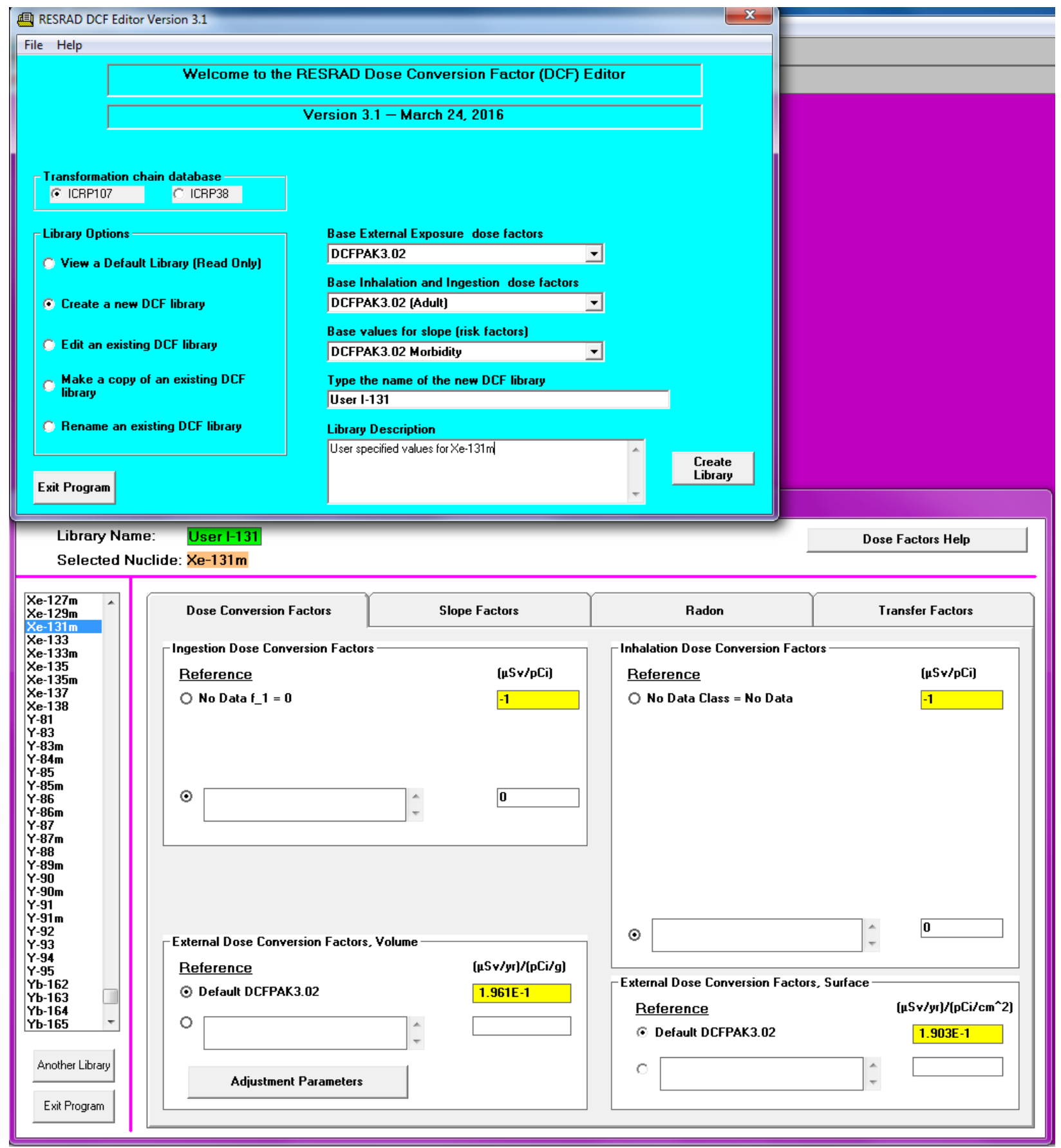

FIGURE 35 Creating a New DCF Library

\subsection{IMPORT AND EXPORT OF DCF LIBRARY}

The DCF Editor allows users to import or export user-created DCF libraries. Click "File" in the menu bar on top. Figure 36 shows the "Export" and "Import" options available in the DCF Editor. 


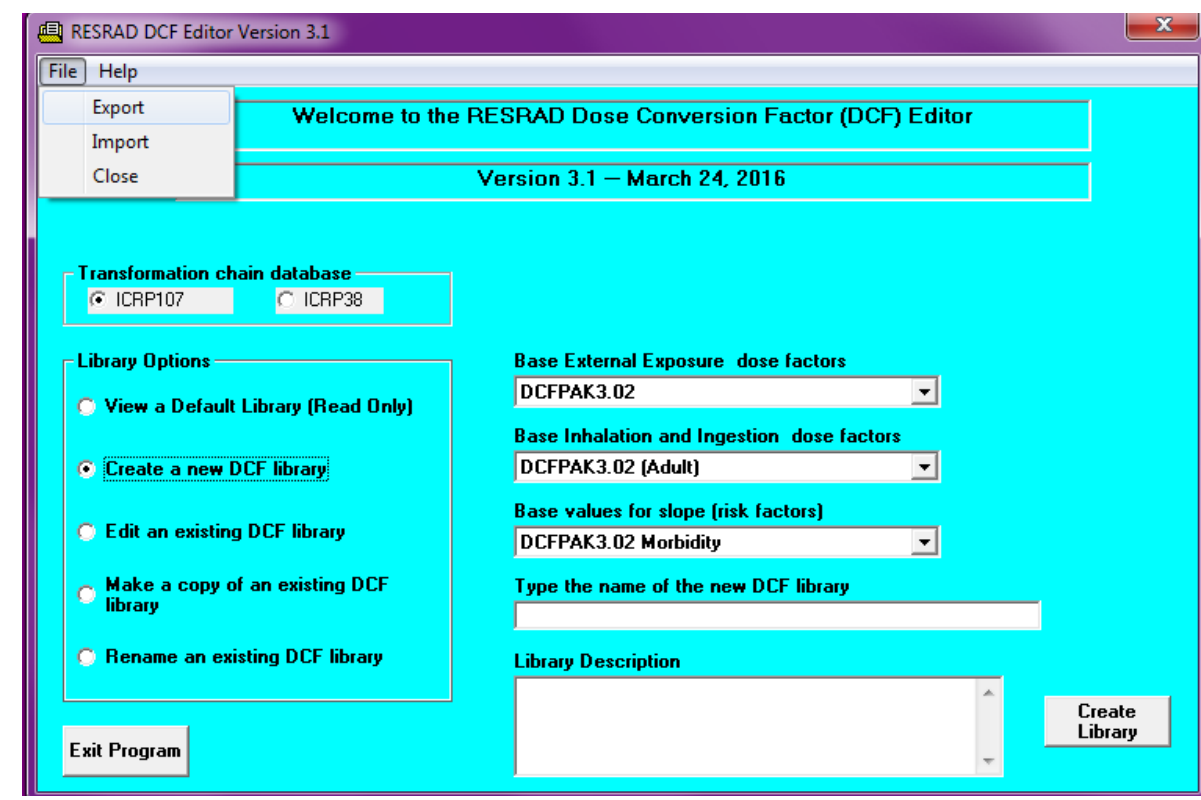

\section{FIGURE 36 Export and Import Options in the DCF Editor}

For exporting a DCF library, select "Export” and click on it.

Now select the library you want to export from the available user-created DCF libraries. Figure 37 shows the UserI-131 library selected.

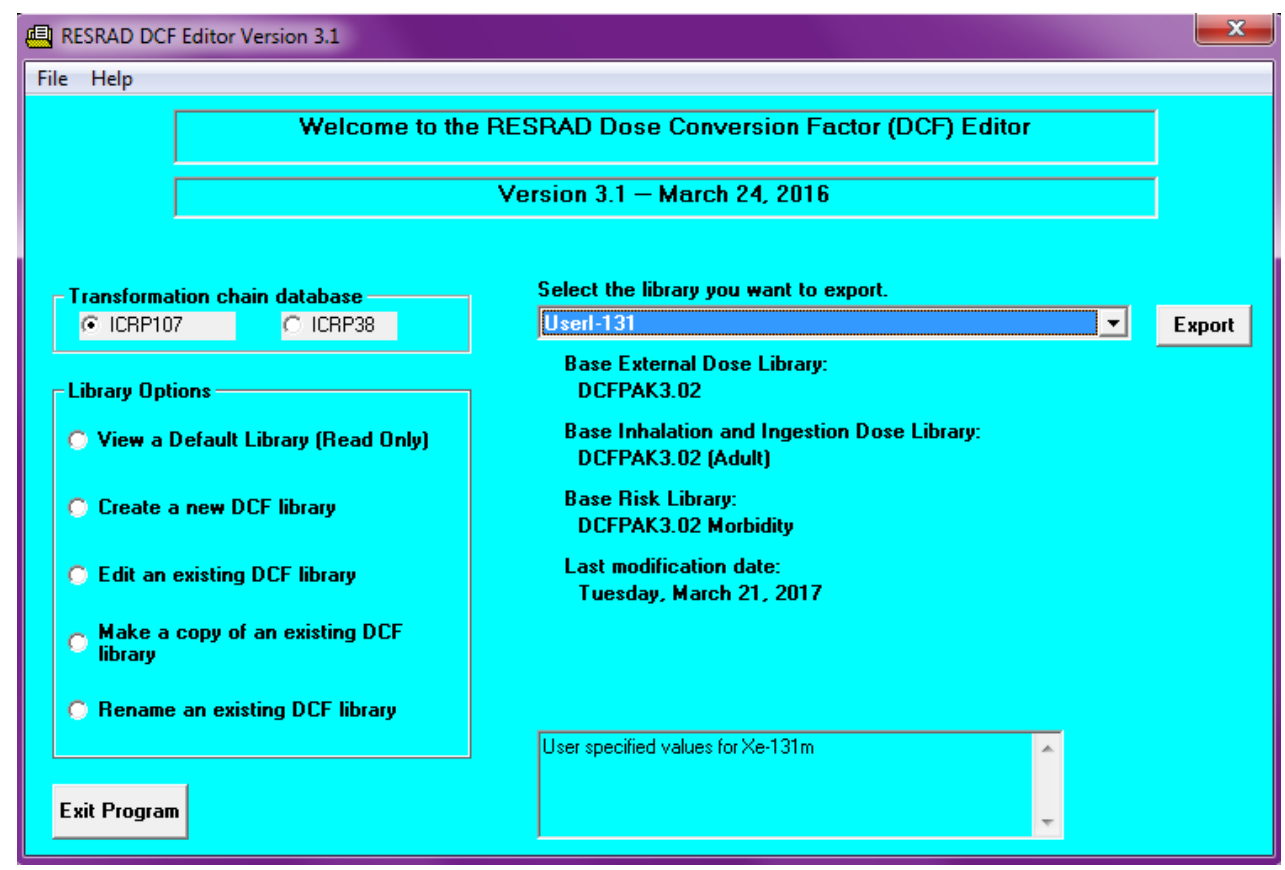

FIGURE 37 Select the User Library for Export 
Click the "Export” button.

Give a file name and select the location where you want to save the file. The file will be saved with the new name "I131-DCFs" in the example.

For importing a DCF library, select "Import" and click on it. Now go the location where DCF library is available. Select the library you want to import and open the file (Figure 38). The file will be saved on your computer. You may get a message as shown in Figure 39 if the file with the same name is already present on your computer.

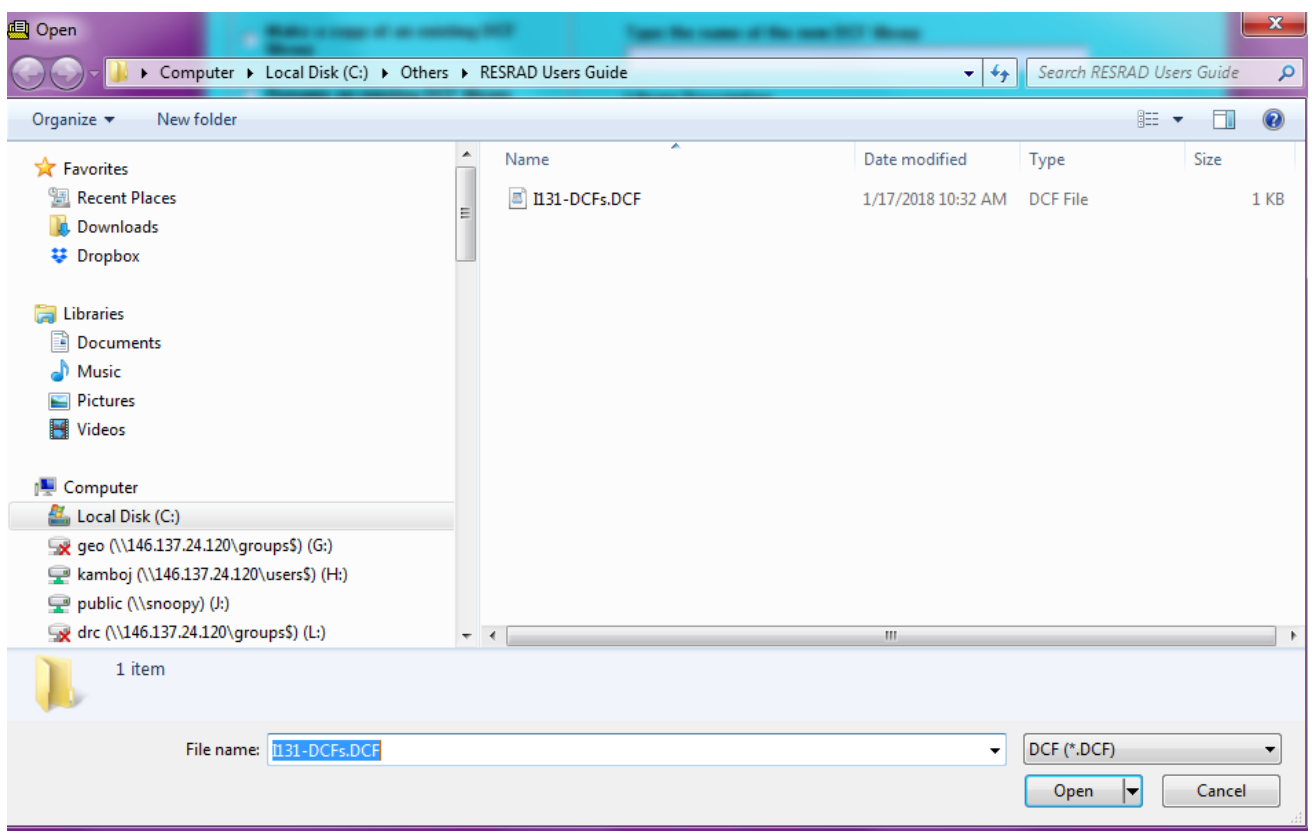

FIGURE 38 Importing DCF Library

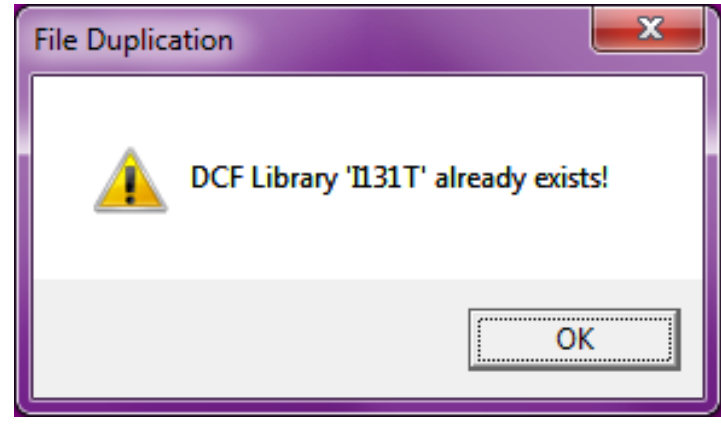

FIGURE 39 DCF Library File Duplication Message 
Click "OK” and a new window will open (Figure 40). Give the name and click "Import." Go back to the DCF Editor and select the "Edit an existing file" library option. The file now will be available in the DCF Editor (Figure 41).

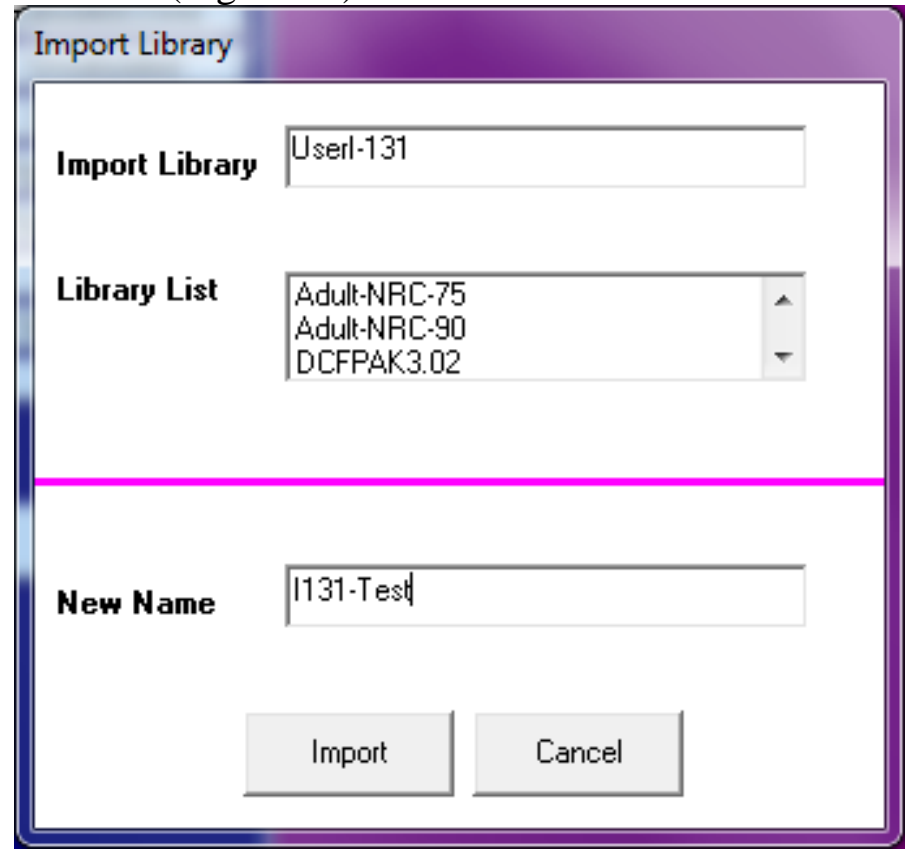

FIGURE 40 Give Name to the DCF Library

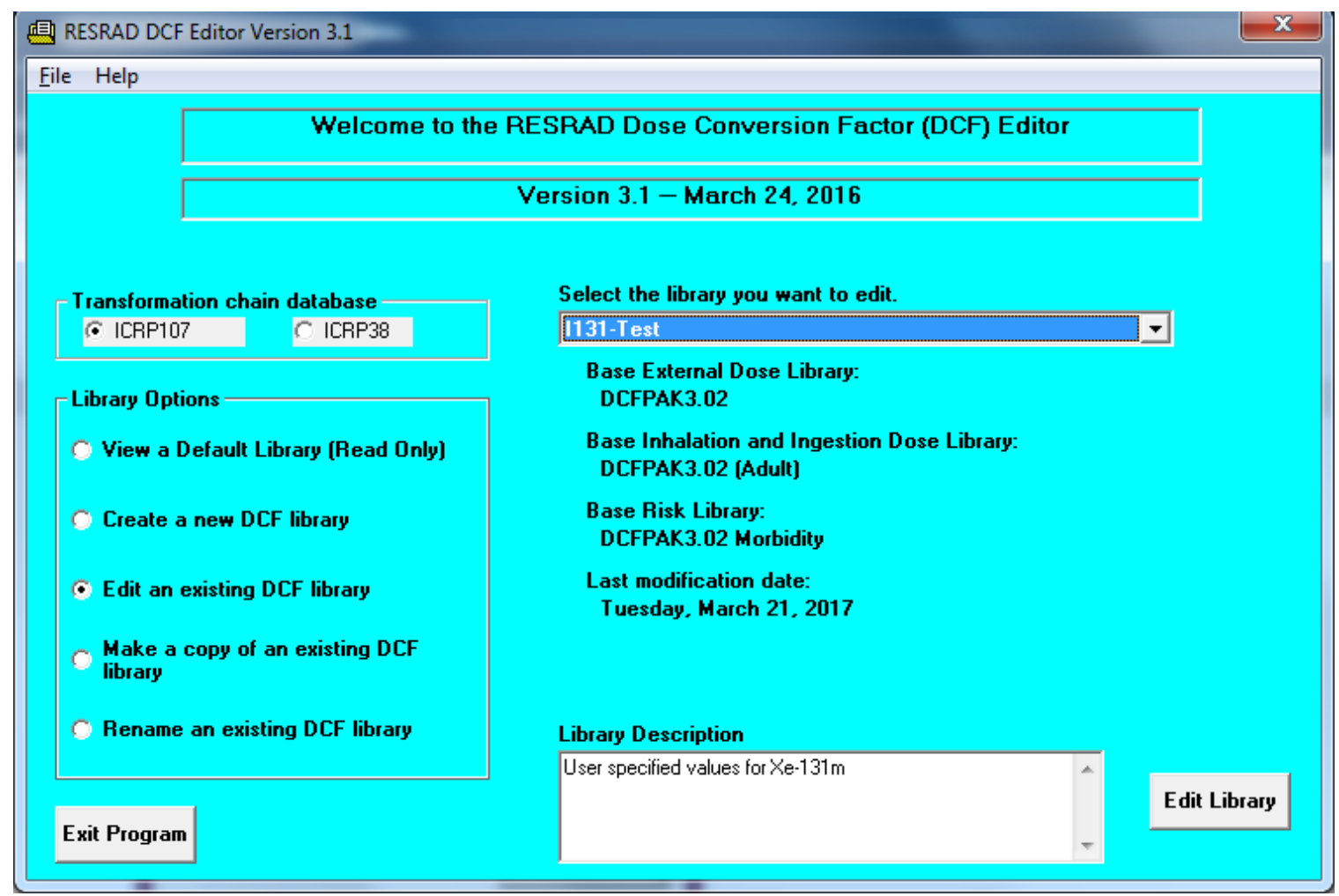

FIGURE 41 Imported File Available in the DCF Editor 


\section{RESULTS}

RESRAD-ONSITE code produces a maximum of eight textual reports and features many graphical options for standard problems. For a deterministic problem, the code produces five text reports; for a probabilistic run, the code produces eight text reports. The first page of each report consists of a table of contents. Sensitivity analysis results can be viewed as an option in the standard graphics window. Uncertainty analysis results are produced in a report and in uncertainty graphics. In this chapter, the contents of the textual reports and the use of the report viewer and the graphics windows are reviewed.

\subsection{STANDARD TEXTUAL REPORTS}

\section{Summary Report}

- Input

- Dose conversion factors

- Site-specific input

- Doses

- User-specified times summary

- Peak dose summary

- Dose components for various times

- Guideline information

- Dose/source ratios

- Soil guidelines

\section{Detailed Report}

- Iteration logs

- Source factors

- Ground pathway

- Inhalation pathway (radon excluded)

- Radon pathway

- Fluxes

- Working levels

- Water pathways Transport times

- Transport times

- Rise time

- Dilution factors

- Food pathways

- Storage times

- Area and depth factors

- Environmental transport factors 


\section{o Dose/source ratios \\ o Concentration ratios}

- Soil Ingestion

\section{Concentration Report}

- Concentrations at user-specified times in media

- Soils (contaminated and surface)

- Air

- Water (well and surface)

- Foodstuffs (milk, meat, vegetables, and fish)

- Fodder

\section{Risk Report}

- Cancer risk slope factors

- Excess cancer risks and intake quantities

\section{Progeny (Daughter) Report}

- Dose contributions by daughter products

\section{Uncertainty Analysis Report}

- Probabilistic input

- Total dose

- Total risk

- Dose for different pathways

- Cumulative probability summary

- Dose summary at graphical times

- Peak of the mean dose at graphical times

- Correlation and regression coefficients

\section{Regression Report}

\section{LHS Report}

\subsection{REPORT VIEWER}

The Report Viewer is launched automatically at the end of each successful run and displays the Summary Report (Figure 42). The Report Viewer may be accessed, however, at any time from the Menu, Toolbar, DOS Emulator, or Navigator. If the viewer is minimized before the code is run, the new report will be loaded in the viewer, but the viewer will remain minimized. 


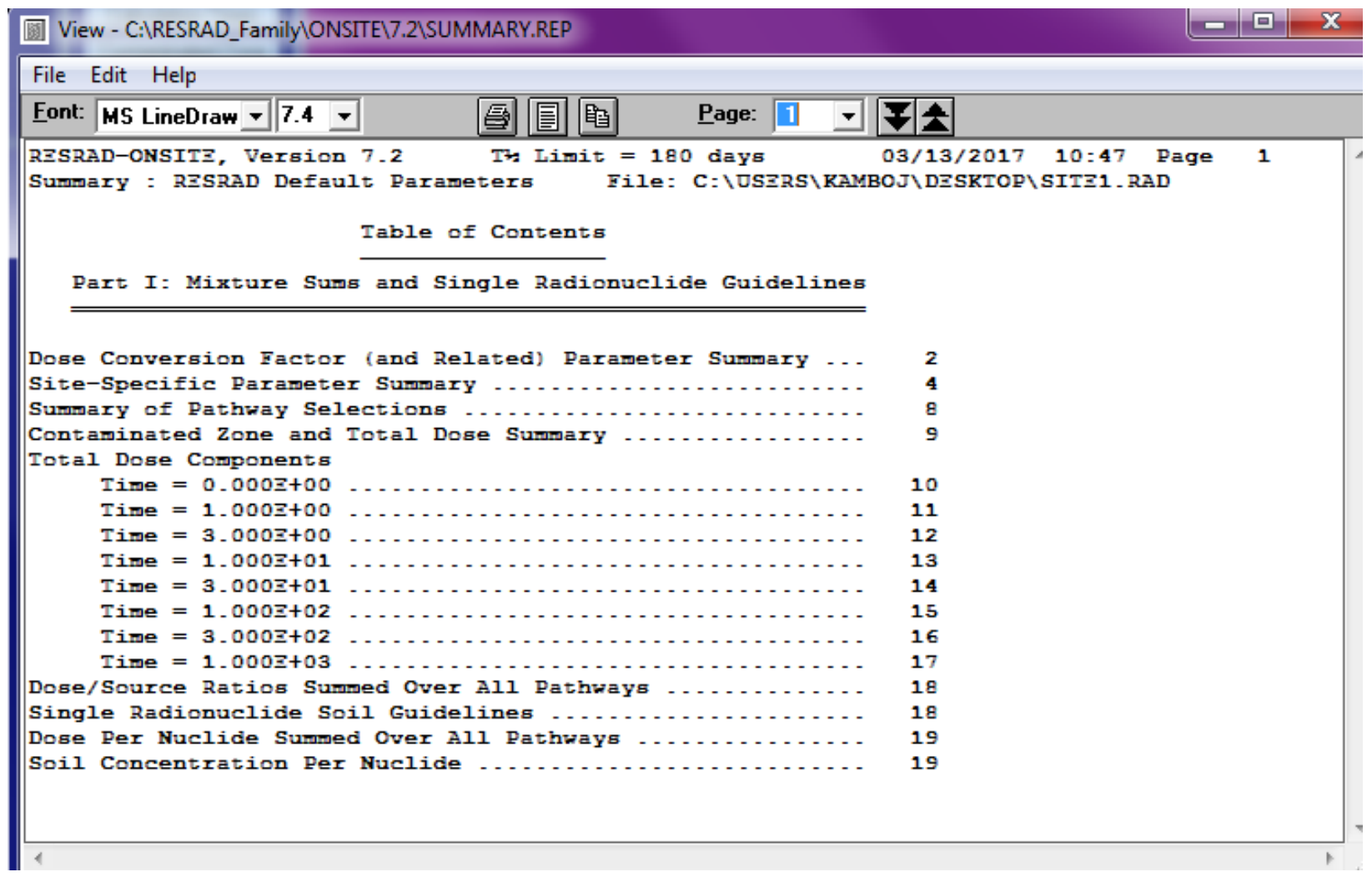

FIGURE 42 RESRAD-ONSITE Summary Report

\section{Getting to the Report Viewer}

- From the Menu: Select "View/Text Output/Summary" or any other report.

- From the Toolbar: Press the report page icon (Summary Report only).

- From the DOS Emulator: Press the "View Output" button and then the "Summary Report” or any other button.

- From the Navigator: Press the "Summary Report” or "Other Report” button when in the "Results" tab window.

\section{Moving Around}

- Pages: To go to another page, choose one of the following methods:

- Enter the page number in the "Page" text box and hit Return.

- Pull down the page list and click on the desired page.

- Advance a page by pressing the Page Down key; click the double down arrows.

- $\quad$ Press the Page Up key or click the double up arrows to go back a page. 
- Within a Page: Use scroll bars to position text.

- Between Reports: Select the "File/View Another File" option from the Main Menu to view another report, or close the viewer and go back to the main window to select a different file.

\section{Saving Files}

Note: Every time a calculation is run, the previous reports and graphics files are overwritten. The results can be saved under different names, thus allowing for later retrieval.

- Save All Files: Select “File/Save All” under the Report Viewer menu. This will save all textual reports to files. If the input filename is xxxx.rad, the reports will be saved as xxxx.yyy, where the extension yyy is "sum" for a summary report, "det” for a detailed report, "dau” for a daughter report, "con" for a concentration report, "int" for an intake and risk report, "prb" for an uncertainty report, and "smp" for a Latin hypercube sampling (LHS) report.

- Save the Open Report: Select "File/Save" under the Report Viewer menu. This will prompt the user to provide a name in order to save the currently displayed report.

\section{Copying Selections}

- Copy the Highlighted Section: Select "Edit/Copy" under the Report Viewer menu. The selected text will be placed on the Windows clipboard and can be placed into any document such as a spreadsheet or a text report.

- Copy the Current Page: Select "Edit/Select All” followed by "Edit/Copy." Alternatively, press the icon that looks like two pages.

- Copy to Excel: If Microsoft Excel is installed on the computer, a table can be highlighted and automatically placed into an Excel spreadsheet.

\section{Printing}

- Select the Printer: RESRAD-ONSITE uses a standard Windows printer. The selection for the printer can be accessed through the "File/Print/General" menu option. Options include printer selection and page selection.

- Set up the Report for Printing: Press the "Single Page" icon button to automatically select the best font size to fit the report to a single page width.

- Print: Select the "File/Print" menu option or press the "Printer" icon button. A dialogue box will appear that will allow printing of the whole report, specific pages, or the currently highlighted text. 


\subsection{GRAPH VIEWER}

\section{Getting to Graph Viewer}

From the DOS Emulator: Click "View Output" to bring up the output form, then click "Standard Graphics” (see Figure 43).

From the Windows Navigator: Click the "Results" tab, then click the "Standard Graphics" icon.

From the Menu: Click "View” on the menu and select "Graphic Output."

From the Toolbar: Click the icon with the button prompt "View RESRAD-ONSITE Standard Graphics"

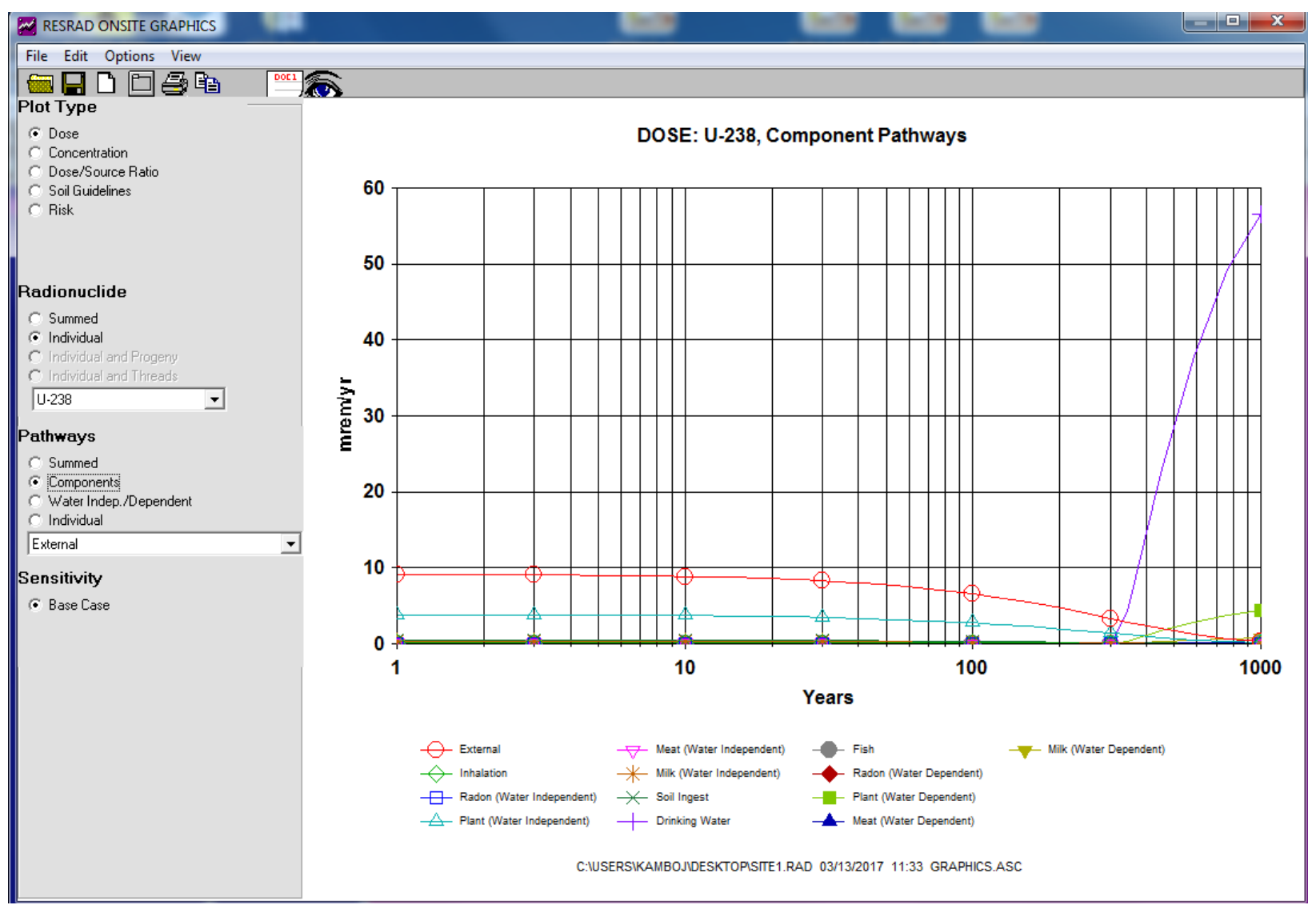

FIGURE 43 RESRAD-ONSITE Deterministic Graphics 


\section{Setting Up}

Data to Plot: Data for radionuclides and pathways can be manipulated to produce a variety of plots. The following parameters can be specified to select a plot.

\section{Plot Type}

Dose: Select "Dose" to view a graphical representation of the dosage contributions of selected radionuclides taken over a user-specified number of years (mrem/yr or mSv/yr).

Concentration: Displays a plot of the concentration of individual radionuclides in various media (pCi/g or $\mathrm{Bq} / \mathrm{g})$.

Dose/Source Ratio: Displays a graphical representation of an individual radionuclide's ratio of dose contribution (mrem/yr or mSv/yr) over concentration ([mrem/yr] / [pCi/g] or $[\mathrm{mSv} / \mathrm{yr}] /[\mathrm{Bq} / \mathrm{g}])$.

Soil Guidelines: Select Soil Guidelines to view a graph.

Risk: Select Risk to display a plot of excess cancer risk.

\section{Radionuclide}

Summed: Plots the sum of all user-selected radionuclides.

Individual: Plots a single user-selected radionuclide. The plot includes the contribution of progeny.

Individual and Progeny: Plots also the contributions of progeny if present.

Individual and Threads: Plots the contributions of different threads if present.

\section{Pathways}

Summed: Plots all pathways summed.

Components: Plots all pathways as individual components.

Water Indep./Dependent: Plots summed water-dependent and summed water-independent pathways only.

Individual: Plots a single selected pathway.

\section{Sensitivity}

Base Case: Indicates not to plot sensitivity results. This is the default setting. 
Parameter: Plots sensitivity results on a user-selected parameter. There is a dropdown list containing variable names of the inputs selected for sensitivity analysis.

\section{Feedback}

Print: Clicking "File” from the menu presents two options: "Print” and "Print Setup." Select "Print" to print the current plot displayed with preset print options. Select "Print Setup" to change these printer options.

Title: The plot's title is divided into three parts; for example, see the title in the Figure 43 at the beginning of this subsection — "DOSE: U-238, Component Pathways." The first part before the colon represents the current Type option selected; in this case, DOSE. The second part after the colon represents the current Radionuclide option selected; in this case, the individual radionuclide U-238. The last part of the title after the comma represents the current pathway selected; in this case, component pathways.

Figure 44 shows the Main Menu and the submenus in the RESRAD-ONSITE deterministic graphics.

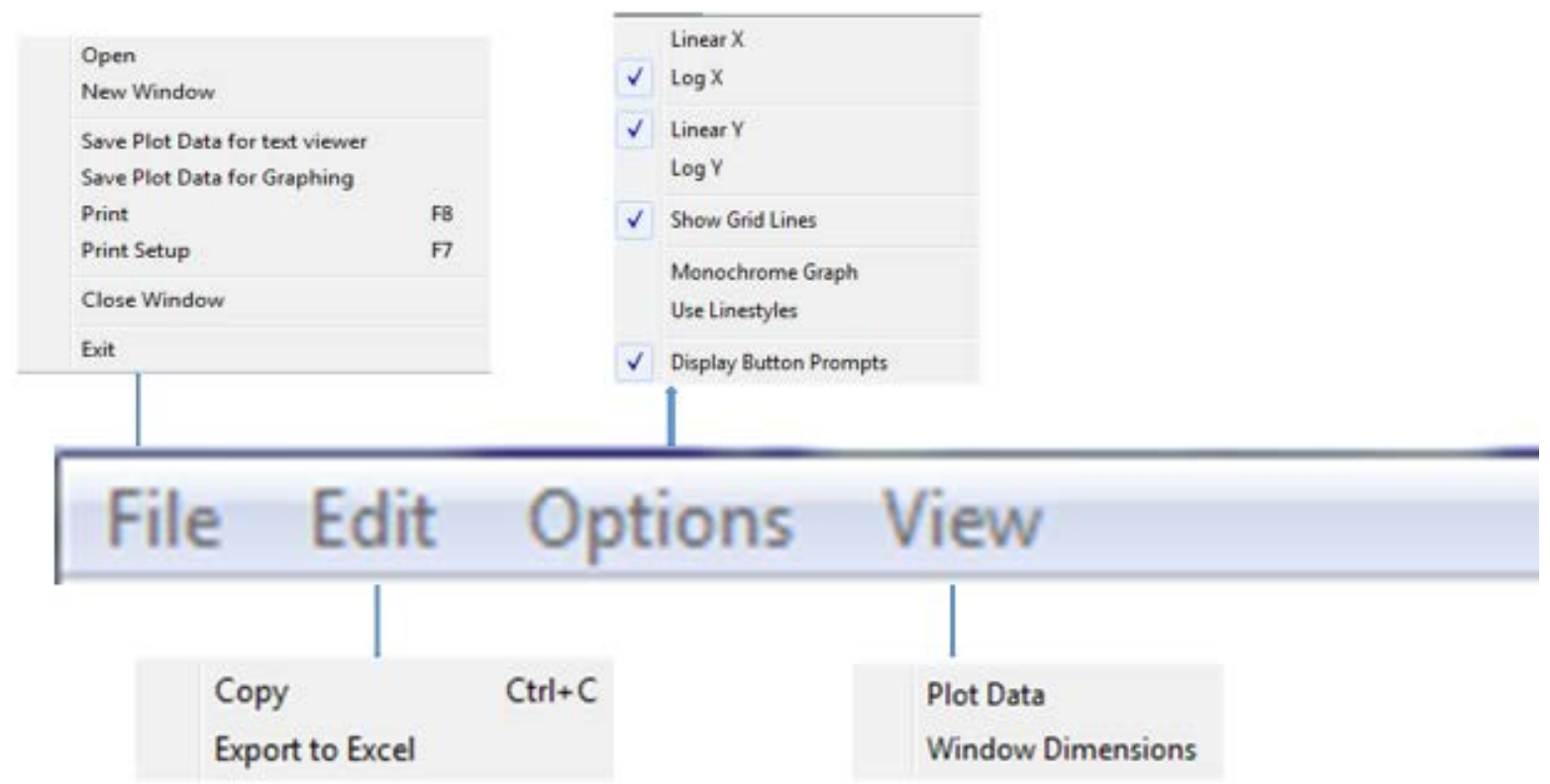

FIGURE 44 Menu Bar in RESRAD-ONSITE Deterministic Graphics

\section{File Submenu}

Open: This command is used to open the deterministic graphics data file from a previous run. The deterministic graphics data file is stored in the same directory as the input files at the end of each run. 
New Window: This command displays another Graph Viewer window. Two plots from the same data file can be viewed.

Save Plot Data for Text Viewer: This command writes the $\mathrm{x}$ and $\mathrm{y}$ values used in the plot in a file "plotdata.dat." A header row is printed after every 61 lines, making it easier to view the data over multiple pages.

Save Plot Data for Graphing: This command writes the $\mathrm{x}$ and $\mathrm{y}$ values used in the plot that is displayed in columns in an ASCII file "GraphData.dat." The header row is printed once at the beginning of the file, making it easier to use these data in other graphing programs.

Print: This command is used to produce a hard (paper) copy of the current plot.

Print Setup: This opens a window displaying the list of available printers and printing specifications.

Close Window: When multiple Graph Viewer windows are open, this command is used to close an individual window.

Exit: This closes all Graph Viewer windows.

\section{Edit Submenu}

Copy: This command saves the plot in a metafile. The print screen (Print Scrn) key on the keyboard produces a much better quality image.

Export to Excel: This command opens a new Excel file and transfers the $\mathrm{x}$ and $\mathrm{y}$ values used in the plot. If multiple lines are displayed in the plot, a pair of columns is output for each line that is displayed. The first three rows contain the plot title, plot footer, and column headers.

Options Submenu: This submenu is used to change the appearance of the plot. The following choices can be made: display either axis in linear or logarithmic scale, display or suppress grid lines, use different colors for different plots or use black for all plots, and use the same or different line styles for the different plots. This menu is also used to hide or show the prompts for the buttons on the toolbar.

View: This menu is used to view the plot data. The plot data must have been saved previously by using the "Save Plot Data" command.

Some of the operations performed by the submenu commands can be performed by the toolbar command buttons, as shown in Figure 45. 


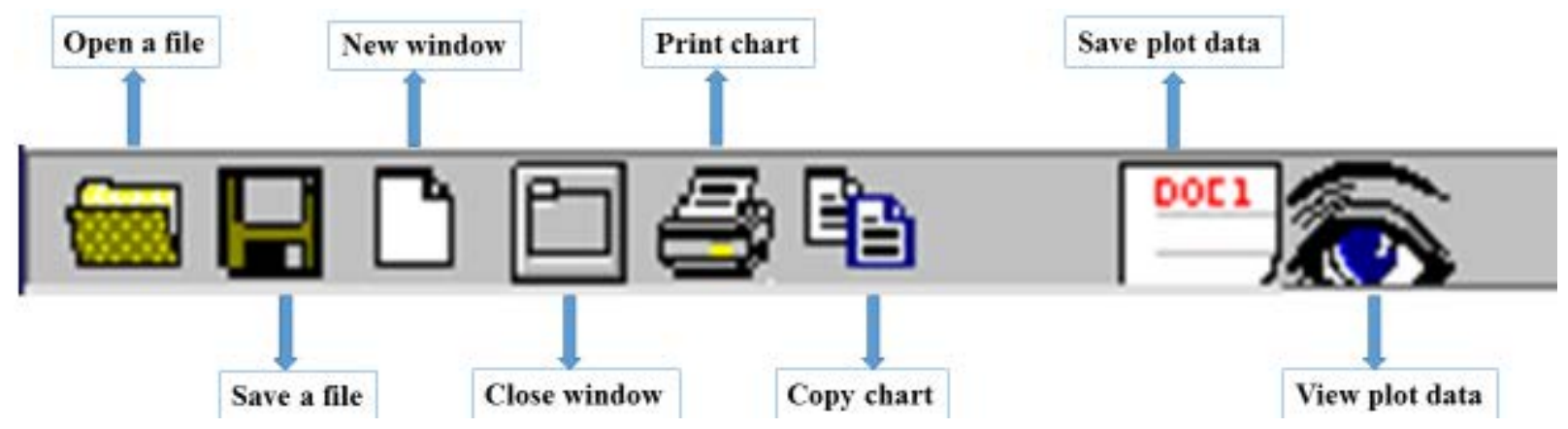

FIGURE 45 Toolbar, Command Buttons, and Associated Functions in Deterministic Graphics Display 


\section{ENHANCEMENTS}

RESRAD-ONSITE for Windows was designed with sensitivity analysis and uncertainty/probabilistic analysis features to enhance normal calculations, increase understanding of specific applications, and identify important input parameters. The sensitivity analysis option can be used to observe the independent influence of each individual parameter. The uncertainty and probabilistic analysis option can be used to study the variation in the prediction and the importance of each individual parameter when a number of parameters are varied simultaneously over their likely ranges.

RESRAD-ONSITE includes a soil strata parameters graphic window. This window presents a cross section of the various zones with scaled thicknesses and allows access to the input form associated with each soil stratum.

The DCF Editor is updated to include both ICRP 107-based and ICRP 38-based radionuclide transformation databases.

\subsection{SENSITIVITY ANALYSIS}

\subsubsection{Purpose}

Sensitivity analysis is used to study the independent influence of each individual parameter on the predicted dose, risk, and concentrations. Each of the selected parameters is varied in turn by a factor that is at first higher than its deterministic (base) value and then lower. Thus, two additional runs of the code are performed for each parameter selected for sensitivity analysis. Three curves are plotted to show the variation of the predictions over time for the three values (low, base, high) of the parameter, while all the other parameters are held at their base values. Figure 46 shows the sensitivity analysis setup screen. 


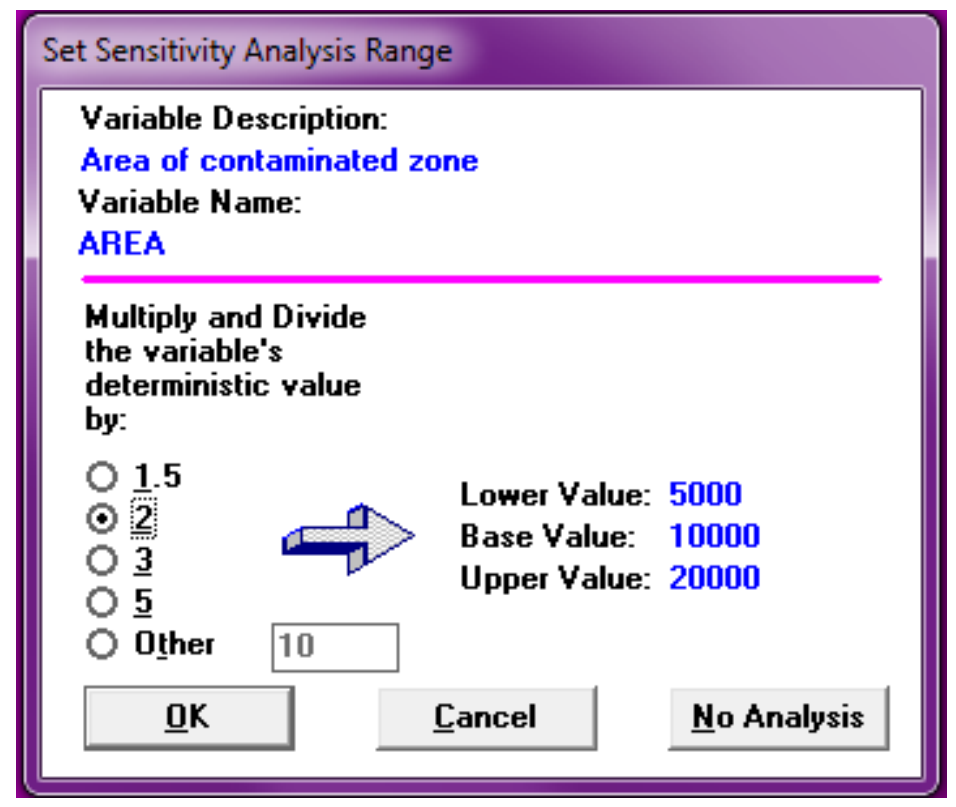

FIGURE 46 Sensitivity Analysis Setup Screen

\subsubsection{Getting to the Sensitivity Analysis}

From the Toolbar: While maintaining focus on the parameter of interest, click the "Sensitivity Analysis” button.

From the Input Window: Click the parameter of interest, then press the F9 function key. This is a short-cut for the menu command "Form Options - Sensitivity Analysis".

From the Status Bar: If the sensitivity for a parameter has already been set, the sensitivity summary bar (shown if "View/Sensitivity Summary" has been selected) will include a button for each sensitivity analysis. The title of the button includes the variable's name and an indicator of the factor to multiply and divide by $(* /)$. Click any button to review, set, or cancel the sensitivity analysis on the parameter. Right-clicking will remove the sensitivity analysis on that parameter.

\subsubsection{Settings}

Factor: Choose one of the options for the multiplication and division factor. The resultant values for the two sensitivity runs will be shown at the right, along with the base value. If you choose "Other," enter any value greater than 1 . If a selection causes a parameter value to exceed its bounds, the sensitivity factor will be reset to the maximum or minimum allowable.

Add: Choose "OK" to add the analysis for the parameter.

Delete: Choose "No Analysis” to cancel or remove the sensitivity analysis. 


\subsubsection{Output}

Sensitivity analysis results are shown only in the graphics, not in any textual report. After a case has been run with sensitivity analysis, the left-hand column of options should have a "Sensitivity" at the bottom. Figure 47 shows the sensitivity analysis results for the thickness of a contaminated zone.

Sensitivity analysis results are not available under the following options:

- “Soil Guidelines” option under "Plot Type.”

- "Individual” and "Progeny" option under "Radionuclides."

• “Components and Water Indep./Dependent” option under "Pathways.”

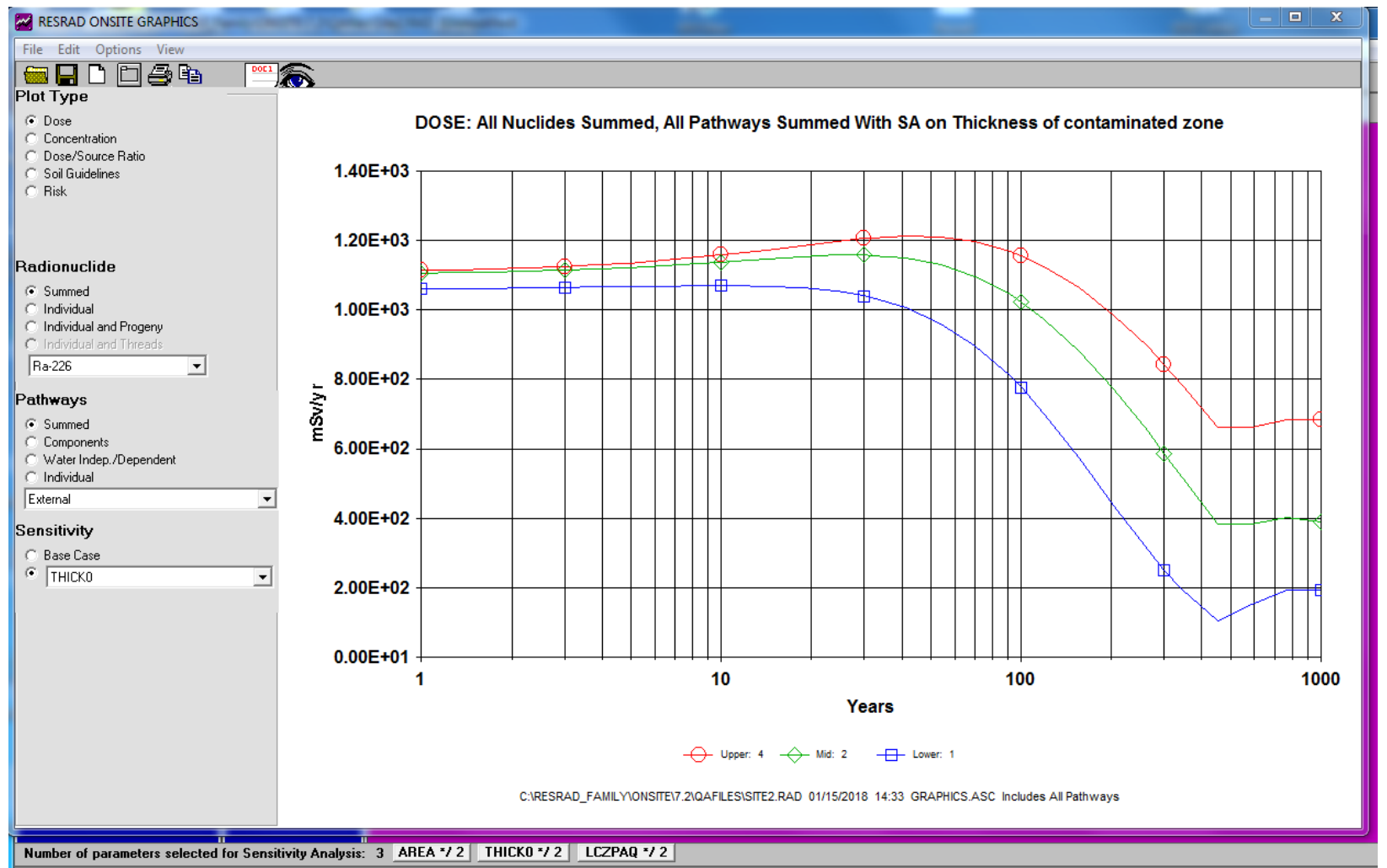

FIGURE 47 Sensitivity Analysis Results

\subsection{UNCERTAINTY/PROBABILISTIC ANALYSIS}

The uncertainty/probabilistic modules have been designed to be flexible and quite independent of the original RESRAD-ONSITE application. They are, however, easily applied and integrated with the application, and they utilize previously written software for Latin hypercube sampling (LHS) and correlation analysis (Iman et al. 1985). 


\subsubsection{Procedures for Using Uncertainty/Probabilistic Analysis}

- Users run the standard software interface (i.e., RESRAD-ONSITE) to set deterministic values for parameters not involved with probabilistic analysis.

- Probabilistic analysis is set by finding parameters in the standard interface and pressing the F8 function key. The probabilistic input window with four tab screens will appear. The parameter, with its default distribution, will be automatically added to the list of parameters for probabilistic analysis. The user can and should replace the default distribution with a site-specific distribution, if available.

- If the probabilistic analysis is activated, after the deterministic run and any sensitivity runs, the probabilistic runs will begin.

- After completion of the calculations, the summary report appears in the text viewer. To view the probabilistic results, the user will need to launch the interactive output or the "Uncertainty Graphics" in the menu command.

- Input: The input window takes information from the default distribution database and from the user's commands to construct the list of parameters, their distributions and correlations, and general sampling options. At run time, the LHS code is activated to perform the sampling.

- Output: The code is then run on these samplings, and the results are stored for incorporation into interactive text and graphs, textual reports, and formatted output for user-controlled processing.

\subsubsection{Four Input Tabs for Uncertainty/Probabilistic Analysis}

Sample Specifications Tab: This tab (Figure 48) specifies how the distributions specified in the "Parameter distributions" tab are sampled and how the samples for the different inputs are to be combined to produce the set of inputs. The frame on the right side of the tab describes the purpose and effect of each of the items on this tab. 


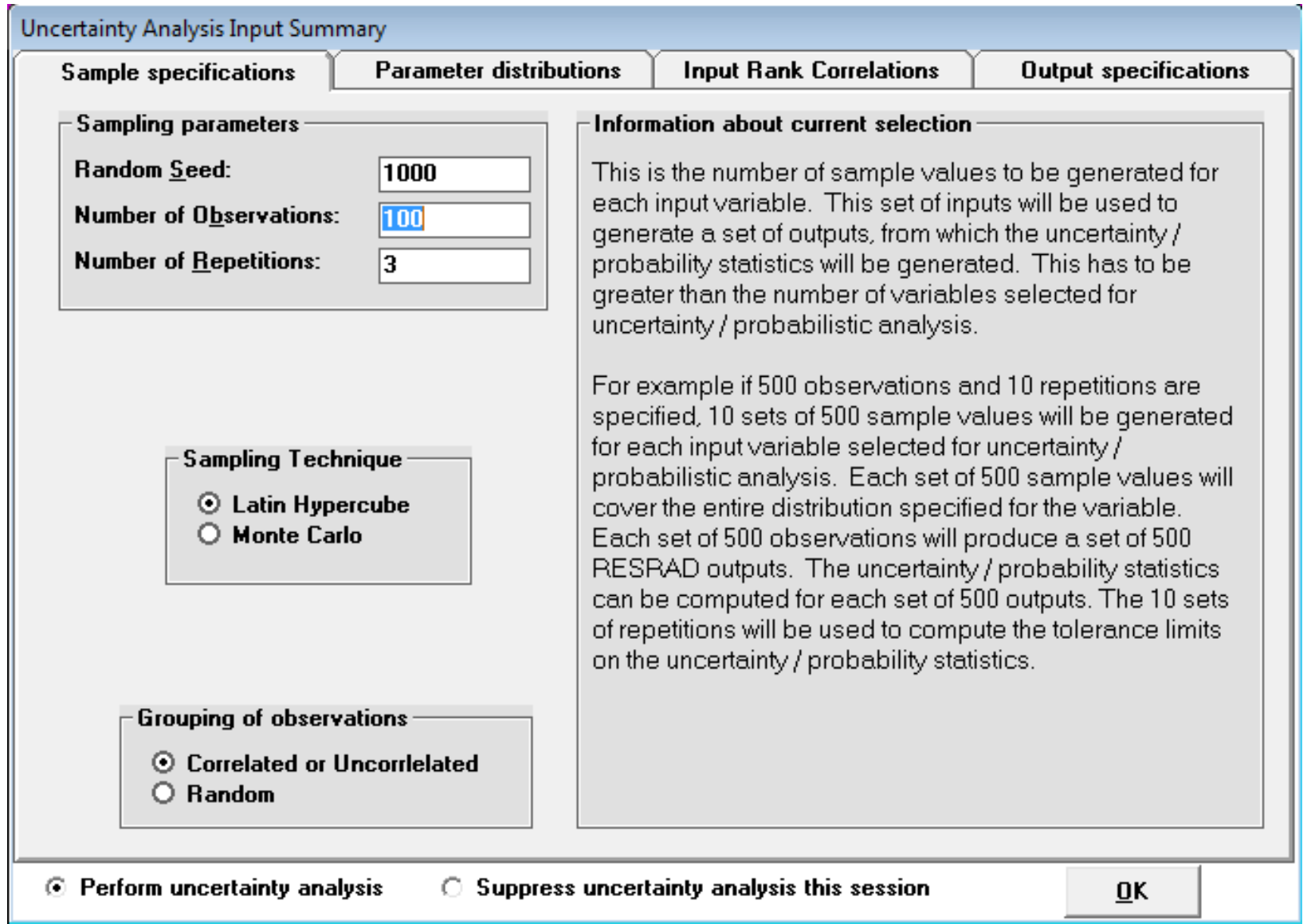

FIGURE 48 Sample Specification Tab

- Number of Observations: This is the number of values that will be sampled from the distribution of each input parameter specified in the "Parameter distributions" tab. This must exceed the number of input parameters, if correlations are specified between inputs or if regression statistics are to be produced. The accuracy of the probabilistic predictions can be improved by increasing the number of observations.

- Sampling Technique: The code offers a choice of two sampling techniques: LHS or Monte Carlo. In the LHS technique, the distribution is divided into equally probable segments, equal in number to the desired number of observations. Then a value is picked at random from each segment according to the probability density function within that segment. This ensures that the sample covers the entire range of the distribution, even when the number of samples is relatively small. In the Monte Carlo technique, the desired observations are each picked at random from the entire distribution according to the probability density function. When the number of samples is small, the sampled values do not represent the distribution as well as the values obtained by using the LHS technique. 
- Random Seed: Both sampling techniques choose the sample value from the appropriate part of the distribution at random according to the probability density function. The sampling code has a random number generator to produce the pseudo-random numbers needed to do the random sampling. The random number generator produces a random number based on the seed it receives. It also increments the seed to the next integer every time a random number is generated. Thus, the sequence of random numbers that is generated to obtain the sample can be exactly reproduced if the same starting seed is used again. The "Random Seed" input is the starting seed; it allows the code to reproduce the same set of probabilistic inputs, should there be a need to rerun the same analysis later on a different computer.

- Grouping of observations: After the code obtains the required number of samples for each input parameter, it produces the probabilistic set of inputs. Each element of the set of inputs will contain one sample from each of the input parameters. The code offers two choices on how the samples from each input parameter are combined to make the set of inputs: (1) "Random" grouping or (2) “Correlated or Uncorrelated” grouping. If it is necessary to have correlations between some of the inputs, or if it is necessary to ensure that there is no correlation between some of the inputs (i.e., zero correlation), the correlated grouping must be used.

- Number of Repetitions: This is the number of times the analysis needs to be repeated in order to obtain a measure of the accuracy of the probabilistic predictions. Increasing the number of observations increases the accuracy of the probabilistic predictions, but a measure of the accuracy can be obtained only if the analysis is repeated. The closeness of the results, or the lack thereof, is an indication of the accuracy, or lack of accuracy, of the predictions.

Parameters Distributions Tab: The "Parameter distributions" tab screen (Figure 49) allows the user to view and edit all currently specified parameter distributions for probabilistic analysis. The parameters are listed in the left frame. The detailed distribution properties are shown in the right frame. 


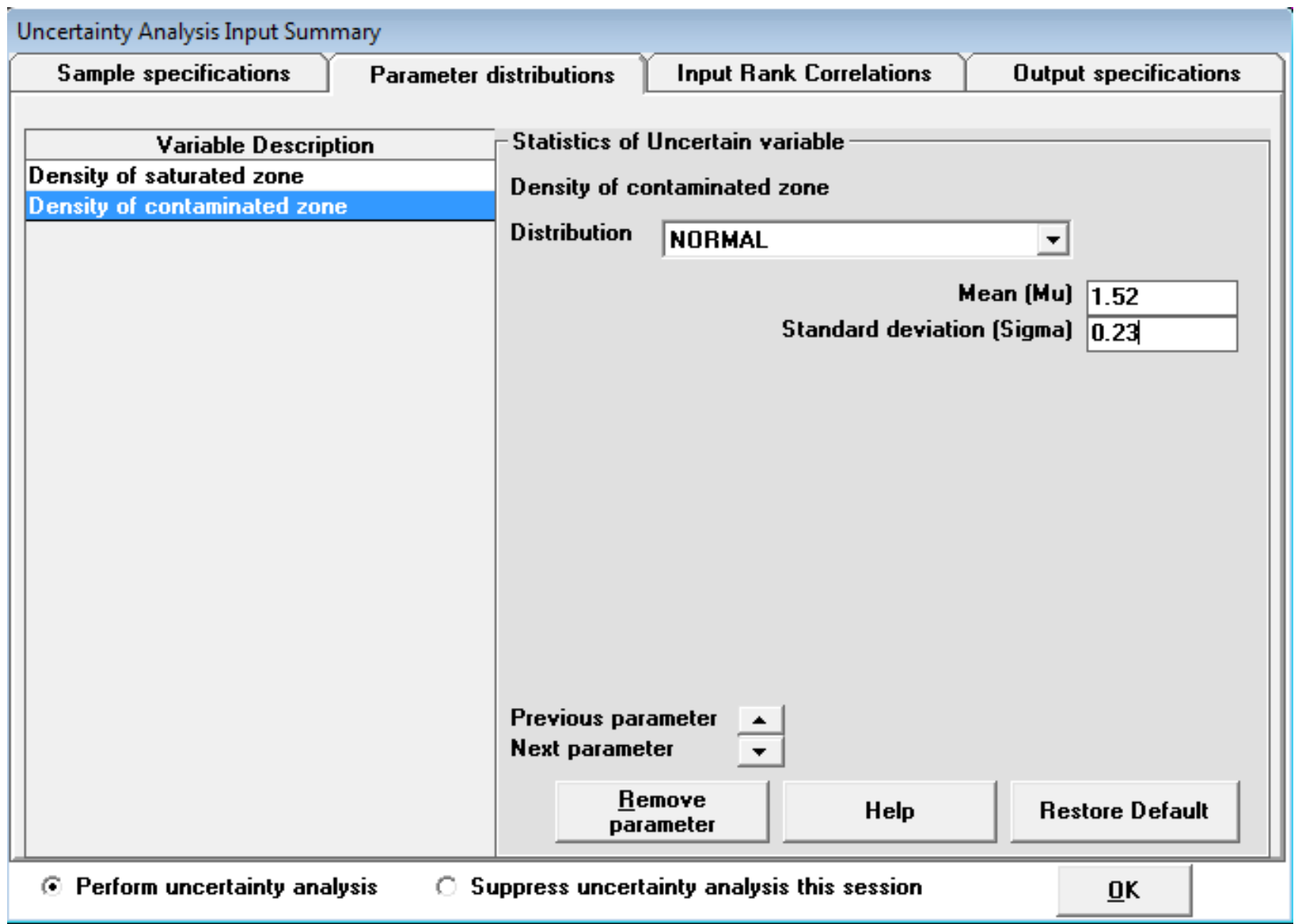

\section{FIGURE 49 Parameter Distribution Tab}

- Navigation: Navigation to other parameter distributions is achieved either by clicking the parameter on the left side or by using the Up-Down arrow control on the left side of the right frame.

- Parameter List for Probabilistic Analysis: The list of the currently chosen parameters is shown on the left frame including the variable description. By clicking on any parameter in the left frame, the complete distribution properties for the parameter will appear for review and edit on the right frame.

- Statistics of Uncertain Variable: The distribution properties are the distribution type, shape parameters concerning the specific distribution type, and upper and lower truncation bounds. In this example, the shape parameters are for the normal distribution (i.e., the mean and standard deviation).

If the user wishes to change the default distribution for the parameter, the "Restore Default" button can be selected. The user can also remove the parameter from further probabilistic consideration by clicking the "Remove Parameter" button. 
Clicking on the "Help" button on the right frame provides help on the distribution (see Figure 50).

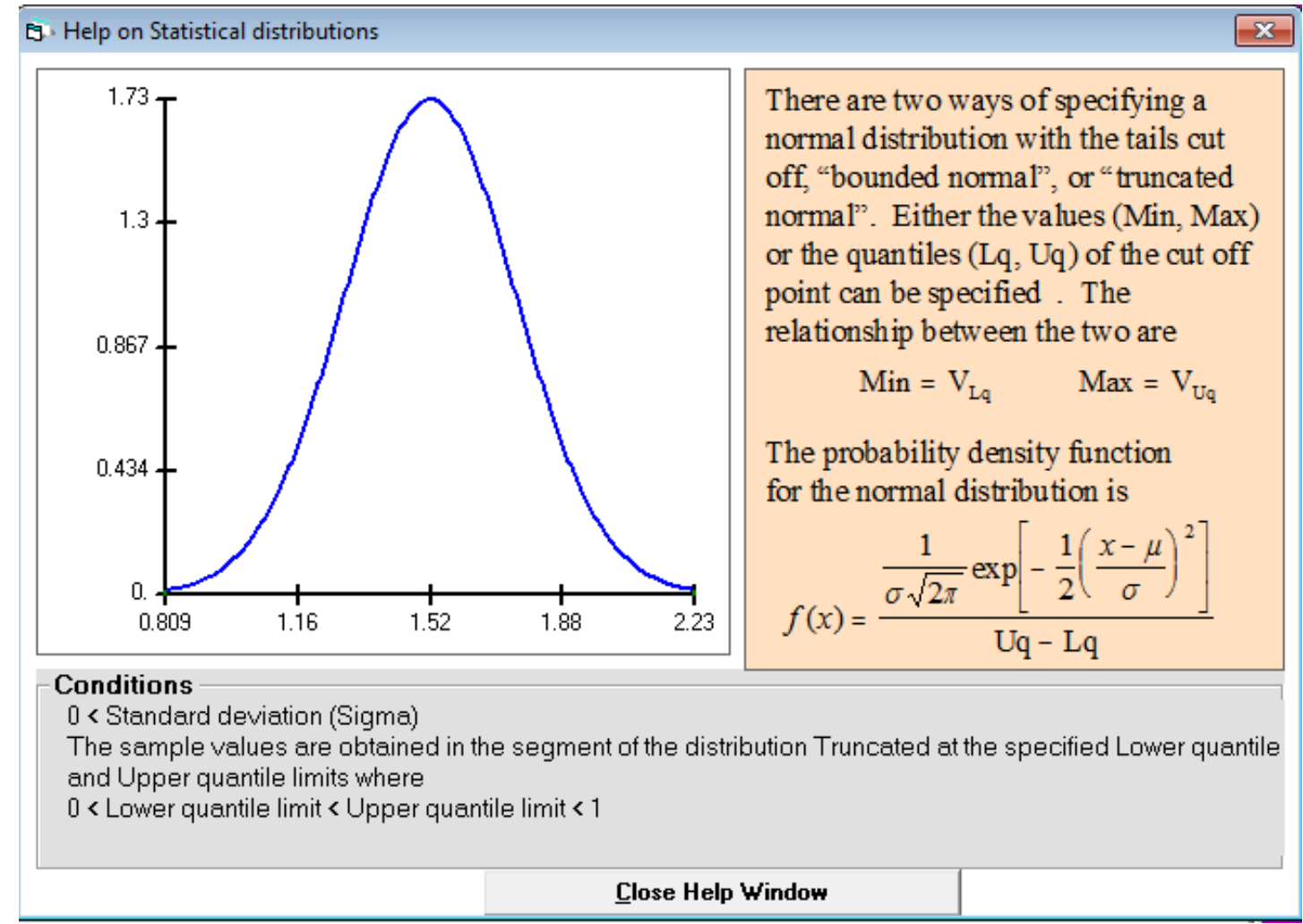

\section{FIGURE 50 Help on Parameter Distribution}

Input Rank Correlations Tab: The “Input Rank Correlations” tab screen (Figure 51) allows the user to view and edit all correlations between input parameters for probabilistic analysis. The paired parameters with nonzero correlations are listed in the left frame. Correlations can be modified, added, or deleted in the right frame. 


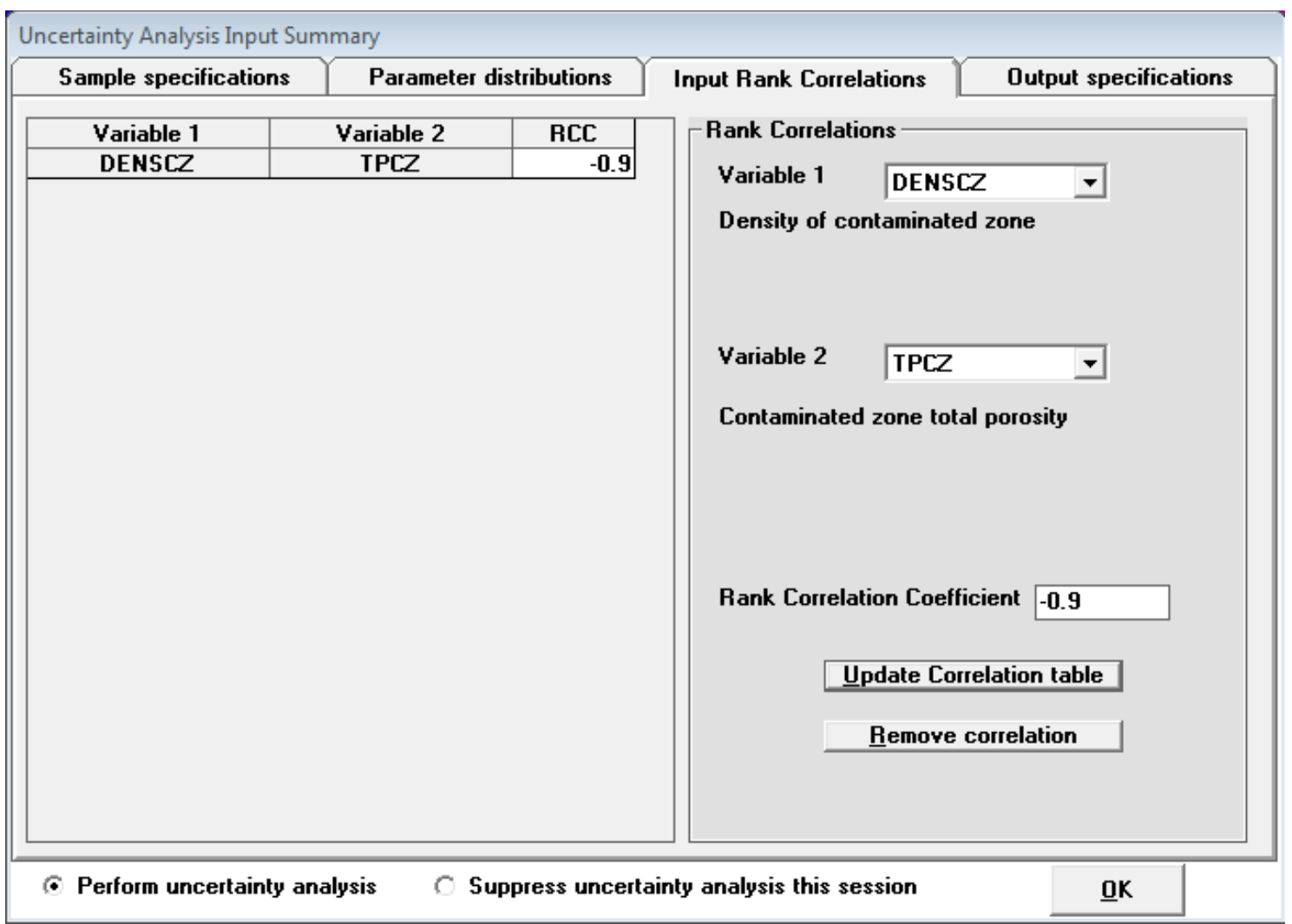

FIGURE 51 Input Rank Correlation Tab

- Navigation: The user can select an existing correlation pair by clicking on its row in the left frame. New pairs are chosen on the right side by selecting the two variables. The edits in this frame are incorporated after clicking on the "Update Correlation table" button. The pair is removed by selecting the "Remove correlation" button.

- Parameter List for Correlation: The currently chosen pairs of parameters are listed in the left frame in a three-column table that shows the variable names in the code and the correlation coefficient. By clicking any element in any row of the table, the correlation can be modified or deleted in the right frame. The range of correlation coefficients is -0.999999 to 0.999999 . The correlation for all pairs not specified here is assumed 0.0. The user can check the results of the sampling correlation after the run has been completed. Full descriptions of the variables can be seen in the right frame. If more parameters are chosen for correlation than fit in the window, the left side becomes a scrolling table.

- Correlation Edit: The two parameters in the correlation and the correlation coefficient are shown in the right frame and can be edited there. The user can also remove the parameter from further probabilistic consideration by clicking the "Remove correlation" button. 
Output Specifications: The user selects what type of output should be generated (Figure 52). More detailed output options (e.g., by pathway, by nuclide, or by user-specified times) take longer to run.

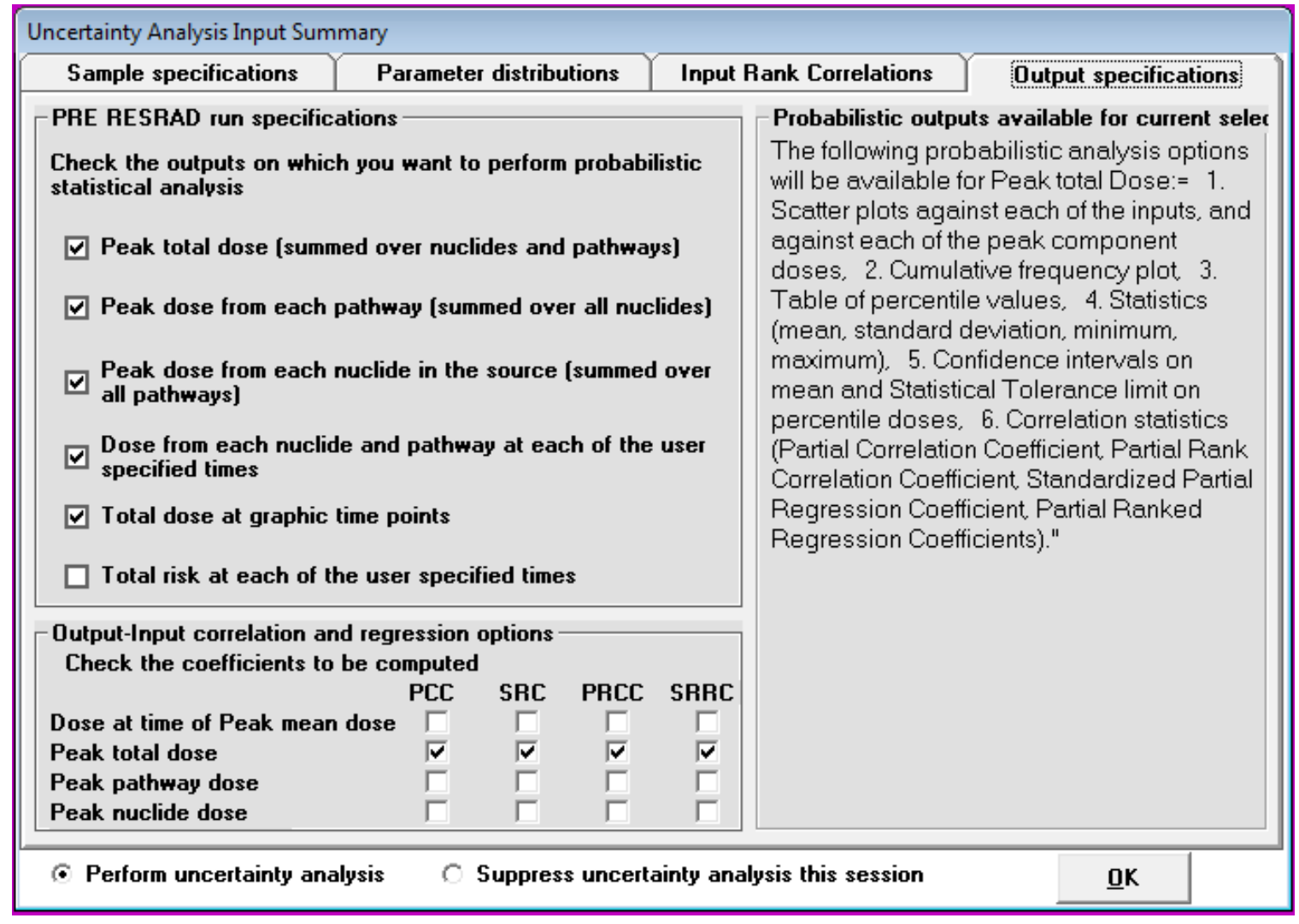

\section{FIGURE 52 Output Specifications Tab}

- Navigation: The output options are selected with the check boxes on the left side. These are the only inputs on this tab screen. The columns on the right show what output options the user will be able to obtain for each of the checked options after running RESRAD-ONSITE. The user will be able to specify and view these options from the interactive table and interactive graphic screens.

Various correlation types are available: PCC (partial correlation coefficient), PRCC (partial ranked correlation coefficient), SRC (standardized regression coefficient), and SRRC (standardized ranked regression coefficient).

\subsubsection{Output Results}

The probabilistic analysis output results include a textual uncertainty report and interactive output. 
The uncertainty report (Figure 53) includes the uncertainty analysis results for total dose and risk, pathway specific dose, cumulative probability, dose summary at graphical times for different repetitions, peak of the mean dose at graphical times, and correlation and regression coefficients.

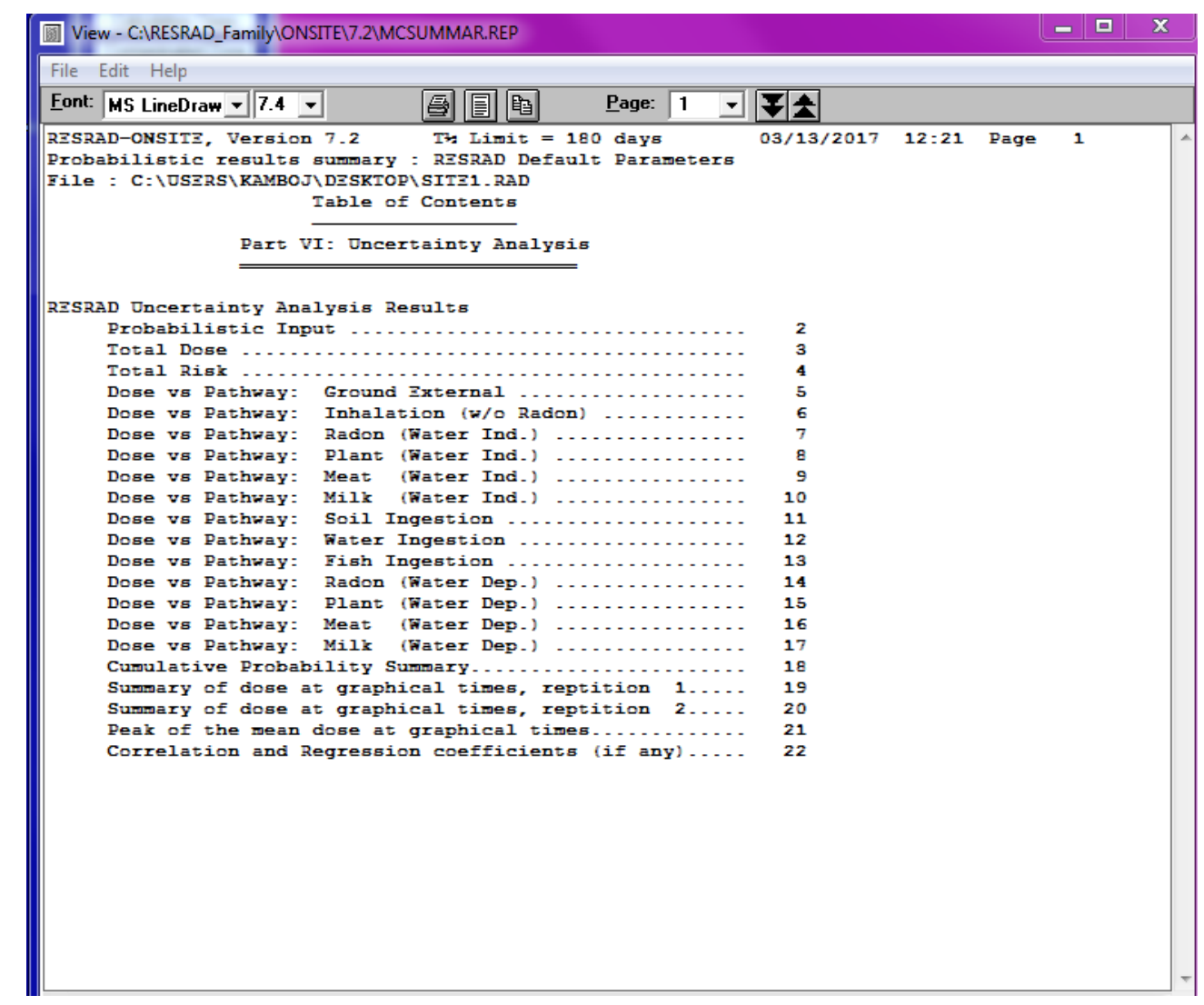

\section{FIGURE 53 RESRAD-ONSITE Uncertainty Report}

The interactive output include three tabs: "Input Specifications," "Parameter Statistics," and "Results.” The "Input Specifications" tab (Figure 54) displays the selected input specifications for an uncertainty analysis run. The "Parameter Statistics" tab (Figure 55) displays the selected parameters, their distributions and FORTRAN name, and input correlations, if any in the uncertainty analysis run. The "Results" tab (Figure 56) displays results in text and graphic form. The text results can be displayed for the peak pathway dose, peak nuclide dose, and dose at user times. The text results include general statistics results and percentiles results (selection under statistical property box). The graphic results include cumulative density, scatter plots, and temporal plots (Figure 57). Under cumulative density and scatter plots, different primary objects - peak pathway dose, peak nuclide dose, dose at user's time, and input vector - can be selected. Temporal plots at mean, $90^{\text {th }}$ percentile, and $95^{\text {th }}$ percentile are displayed for different repetitions. 


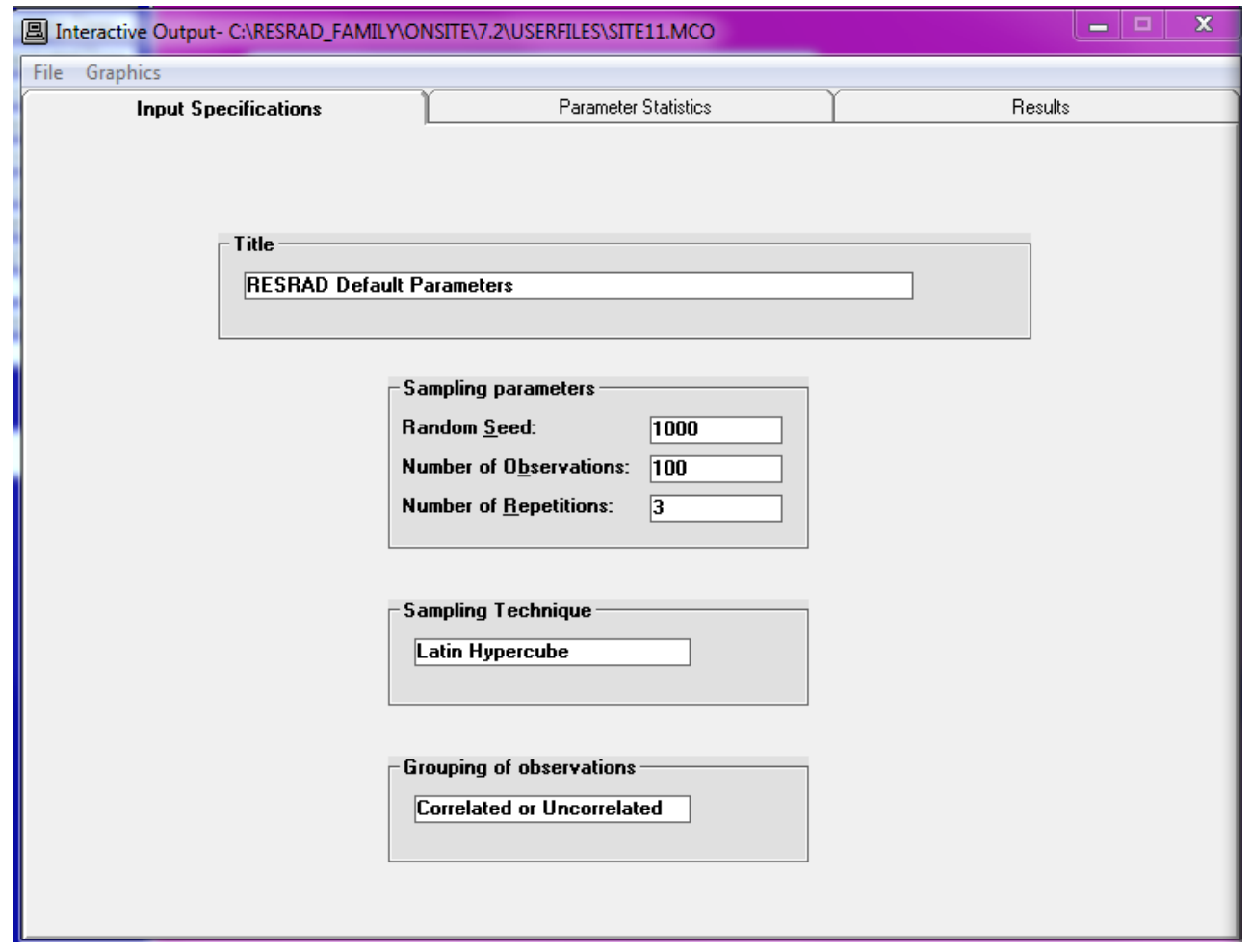

FIGURE 54 RESRAD-ONSITE Interactive Output Input Specification Tab

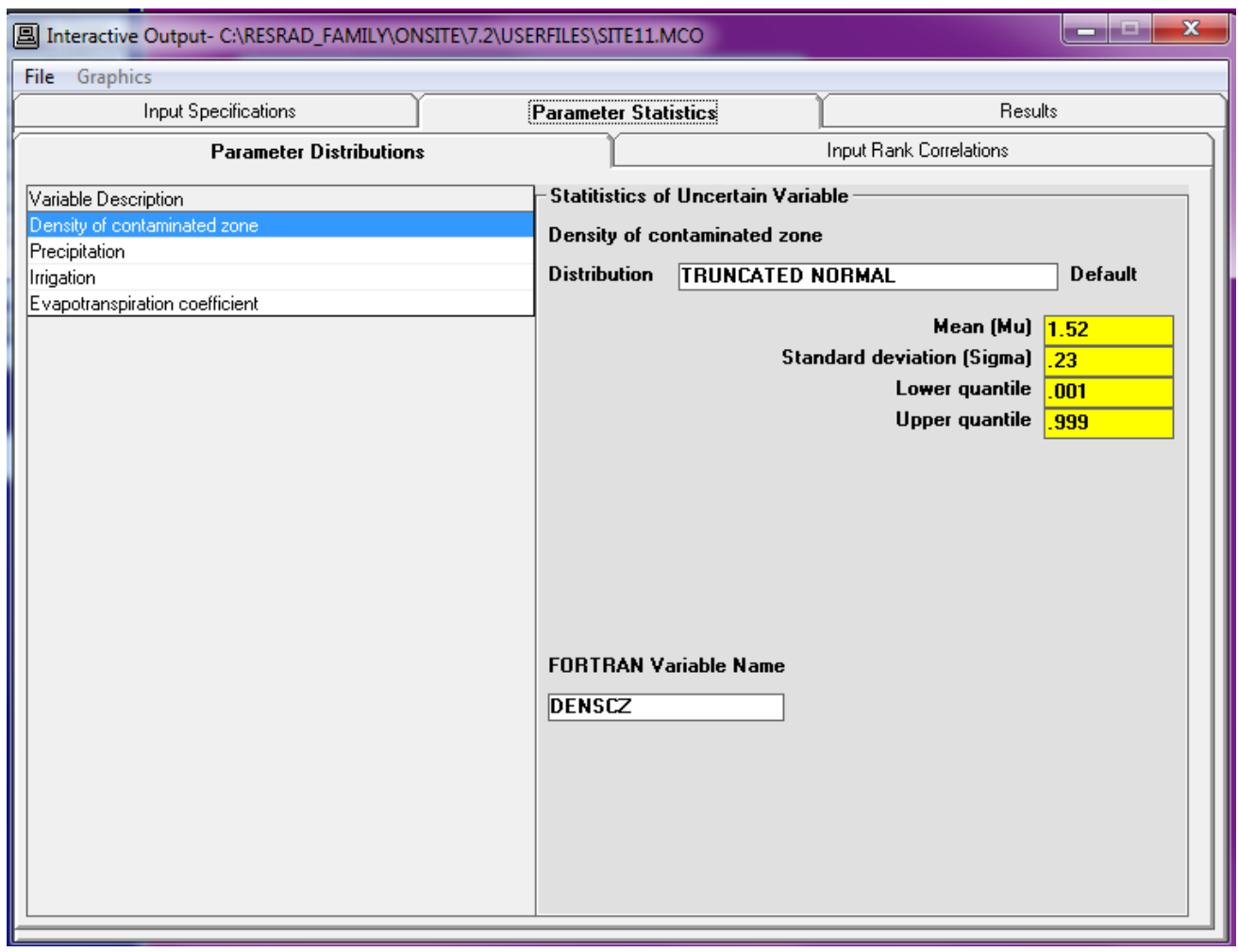

FIGURE 55 RESRAD-ONSITE Interactive Output Parameter Statistics Tab 


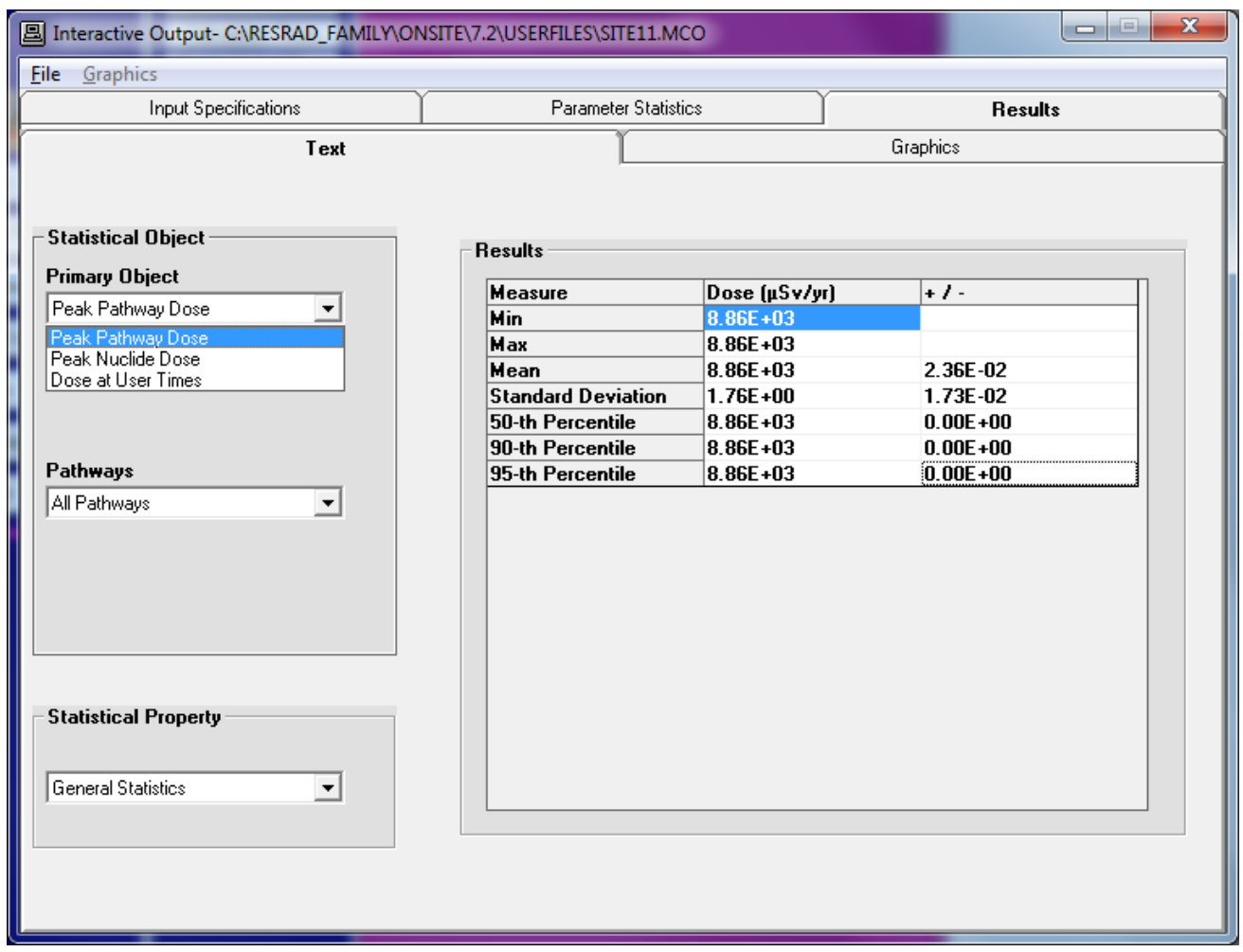

FIGURE 56 RESRAD-ONSITE Interactive Output Results Tab

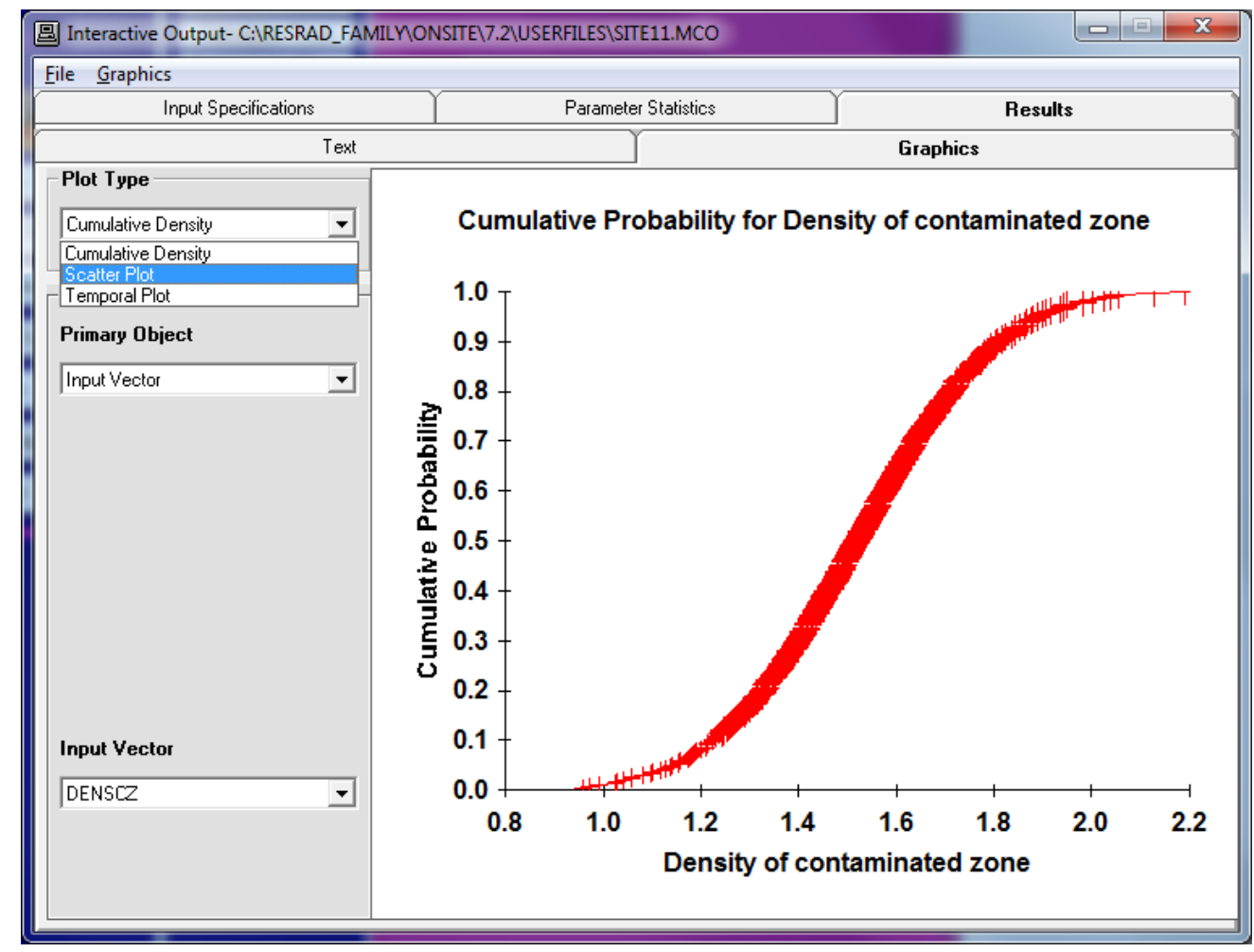

FIGURE 57 RESRAD-ONSITE Interactive Graphic Results 


\subsection{SOIL GRAPHIC FEEDBACK}

\section{Getting to the Soil Strata Parameters Window}

- Select the "View”/Soil Graphics" option from the menu bar (Figure 58).

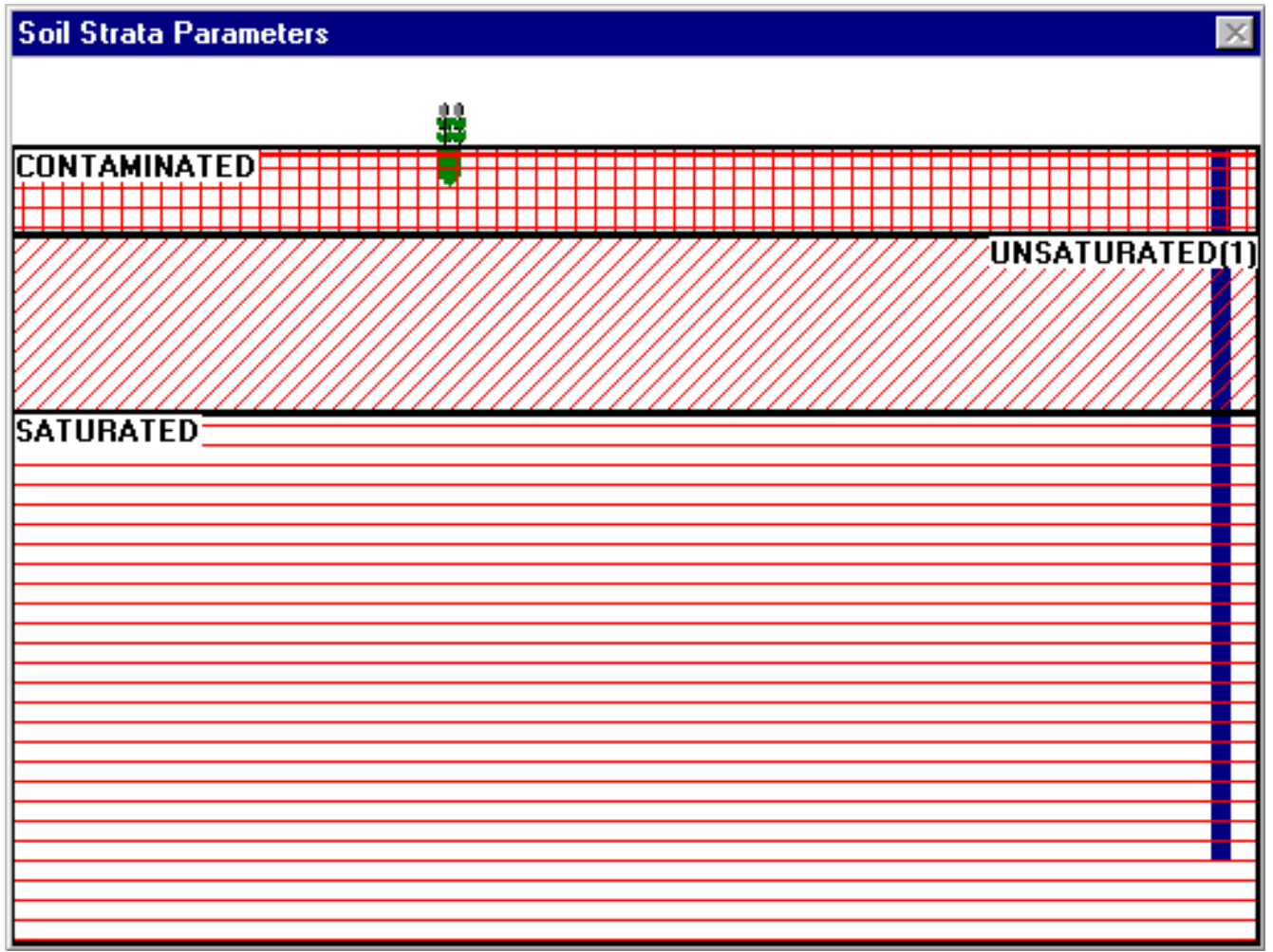

FIGURE 58 Soil Strata Parameters Window

\section{Information Feedback}

- Scale set by the 1-m-high corn stalk

- Number of layers considered

- Depth of layers considered

- Depth of the mixing layer (solid red line)

- Depth of plant roots

- Well depth

\section{Navigation}

- To open the data input window for a specific soil layer, click on that soil layer. For example, the window below (Figure 59) is shown when the first unsaturated zone is clicked. 


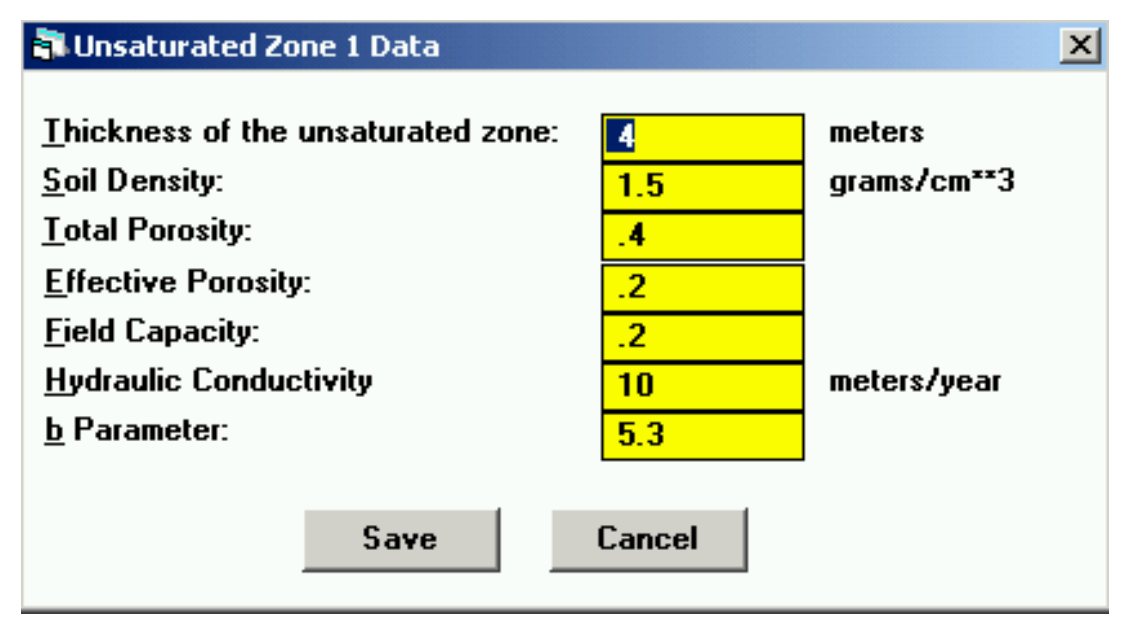

FIGURE 59 First Unsaturated Zone Data Window

\subsection{RADIONUCLIDE TRANSFORMATION DATABASES}

The DCF Editor is updated to include the ICRP 107 radionuclide transformation database and associated dose coefficients and the cancer risk conversion factor library. ICRP 107 includes radionuclide transformation data for 1,252 nuclides, whereas ICRP 38 had radionuclide transformation data for 838 nuclides.

\subsubsection{Radionuclide Transformation Databases}

Starting with RESRAD-ONSITE Version 7.2, the user has an option to select the ICRP 107 (ICRP 2008)-based or ICRP 38 (ICRP 1983)-based radionuclide transformation database. For some isomers, the notation in ICRP 107 has changed from the ICRP 38 notations. In ICRP 107, isomers of energy above the ground state are identified by appending " $m$ ", "n", "p", or "q" to the mass number; whereas the information during the preparation of ICRP 38 was insufficient to identify the ground and excited states of a few radionuclides. The few radionuclides that did not have sufficient information were assigned an ad-hoc designation based on their physical half-life. Table 1 shows the correspondence between the ICRP 38 and ICRP 107 isomers. Some radionuclides in ICRP 38 are not in the ICRP 107 database (see footnote 4 in Table 1). If any of the radionuclides not in ICRP 107 was selected using ICRP 38 radionuclide transformation data and if the transformation database is later changed to ICRP 107, an alert message will be displayed and these nuclides will be deleted from the analysis. 
TABLE 1 Identification of ICRP 38 and ICRP 107 Isomers

\begin{tabular}{|c|c|c|c|}
\hline \multicolumn{2}{|c|}{ ICRP 38 Notation ${ }^{1,4}$} & \multicolumn{2}{|c|}{ ICRP 107 Notation ${ }^{1}$} \\
\hline ICRP 38²) & $\mathrm{T}_{1 / 2}$ & ICRP 107 & $\mathrm{~T}_{1 / 2}$ \\
\hline Nb-89a & $66 \mathrm{~m}$ & Nb-89m & $66 \mathrm{~m}$ \\
\hline $\mathrm{Nb}-89 \mathrm{~b}$ & $122 \mathrm{~m}$ & Nb-89 & $2.03 \mathrm{~h}$ \\
\hline Nb-98 & $51.5 \mathrm{~m}$ & Nb-98m & $51.3 \mathrm{~m}$ \\
\hline Rh-102 & $2.9 \mathrm{y}$ & Rh-102m & 3.742 y \\
\hline Rh-102m & $207 \mathrm{~d}$ & Rh-102 & $207 \mathrm{~d}$ \\
\hline In-110a & $69.1 \mathrm{~m}$ & In-110m & $69.1 \mathrm{~m}$ \\
\hline In-110b & $4.9 \mathrm{~h}$ & In-110 & $4.9 \mathrm{~h}$ \\
\hline Sb-120a & $15.89 \mathrm{~m}$ & Sb-120 & $15.89 \mathrm{~m}$ \\
\hline Sb-120b & $5.76 \mathrm{~d}$ & Sb-120m & $5.76 \mathrm{~d}$ \\
\hline Sb-124n & $20.2 \mathrm{~m}$ & Sb-124n ${ }^{(3)}$ & $20.2 \mathrm{~m}$ \\
\hline Sb-128a & $10.4 \mathrm{~m}$ & Sb-128m & $10.4 \mathrm{~m}$ \\
\hline Sb-128b & $9.01 \mathrm{~h}$ & Sb-128 & $9.01 \mathrm{~h}$ \\
\hline Eu-150a & $12.62 \mathrm{~h}$ & Eu-150m & $12.8 \mathrm{~h}$ \\
\hline Eu-150b & $34.2 \mathrm{y}$ & Eu-150 & $36.9 \mathrm{y}$ \\
\hline Tb-156n & $5.0 \mathrm{~h}$ & Tb- $156 n^{3}$ & $5.3 \mathrm{~h}$ \\
\hline Tb-156m & $24.4 \mathrm{~h}$ & Tb-156m & $24.4 \mathrm{~h}$ \\
\hline Тa-178a & $9.31 \mathrm{~m}$ & Та-178 & $9.31 \mathrm{~m}$ \\
\hline Тa-178b & $2.2 \mathrm{~h}$ & Тa-178m & $2.36 \mathrm{~h}$ \\
\hline Та-180m & $8.1 \mathrm{~h}$ & Та-180 & 8.152 h \\
\hline Та-180 & $1.0 \mathrm{E} 13 \mathrm{y}$ & Ta-180m & 5 \\
\hline Re-182a & $12.7 \mathrm{~h}$ & Re-182m & $12.7 \mathrm{~h}$ \\
\hline Re-182b & $64.0 \mathrm{~h}$ & Re-182 & $64.0 \mathrm{~h}$ \\
\hline Ir-186b & $1.75 \mathrm{~h}$ & Ir-186m & $1.92 \mathrm{~h}$ \\
\hline Ir-186a & $15.8 \mathrm{~h}$ & Ir-186 & $16.64 \mathrm{~h}$ \\
\hline Ir-190m & $1.2 \mathrm{~h}$ & Ir-190m & $1.120 \mathrm{~h}$ \\
\hline Ir-190n & $3.1 \mathrm{~h}$ & Ir-190n & $3.087 \mathrm{~h}$ \\
\hline Ir-192m & $241 \mathrm{y}$ & Ir-192n ${ }^{(3)}$ & 241 y \\
\hline Np-236b & $22.5 \mathrm{~h}$ & $\mathrm{~Np}-236 \mathrm{~m}$ & $22.5 \mathrm{~h}$ \\
\hline $\mathrm{Np}-236 \mathrm{a}$ & 115E3 y & $\mathrm{Np}-236$ & $1.54 \mathrm{E} 5 \mathrm{y}$ \\
\hline Es-250 & $2.1 \mathrm{~h}$ & Es-250m & $2.22 \mathrm{~h}$ \\
\hline $\begin{array}{l}\text { Half-life } \\
\text { days; y, }\end{array}$ & $\begin{array}{l}\left.\Gamma_{1 / 2}\right) \text { units: } \\
\text { ars. }\end{array}$ & nutes; h, ho & rs; d, \\
\hline $\begin{array}{ll}\text { Ad-hoc } \\
\text { database }\end{array}$ & notation "a" & "b" used in I & CRP 38 \\
\hline 3 Metasta & $\begin{array}{l}\text { le state of } ~ \\
\text { le state. }\end{array}$ & er energy thar & the first \\
\hline $\begin{array}{l}4 \quad \mathrm{Nb}-97 \mathrm{~m} \\
\mathrm{Ta}-180 \mathrm{r} \\
(55 \mathrm{~d}) \mathrm{h} \\
\text { ICRP 38}\end{array}$ & $\begin{array}{l}\text { (60 s), W-1 } \\
(8.1 \mathrm{~h}), \mathrm{M} \\
\text { ere in ICRP } \\
\text { ) but are no }\end{array}$ & $\begin{array}{l}2.3 \mathrm{~h}), \mathrm{Re}-17 \\
7(5.2 \mathrm{~h}) \text { and } \\
\left(\mathrm{T}_{1 / 2} \text { values fr }\right. \\
\text { Publication } 1\end{array}$ & $\begin{array}{l}7(14 \mathrm{~m}) \\
\mathrm{Md}-258 \\
\text { om } \\
07 .\end{array}$ \\
\hline $\begin{array}{l}\text { Ta-180r } \\
\text { not beer }\end{array}$ & $\begin{array}{l}\mathrm{T}_{1 / 2} \text { in } \\
\text { bservec }\end{array}$ & $\begin{array}{l}\text { f } 1.2 \mathrm{E} 15 \\
\text { servation }\end{array}$ & $\begin{array}{l}\text { ecay has } \\
\text { stable. }\end{array}$ \\
\hline
\end{tabular}


RESRAD-ONSITE code handles these differences internally when the radionuclide transformation databases are interchanged in the input file. Figure 60 shows the isomer notations when the ICRP 38 transformation database is selected, and Figure 61 shows the change in isomer notations when the transformation database is changed to ICRP 107. Also note the change in the number of nuclides in the database with greater than the cut-off half-life in the ICRP 38 and ICRP 107 databases.

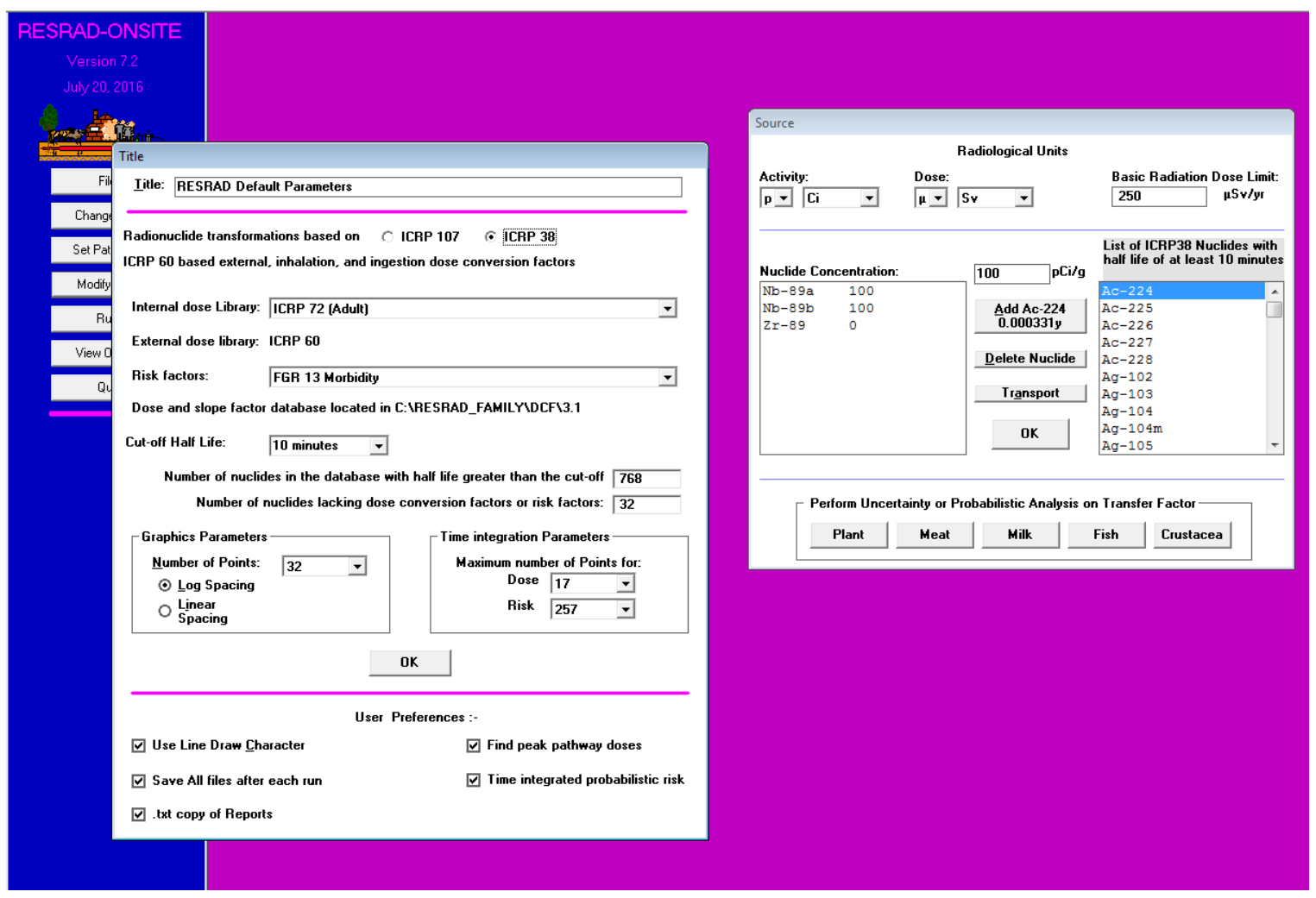

FIGURE 60 Selection of ICRP 38 Radionuclide Transformation Database 


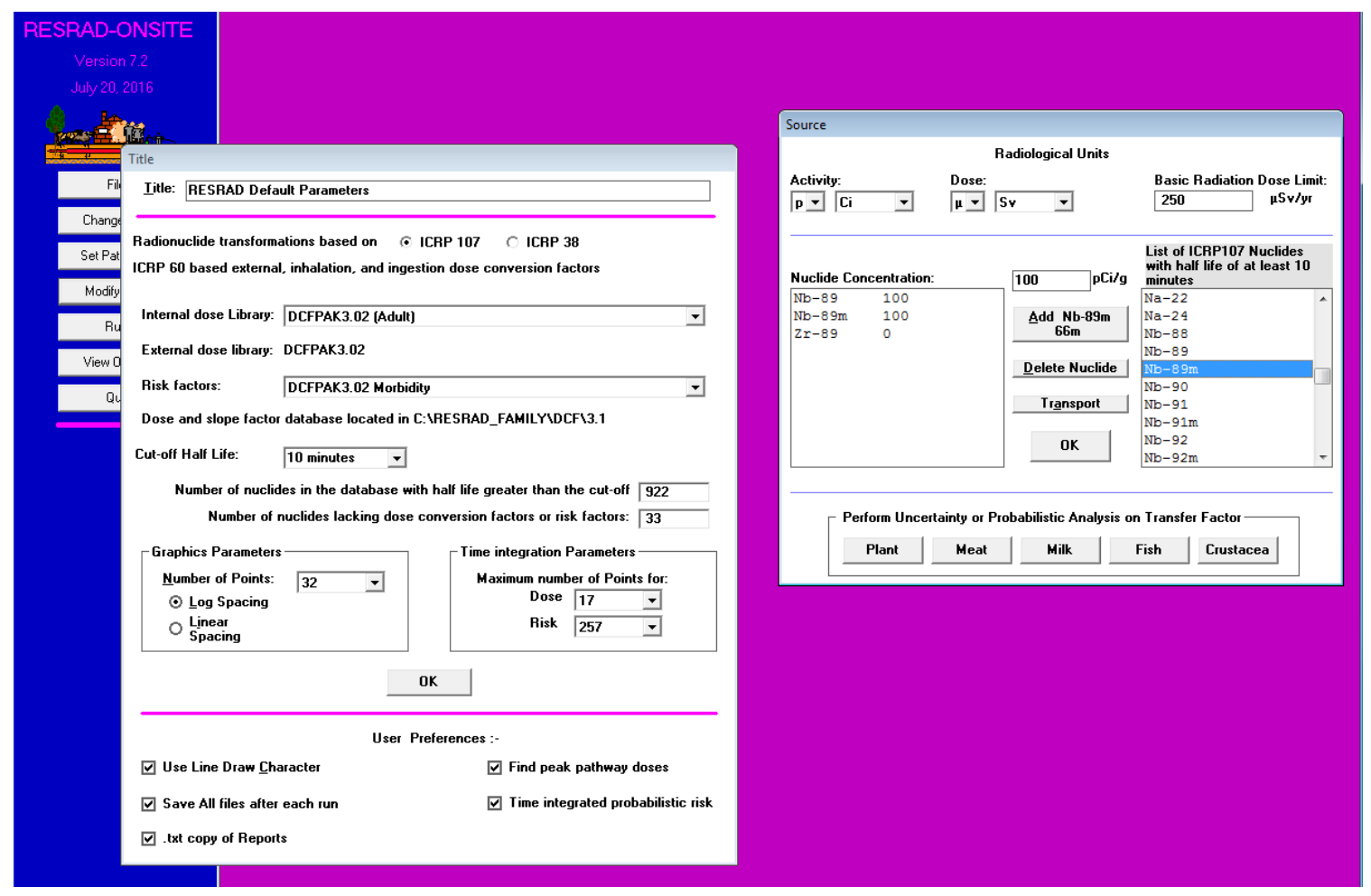

FIGURE 61 Selection of ICRP 107 Radionuclide Transformation Database

\subsubsection{DCF Selection}

If the ICRP 107 radionuclide transformation database is selected, only ICRP 60 (ICRP 1991)-based external, inhalation, and ingestion dose coefficients are available. If the ICRP 38 radionuclide transformation database is selected, ICRP 26/ICRP 30 (ICRP 1977)-based external, inhalation, and ingestion dose coefficients are available. The Title forms in Figure 60 and Figure 61 also show the number of nuclides that lack DCFs in the database.

\subsubsection{Dose Estimation Methodology}

The absorbed dose is a fundamental dosimetric quantity in radiological protection. To estimate the total whole body dose from external and internal radiation exposure, doses are estimated separately from external and internal exposure and later added. Doses are initially estimated for different organs/tissues, multiplied by organ/tissue weighting factors, and added to the estimated external or internal dose. Organ/tissue doses depend on the absorbed dose and quality factors/radiation weighting factors. The radiation weighting factors depend on the radiation type and energy. Table 2 and Table 3 show the organ/tissue weighting factors and quality factors/radiation weighting factors used in ICRP 26 and ICRP 60. The tissue/organ weighting factors were further updated in ICRP 103. The ICRP 103 methodology-based DCFs are currently not available. Table 4 shows the different dose terms used in ICRP 26 and ICRP 60. 
TABLE 2 Tissue Weighting Factors in ICRP 26 and ICRP 60

\begin{tabular}{|c|c|c|}
\hline \multirow[b]{2}{*}{ Organ/Tissue } & \multicolumn{2}{|c|}{ Weighting Factors } \\
\hline & ICRP 26 & ICRP 60 \\
\hline Gonads & 0.25 & 0.20 \\
\hline Breast & 0.15 & 0.05 \\
\hline Colon & -1 & 0.12 \\
\hline Red Marrow & 0.12 & 0.12 \\
\hline Lungs & 0.12 & 0.12 \\
\hline Stomach & $-{ }^{1}$ & 0.12 \\
\hline Urinary Bladder & -1 & 0.05 \\
\hline Liver & -1 & 0.05 \\
\hline Esophagus & -1 & 0.05 \\
\hline Thyroid & 0.03 & 0.05 \\
\hline Bone Surface & 0.03 & 0.01 \\
\hline Skin & $-{ }^{1}$ & 0.01 \\
\hline Remainder & $0.30^{2}$ & $0.05^{3,4}$ \\
\hline
\end{tabular}

1 Weighting factor not assigned in ICRP 26.

2 The value 0.30 is applied to the average dose among the five remaining organs or tissues receiving the highest dose, excluding the skin, lens of the eye, and the extremities.

3 The remainder is composed of the following tissues and organs: adrenals, brain, small intestine, upper large intestine, kidney, muscle, pancreas, spleen, thymus, and uterus.

4 The value 0.05 is applied to the average dose to the remainder tissue group. However, if a member of the remainder receives a dose in excess of the highest dose in any of the twelve organs for which weighting factors are specified, a weighting factor of 0.025 is applied to that organ and a weighting factor of 0.025 is applied to the average dose in the rest of the remainder.

Source: ICRP 26 (ICRP 1977) and ICRP 60

(ICRP 1991) 
TABLE 3 Quality Factors in ICRP 26 and Radiation Weighting Factors in ICRP 60

\begin{tabular}{lcc}
\hline \multicolumn{1}{c}{ Radiation Type and Energy Range } & $\begin{array}{c}\text { Quality } \\
\text { Factor }\end{array}$ & $\begin{array}{c}\text { Radiation } \\
\text { Weighting } \\
\text { Factor }^{1}\end{array}$ \\
\hline Photons, all energies & 1 & \\
Electrons and muons, all energies & & 1 \\
Neutrons, energy $<10 \mathrm{keV}$ & 1 & 1 \\
$10 \mathrm{keV}$ to $100 \mathrm{keV}$ & -3 & 5 \\
$>100 \mathrm{Kev}$ to $2 \mathrm{MeV}$ & - & 10 \\
$>2 \mathrm{MeV}$ to $20 \mathrm{MeV}$ & - & 20 \\
$>20 \mathrm{MeV}$ & - & 10 \\
Protons, other than recoil protons, energy $>2 \mathrm{MeV}$ & - & 5 \\
Alpha particles, fission fragments, heavy nuclei & 1 & 5 \\
\hline
\end{tabular}

1 All values relate to the radiation incident on the body or, for internal sources, emitted from the source.

2 Excluding Auger electrons emitted from nuclei bound to DNA.

3 In ICRP 26, quality factor for neutrons was recommended to be 10 for unknown energies, otherwise to be calculated, and a value of 2.3 for thermal neutrons.

Source: ICRP 60 (ICRP 1991)

TABLE 4 Dose Terms Used in ICRP 26 and ICRP 60

\begin{tabular}{|c|c|c|}
\hline Dose Quantity & ICRP 26/30 & ICRP 60 \\
\hline Organ/tissue dose & Absorbed dose in tissue or organ, $\mathrm{D}_{\mathrm{T}}$ & Absorbed dose in tissue or organ, $\mathrm{D}_{\mathrm{T}}$ \\
\hline $\begin{array}{l}\text { Absorbed organ/tissue dose } \\
\text { adjusted for radiation type }\end{array}$ & $\begin{array}{l}\text { Dose equivalent in tissue or organ } \mathrm{T} \text {, } \\
\mathrm{H}_{\mathrm{T}}=\mathrm{D}_{\mathrm{T}} \times \mathrm{Q} \times \mathrm{N}\end{array}$ & $\begin{array}{l}\text { Equivalent dose in tissue or organ } T \text {, } \\
\mathrm{H}_{\mathrm{T}}=\sum_{\mathrm{R}} \mathrm{W}_{\mathrm{R}} \times \mathrm{D}_{\mathrm{T}, \mathrm{R}} \text { (average absorbed } \\
\text { dose in tissue } \mathrm{T} \text { from radiation type } \mathrm{R} \text { ) }\end{array}$ \\
\hline $\begin{array}{l}\text { Committed organ/tissue dose } \\
\text { (over a period of time } \\
\text { following intake) }\end{array}$ & Committed dose equivalent, $\mathrm{H}_{\mathrm{T}, 50}$ & Committed equivalent dose, $\mathrm{H}_{\mathrm{T}, 50}$ \\
\hline Whole body dose & $\begin{array}{l}\text { Effective dose equivalent (EDE), } \mathrm{H}_{\mathrm{E}} \\
=\sum_{\mathrm{T}} \mathrm{W}_{\mathrm{T}} \times \mathrm{H}_{\mathrm{T}}\end{array}$ & Effective dose (E), $\mathrm{E}=\sum_{\mathrm{T}} \mathrm{W}_{\mathrm{T}} \times \mathrm{H}_{\mathrm{T}}$ \\
\hline $\begin{array}{l}\text { Whole body committed dose } \\
\text { (internal only) }\end{array}$ & $\begin{array}{l}\text { Committed effective dose equivalent } \\
(\mathrm{CEDE})=\sum_{\mathrm{T}} \mathrm{W}_{\mathrm{T}} \times \mathrm{H}_{\mathrm{T}, 50}\end{array}$ & $\begin{array}{l}\text { Committed effective dose (CED), } \\
\mathrm{E}_{50}=\sum_{\mathrm{T}} \mathrm{W}_{\mathrm{T}} \times \mathrm{H}_{\mathrm{T}, 50}\end{array}$ \\
\hline $\begin{array}{l}\text { Total committed whole body } \\
\text { dose }\end{array}$ & $\begin{array}{l}\text { Total effective dose equivalent } \\
\text { (TEDE) = EDE (ext) + CEDE (int) }\end{array}$ & $\begin{array}{l}\text { Total effective dose }(\text { TED) }=\mathrm{E}(\text { ext })+ \\
\text { CED (int) }\end{array}$ \\
\hline
\end{tabular}




\section{ICRP 26 Methodology}

In ICRP 26, tissue dose was estimated at a point in an organ or tissue and was defined as dose equivalent, $\mathrm{H}$, which was the product of absorbed dose in the organ/tissue, quality factor $(\mathrm{Q})$, and a modifying factor $(\mathrm{N})$ (with a recommended value of 1 ). When an organ/tissue dose equivalent is multiplied by an organ/tissue weighting factor $\left(\mathrm{W}_{\mathrm{T}}\right)$ and then summed over all organs/tissues, it was defined as effective dose equivalent (EDE). ICRP 26 used the quantity committed dose equivalent to define a dose to a given organ or tissue from a single intake of radionuclide material as the integral of effective dose up to 50 years after intake, and when organ doses multiplied by organ/tissue weighting factors were added over all tissues/organs, it was defined as committed effective dose equivalent (CEDE). Total effective dose equivalent (TEDE) is sum of the EDE from external radiation and CEDE from internal radiation.

\section{ICRP 60 Methodology}

In ICRP 60, tissue dose was an average dose over an organ or tissue and was defined as equivalent dose, $\mathrm{H}_{\mathrm{T}}$, which was the product of absorbed dose and the radiation weighting factor $\left(\mathrm{W}_{\mathrm{R}}\right)$. When an organ/tissue equivalent dose is multiplied by an organ/tissue weighting factor and summed over all organs/tissues, it was defined as effective dose (E). ICRP 60 used the quantity committed dose equivalent to define a dose to a given organ or tissue from a single intake of radionuclide material as the integral of effective dose up to 70 years after intake for children and 50 years after intake for adults. When organ doses multiplied by organ/tissue weighting factors were added over all tissues/organs, it was defined as committed effective dose $\left(E_{i}\right)$. Where $i$ is the integration time (in years) following the intake; for an adult, it is 50. Total effective dose (TED) is the sum of E from external radiation and $\mathrm{E}_{50}$ from internal radiation for an adult.

ICRP 60 uses newer biokinetic models in calculating DCFs for six different age groups (3 months, 1 year, 5 year, 10 year, 15 year, and adult). Inhalation class types D (days), W (week), and Y (year) in ICRP 26/30 are replaced with F (fast), M (medium), S (slow), and V (very fast). The V class applies to gases and vapors in ICRP 60. 


\section{HELP}

Various levels of help are available in RESRAD-ONSITE. The term "RESRAD” in the help files indicates "RESRAD-ONSITE.”

Application Help Form: A help file that is accessible from the code that gives a description of each input and explains how the parameter is used in the code.

Message Log (View - OUTPUT.FIL) Form: A message log that is produced during the execution of the computational code that is useful for debugging, if the code should terminate before completion.

RESRAD Website: The RESRAD website has documents that relate to the RESRAD family of codes. The latest code is available for downloading from the site. The "About RESRADONSITE" form from the "Help" menu of the code contains a link to the RESRAD website and the e-mail address of the RESRAD team.

Documents: This guide and other RESRAD-ONSITE-related documents can be accessed in pdf form.

\subsection{APPLICATION HELP}

Pressing F1 on the highlighted parameter takes the user to the "General Help" window (Figure 62).

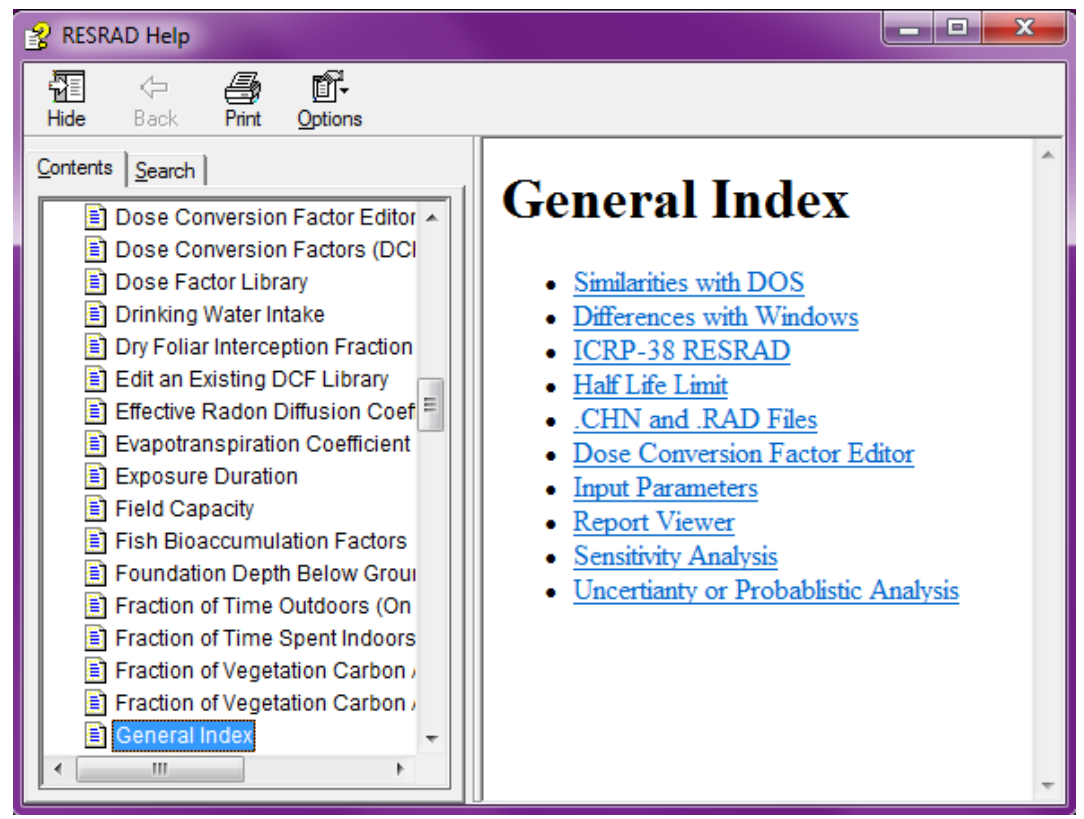

FIGURE 62 General Help Window 


\section{Getting To the General Help Window}

- Choose the input box of the input parameter of interest, then press the F2 function key.

- Click the parameter description in the "Textual Help" list found on the Navigator”s “Help” tab window.

- If the "Help” window is open, click "Contents" and follow the table of contents to find the parameter of interest.

\section{Contents}

The "Help" file has a simple description of the input parameter selected (Figure 63) by the user and how the parameter is used in the code. For a more detailed description of the parameter and for information on how to obtain site-specific values, please refer to the RESRAD Data Collection Handbook (Yu et al. 2015).

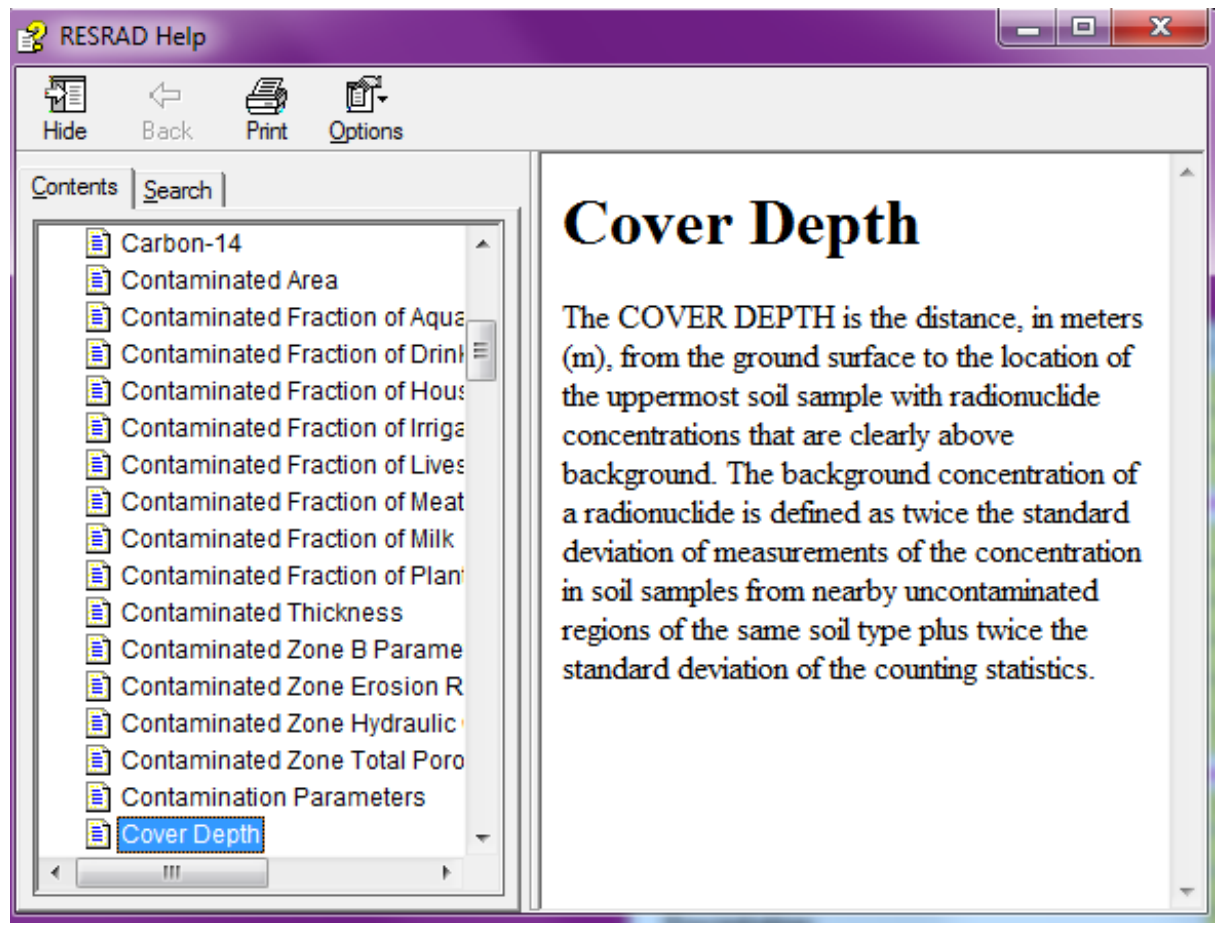

FIGURE 63 Parameter Descriptions in RESRAD-ONSITE Help 


\subsection{MESSAGE LOG}

\section{Getting To the Message Log}

From the main menu, choose "View/Message Log."

\section{Interpreting Message Log File Content}

This file contains calculation execution information that normally can be disregarded. If there are any problems with the calculation, this file should show some type of diagnostic that can be useful in solving the problem. The execution time is displayed at the end (see Figure 64).

\section{Reporting Problems}

The e-mail address for communicating problems and questions is resrad@anl.gov.

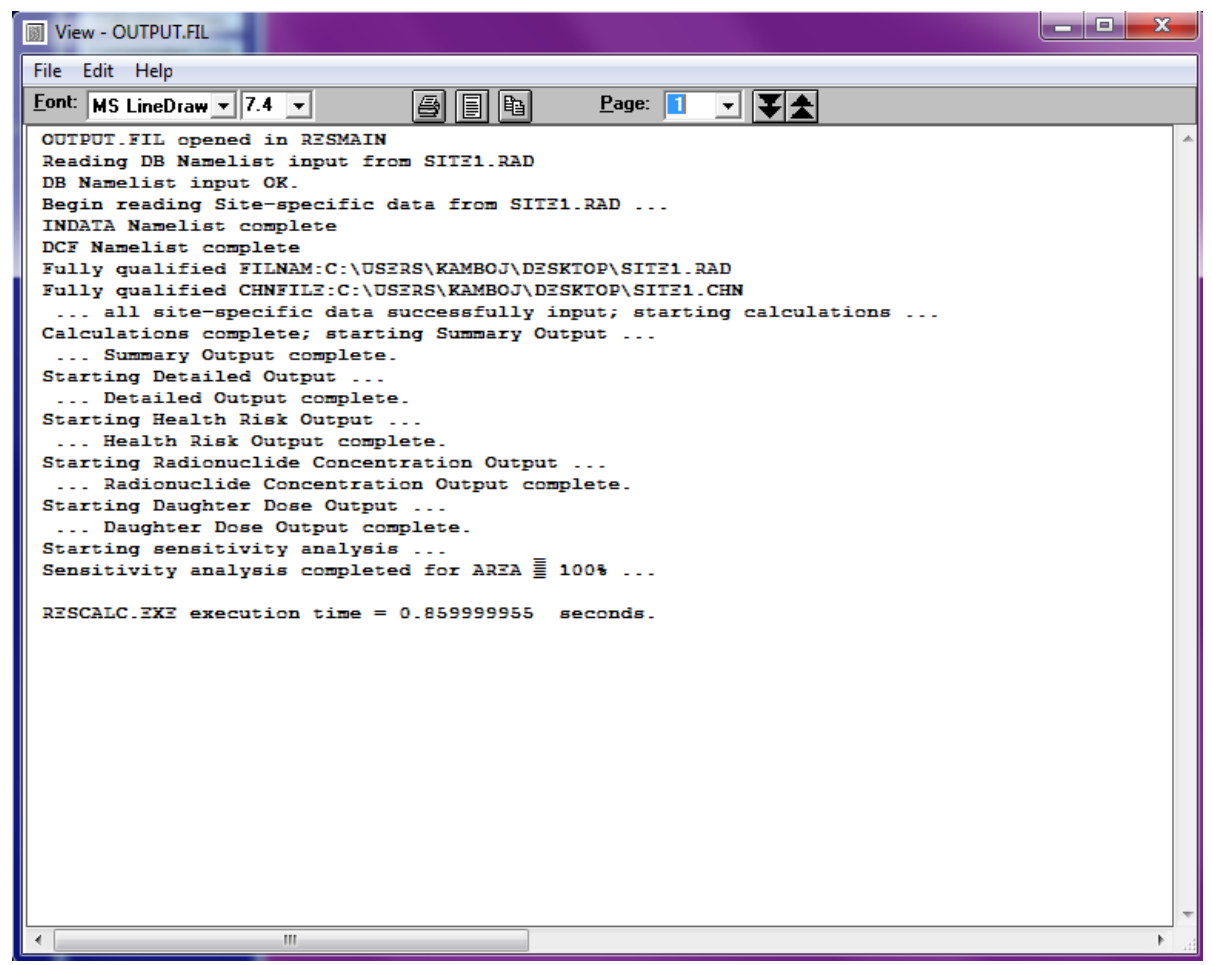

FIGURE 64 Message Log after RESRAD-ONSITE Run 


\subsection{WEB SITE}

\section{Getting To RESRAD Websites}

Type the RESRAD website address, http://resrad.evs.anl.gov, in your Web browser to get to the RESRAD family of codes Web page (Figure 65). The links for RESRAD-ONSITE code are found on the RESRAD family of codes Web page or are found on the "About RESRADONSITE" form in the "Help" tab accessed from the main menu and in the "Help" tab of the Navigator window (Figure 66).

\section{Contents}

- Descriptions of the RESRAD family of codes.

- Downloadable version of currently available codes.

- Table of current versions and release status.

- Available RESRAD documents on the Web.

- Upcoming training workshops and pictures from previous workshops.

- Listing of version releases and dates, along with short descriptions of the included modifications.

- Frequently asked questions.

- E-mail contact. 


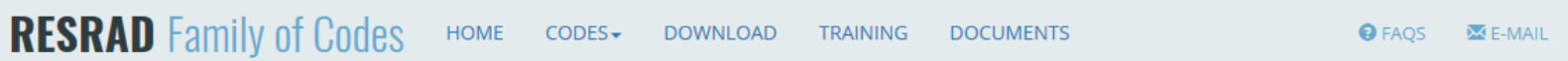

The RESRAD family of codes is developed at Argonne National Laboratory to analyze potential human and biota radiation exposures from the environmental contamination of RESidual RADioactive materials. The codes use pathway analysis to evaluate radiation exposure and associated risks, and to derive cleanup criteria or authorized limits for radionuclide concentrations in the contaminated source medium. The RESRAD family of codes is widely used by regulatory agencies, the risk assessment community, and universities in more than 100 countries around the world.

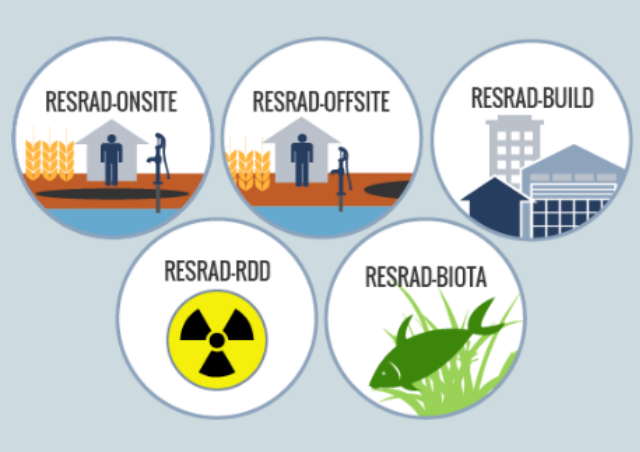

\section{UPCOMING EVENTS}

August 14 - August 18, 2017

RESRAD Training: RESRAD-ONSITE,

RESRAD-OFFSITE and RESRAD-BUILD

Register \$

August 21 - August 25, 2017

RESRAD Training: Advanced RESRAD

ONSITE \& RESRAD-OFFSITE, RESRAD-

BIOTA, and RESRAD-RDD

Register \$

Learn more about the training "

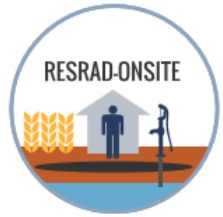

RESRAD-ONSITE

For assessing radiation exposures of a human receptor located on top of soils contaminated with radioactive materials

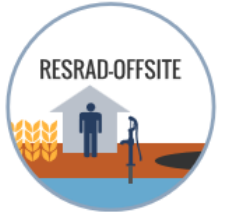

RESRAD-OFFSITE

For assessing radiation exposures of a human receptor located on top of or at some distance from soils contaminated with radioactive materials

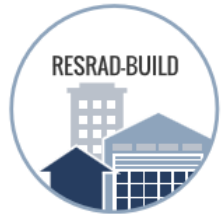

RESRAD-BUILD

For assessing radiation exposures of a human receptor in a contaminated building or a building housing contaminated furniture or equipment

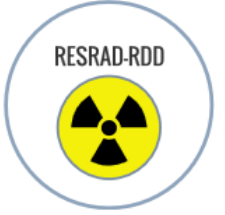

RESRAD-RDD

For evaluating human radiation exposures during the early, intermediate, or late phase of response after a radiological dispersal device (RDD) incident

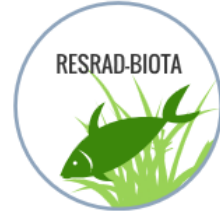

RESRAD-BIOTA

For evaluating radiation exposures of nonhuman biota, including flora and fauna, in a terrestrial or aquatic ecosystem
OTHER RESRAD CODES

RESRAD-RECYCLE RESRAD-BASELINE RESRAD-CHEM RESRAD-ECORISK

About Us Contact Us

Argonne National Laboratory | Environmental Science Division

\section{FIGURE 65 RESRAD Family of Codes Home Page}




RESRAD Family of Codes home cOdes- DOWNLOAD training DOCUMENTS
RESRAD-ONSITE is used to assess radiation exposures of a human receptor located on top of soils
contaminated with radioactive materials.

\section{Objectives}

RESRAD-ONSITE (formerly just RESRAD) is a computer code designed at Argonne National Laboratory for estimating radiation doses and cancer risks to an individual located on top of radioactively contaminated soils and to derive radionuclide soil guideline levels corresponding to a specific dose criterion.

\section{Modeling Approach}

The calculation of dose and cancer risk by the RESRAD-ONSITE code is scenario driven, with the use of parameter values specified by the user. Nine exposure pathways are provided which can be selected or suppressed to reflect the land use and receptor scenario under consideration. These nine exposure pathways are: (1) direct external radiation from radionuclides in soil, (2) inhalation of airborne radionuclides resuspended or volatilizing ( $\mathrm{H}-3$ and $\mathrm{C}-14)$ from soil, (3) incidental ingestion of soil, (4) ingestion of plant foods grown in contaminated soil and irrigated with contaminated water, (5) ingestion of meat and (6) ingestion of milk produced by livestock fed with contaminated fodder and water, (7) ingestion of drinking water from a well or pond adjacent to the contaminated area, (8) ingestion of aquatic foods from the pond, and (9) inhalation of radon emitted from contaminated soil. Input information needed for the calculation include characteristics of the contamination, properties of surface, sub-surface, and saturated soil strata, site-specific meteorological, hydraulic, and hydrogeological data, as well as exposure pattern of the receptor.

The modeling of RESRAD-ONSITE considers radiological decay and ingrowth and environmental transport, partitioning, and dilution, governed by the principle of mass conservation over time. Essentially all the input parameters used for the calculation can be specified by the user; therefore, the user can control the level of conservatism of each calculation, and apply the RESRAD-ONSITE code for screening, site-specific screening, or site-specific evaluation purposes.

\section{Features}

The RESRAD-ONSITE code is equipped with a user-friendly interface to facilitate data entry, performing calculations, displaying calculation results, and accessing general and context-specific help. The user has the option of choosing either ICRP-38 or ICRP-107 radionuclide transformation database, and a compatible dose conversion factors and cancer risk slope factors library for his analysis. Depending on the cut-off half-life specified, the code automatically assembles the branching and decay chains of the initially present radionuclides in soil, and calculates the effective DCFs for each principle nuclide in the decay chains, assuming secular equilibrium for short-lived associated progenies. Deterministic and probabilistic sensitivity analysis can be easily conducted on selected input parameters, which can be applied to prioritize efforts for input data collection.

\section{Use and Applications}

RESRAD-ONSITE is the only code designated by DOE in Order 458.1 for the evaluation of radioactively contaminated sites. It is also approved by NRC for use by licensees to evaluate radiation dose and demonstrate compliance concerning decommissioning of a licensed facility and by NRC staff to review license termination plans. The EPA Science Advisory Board reviewed the RESRAD model and used it in their rulemaking on radiation site cleanup regulations.

RESRAD-ONSITE has been used widely in the risk assessment community, including in the IAEA's VAMP and BIOMOVS II projects to compare environmental transport models. It has been applied to more than 300 sites in the U.S. and other countries. More than 1,000 people have been trained to use the code through its training workshops, which are held twice a year at Argonne National Laboratory.

Learn more about the use and applications of RESRAD-ONSITE at a training workshop at Argonne National Laboratory.

\section{FIGURE 66 RESRAD-ONSITE Code Home Page}




\subsection{DOCUMENTS}

\section{Getting To RESRAD Documents}

Figure 67 lists the available general and RESRAD-ONSITE documents on the website, which can be accessed at http://resrad.evs.anl.gov/documents. The RESRAD Data Collection Handbook (Yu et al. 2015) can be viewed from here.

RESRAD Family of Codes home codes- download training documents $\quad$ ofaqs

\section{Documents}

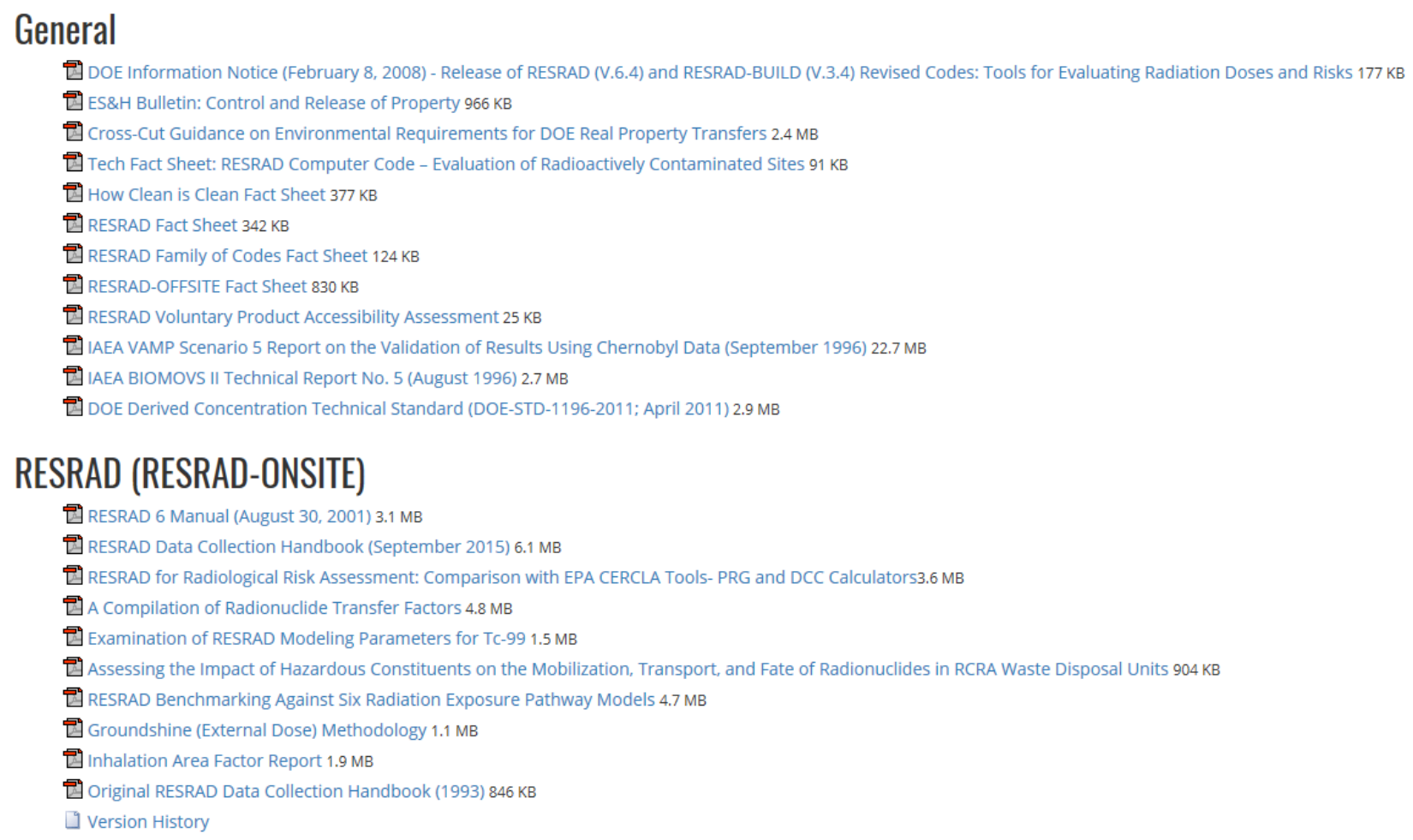

FIGURE 67 Available General and RESRAD-ONSITE Documents on the Website 


\section{REFERENCES}

DOE: See U.S. Department of Energy

Eckerman, K.F., et al., 1988, Limiting Values of Radionuclide Intake and Air Concentration and Dose Conversion Factors for Inhalation, Submersion, and Ingestion, EPA-520/1-88-020, Federal Guidance Report No. 11, prepared by Oak Ridge National Laboratory, Oak Ridge, Tenn., for U.S. Environmental Protection Agency, Office of Radiation Programs, Washington, D.C.

Eckerman, K.F., and J.C. Ryman, 1993, External Exposure to Radionuclides in Air, Water, and Soil, Exposure to Dose Coefficients for General Application, Based on the 1987 Federal Radiation Protection Guidance, EPA 402-R-93-076, Federal Guidance Report No. 12, prepared by Oak Ridge National Laboratory, Oak Ridge, Tenn., for U.S. Environmental Protection Agency, Office of Radiation and Indoor Air, Washington, D.C.

Eckerman, K.F., et al., 1999, Cancer Risk Coefficients for Environmental Exposure to Radionuclides, EPA-402-R-99-001, Federal Guidance Report No. 13, prepared by Oak Ridge National Laboratory, Oak Ridge, Tenn., for U.S. Environmental Protection Agency, Office of Radiation Programs, Washington, D.C.

EPA: See U.S. Environmental Protection Agency.

ICRP (International Commission on Radiological Protection), 1977, Recommendations of the International Commission on Radiological Protection, ICRP Publication 26, Annals of the ICRP, 1(2), Pergamon Press, New York, N.Y.

ICRP, 1983, Radionuclide Transformations: Energy and Intensity of Emissions, ICRP Publication 38, Annals of the ICRP, Vols. 11-13, Pergamon Press, New York, N.Y.

ICRP, 1991, 1990 Recommendations of the International Commission on Radiological Protection, ICRP Publication 60, Annals of the ICRP, 21(1-3), Pergamon Press, New York, N.Y.

ICRP, 1996, Age-Dependent Doses to Members of the Public from Intake of Radionuclides: Part 5 - Compilation of Ingestion and Inhalation Dose Coefficients, ICRP Publication 72, Annals of the ICRP, Vol. 26(1), Pergamon Press, New York, N.Y.

ICRP, 2008, Nuclear Decay Data for Dosimetric Calculations, ICRP Publication 107, Pergamon Press, New York, N.Y.

Iman, R.L., et al., 1985, A Fortran 77 Program and User's Guide for the Calculation of Partial Correlation and Standard Regression Coefficients, NUREG/CR-4122, SAND85-0044 RG, prepared by Sandia National Laboratories, Albuquerque, N.M., for U.S. Nuclear Regulatory Commission, Washington, D.C., June. 
U.S. Environmental Protection Agency, 1994, Estimating Radiogenic Cancer Risks, EPA 402-R93-076, Washington, D.C.

U.S. Environmental Protection Agency, 2001, Radionuclide Table: Radionuclide Carcinogenicity - Slope Factors (morbidity risk coefficients), Washington, D.C.

Yu, C., A.J. Zielen, J-J. Cheng, D.J. LePoire, E. Gnanapragasam, S. Kamboj, J. Arnish, A. Wallo III, W.A. Williams, and H. Peterson, 2001, User's Manual for RESRAD Version 6, ANL/EAD-4, Argonne National Laboratory, July.

Yu, C., S. Kamboj, C. Wang, J.J. Cheng, 2015, Data Collection Handbook to Support Modeling Impacts of Radioactive Material in Soil and Building Structures, ANL/EVS/TM-14/4. Argonne National Laboratory, September.

U.S. Department of Energy, 2011, DOE Standard: Derived Concentration Technical Standard, DOE-STD-1196-2011, Washington, D.C., April. 


\section{Argonne}

\section{Environmental Science Division}

Argonne National Laboratory

9700 South Cass Avenue, Bldg. 240

Argonne, IL 60439-4854

www.anl.gov

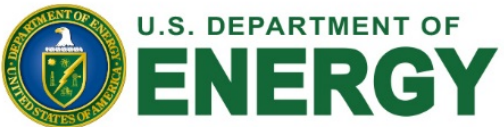

Argonne National Laboratory is a U.S. Department of Energy

laboratory managed by UChicago Argonne, LLC 